$\frac{\text { PNL-2521 Rev } 1}{\text { UC-60 }}$

\title{
A Siting Handbook for Small Wind Energy Conversion Systems
}

Harry L. Wegley

James V. Ramsdell

Montie M. Orgill

Ron L. Drake

March 1980

Prepared for the U.S. Department of Energy under Contract DE-AC06-76 RLO 1830

Pacific Northwest Laboratory Operated for the U.S. Department of Energy by Battelle Memorial Institute 


\section{NOTICE}

This report was prepared as an account of work sponsored by the United States Government. Neither the United States nor the Department of Energy, nor any of their employees, nor any of their contractors, subcontractors, or their employees, makes any warranty, express or implied, or assumes any legal liability or responsibility for the accuracy, completeness or usefulness of any information, apparatus, product or process disclosed, or represents that its use would not infringe privately owned rights.

The views, opinions and conclusions contained in this report are those of the contractor and do not necessarily represent those of the United States Government or the United States Department of Energy.

PACIFIC NORTHWEST LABORATORY

operated by

BATTELLE

for the

UNITED STATES DEPARTMENT OF ENERGY

Under Contract EY-76-C-06-1830

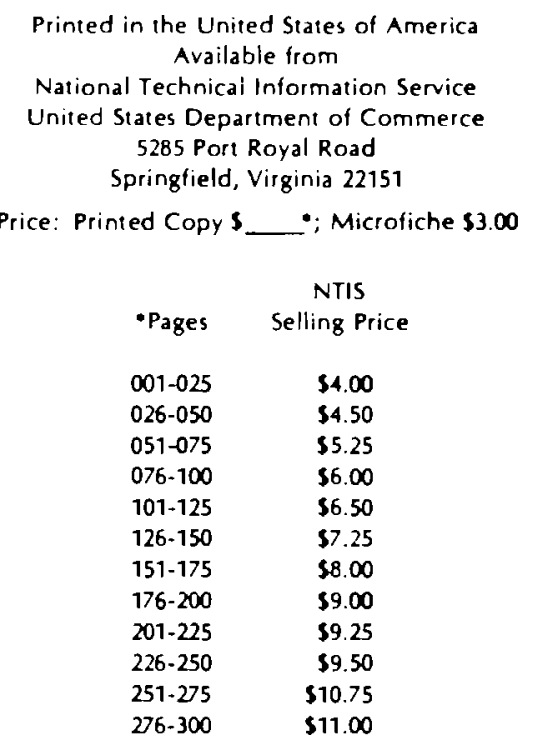




\title{
A Siting Handbook for Small Wind Energy Conversion Systems
}

\author{
Harry L. Wegley \\ James V. Ramsdell \\ Montie M. Orgill \\ Ron L. Drake
}

March 1980

Prepared for

the U.S. Department of Energy under Contract DE-AC06-76RLO 1830

Pacific Northwest Laboratory

Richland, Washington 99352 



\section{Acknowledgments}

The authors wish to thank Dr. William Pennell for the technical guidance he provided; Dr. Carl Aspliden, Dr. Craig Hansen, and Mr. Gary Thomann for their review; Jeanne McPherson, Chris Gilchrist, Pam Partch, and Pat Hays for their help in editing; Rosemary Ellis for her helpful suggestions and the many hours of typing she contributed; and Mary Carlile for her advice and cooperation in typesetting this handbook. The writing of this handbook and the associated research were sponsored by the U.S. Department of Energy, Wind Systems Branch. 



\section{Contents}

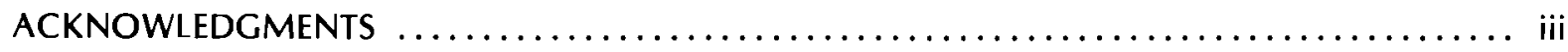

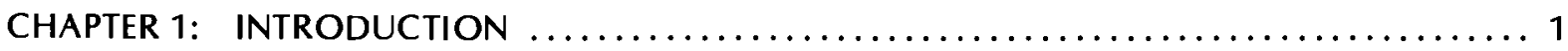

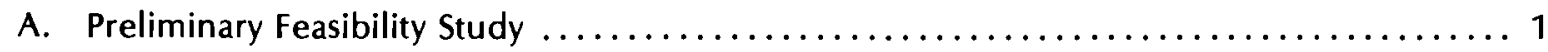

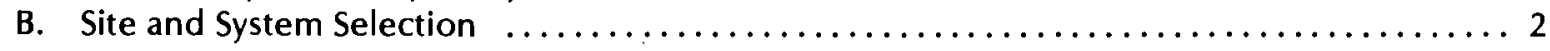

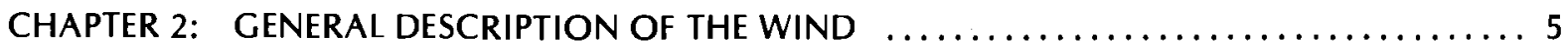

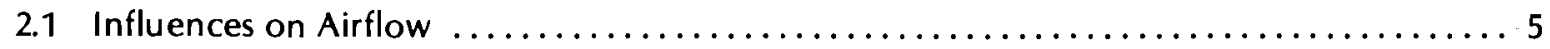

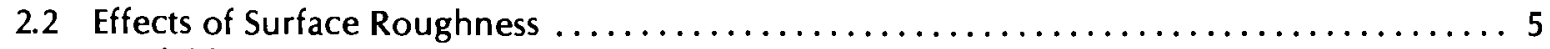

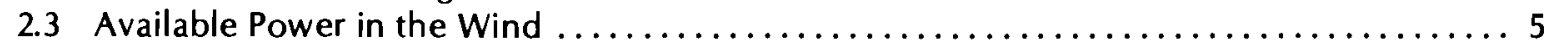

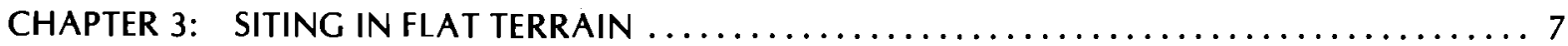

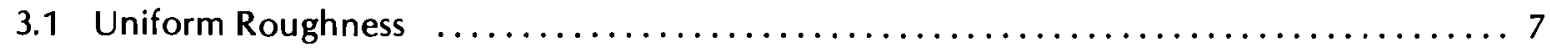

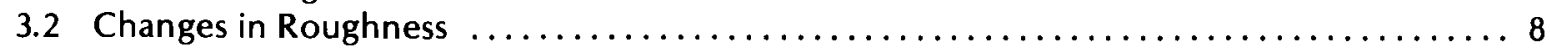

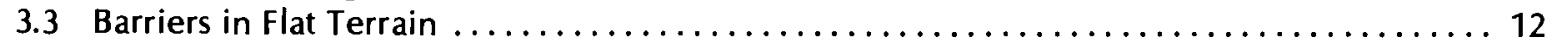

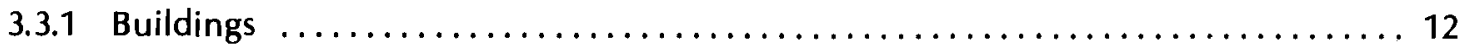

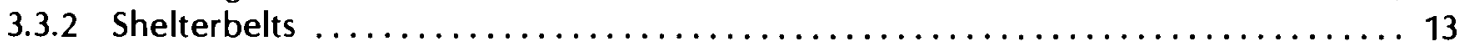

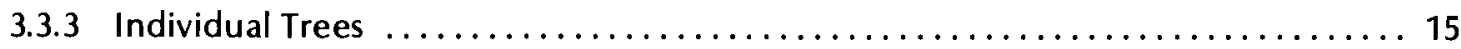

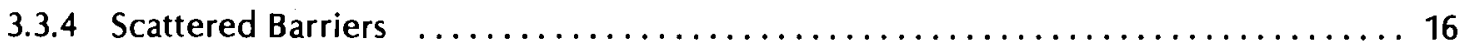

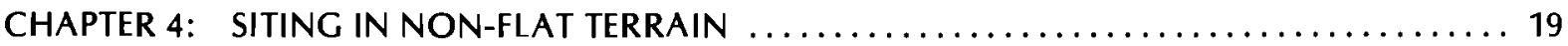

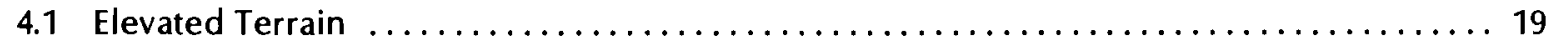

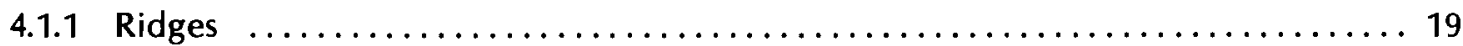

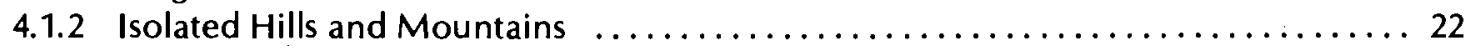

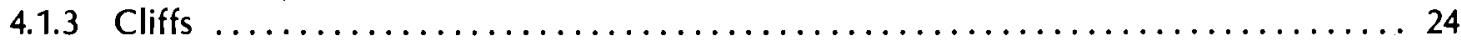

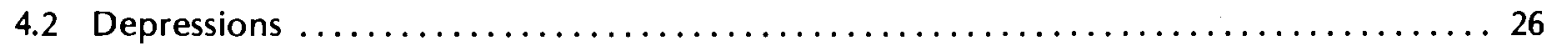

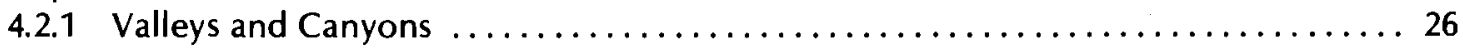

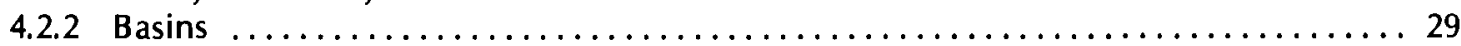

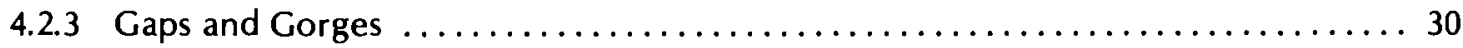

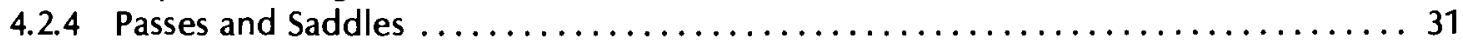

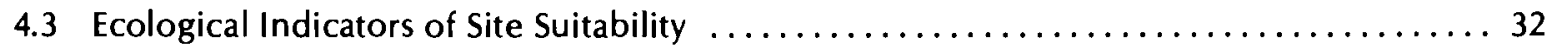

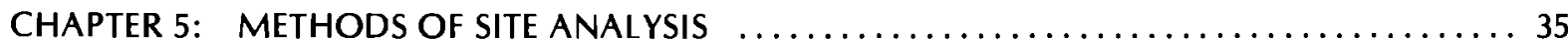

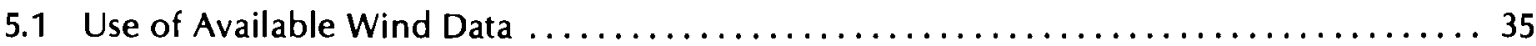

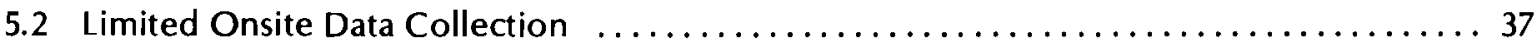

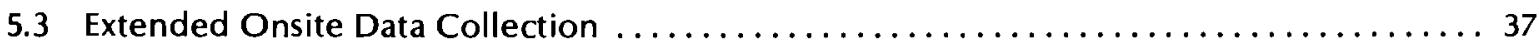

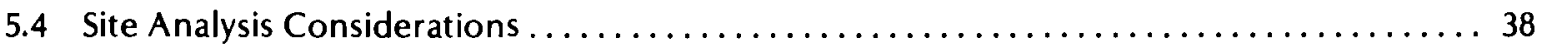

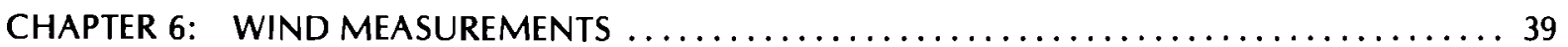

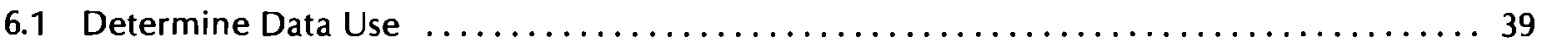

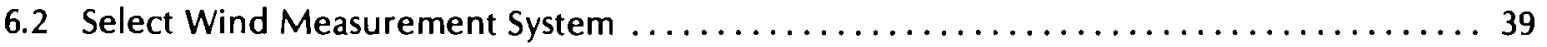

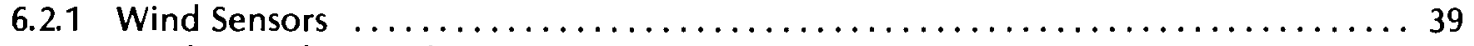

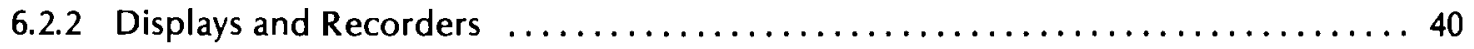

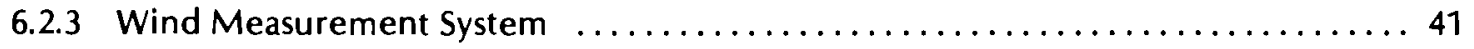

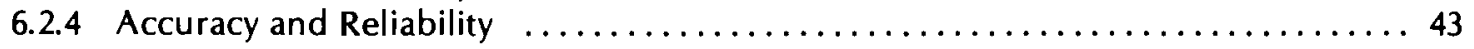

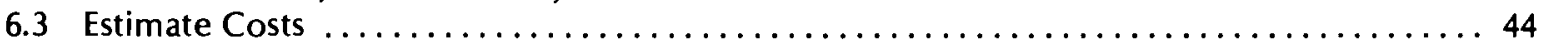

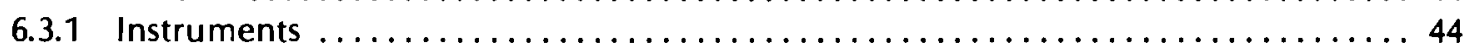

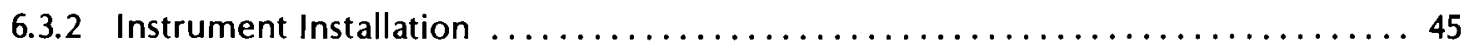

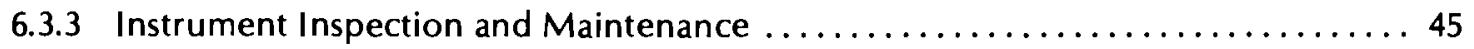

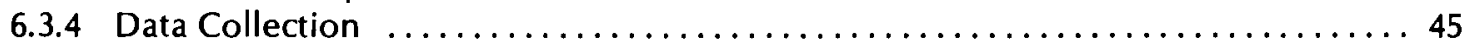

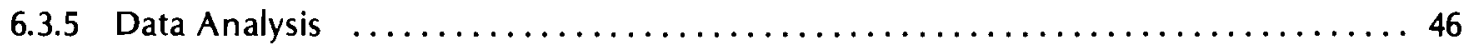

6.3.6 Measurement Program Duration ................................ 46

6.3.7 Example ..................................... 47 


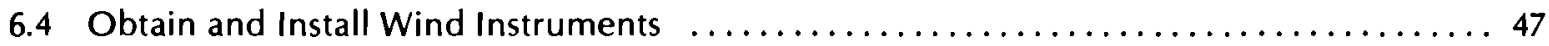

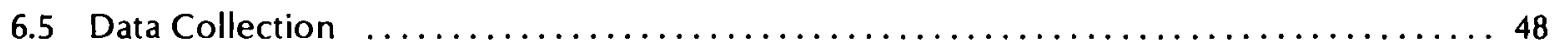

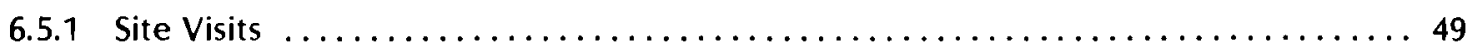

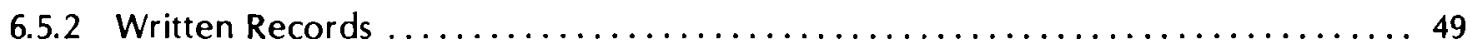

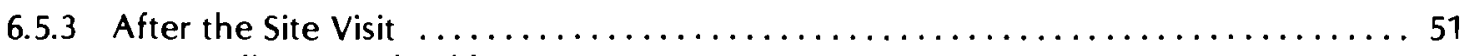

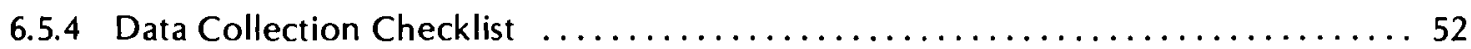

CHAPTER 7: ENVIRONMENTAL HAZARDS FOR WECS OPERATIONS ............

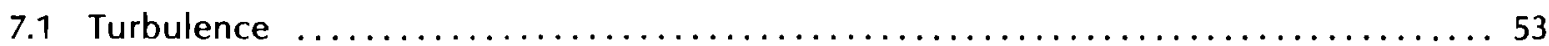

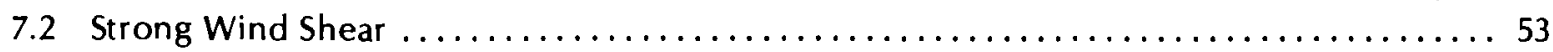

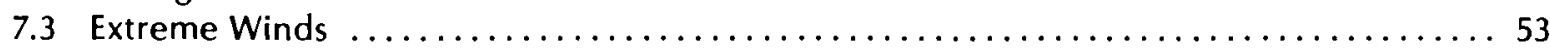

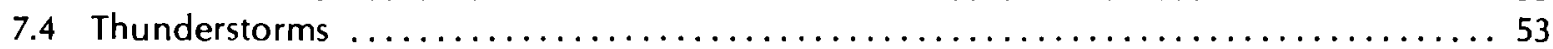

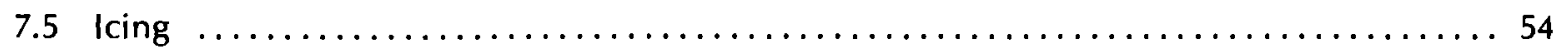

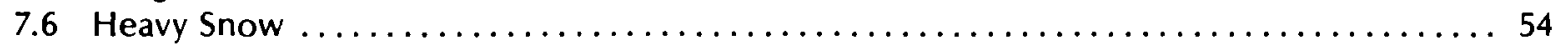

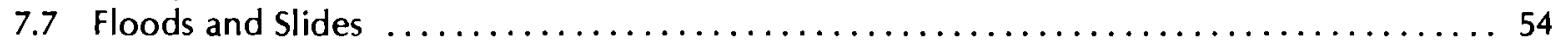

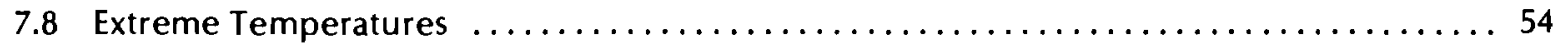

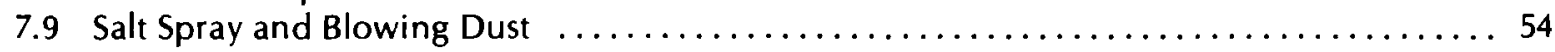

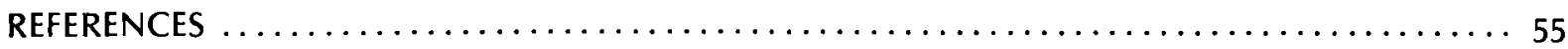

APPENDIX A: SOURCES AND USES OF WIND CLIMATOLOGY $\ldots \ldots \ldots \ldots$

APPENDIX B: INITIAL ESTIMATE OF WIND ENERGY POTENTIAL $\ldots \ldots \ldots \ldots . \ldots \ldots$

$\begin{array}{ll}\text { APPENDIX C: } & \text { ESTIMATING OUTPUT POWER FROM ANNUAL AVERAGE } \\ & \text { WIND SPEEDS AND WECS CHARACTERISTICS } \ldots \ldots \ldots \ldots \ldots \ldots \ldots \ldots\end{array}$

APPENDIX D: COMPUTATION OF OUTPUT POWER FROM WIND SUMMARIES ....... D.1

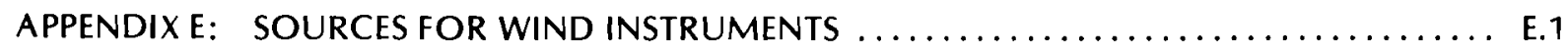

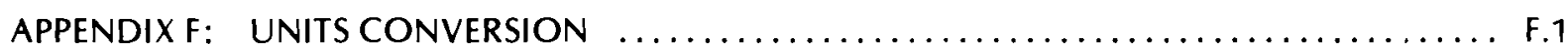

DISTRIBUTION $\ldots \ldots \ldots \ldots \ldots \ldots \ldots \ldots \ldots \ldots \ldots \ldots \ldots \ldots \ldots \ldots \ldots \ldots \ldots \ldots \ldots$ 


\section{List of Figures}

Development of a Siting Strategy Based on Terrain Classification $\ldots \ldots \ldots \ldots \ldots \ldots \ldots \ldots$. 2

Effect of Surface Friction on Low-Level Wind ............................. 5

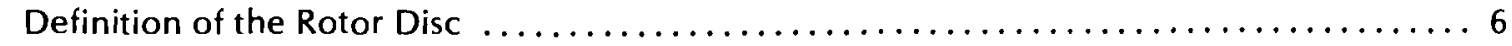

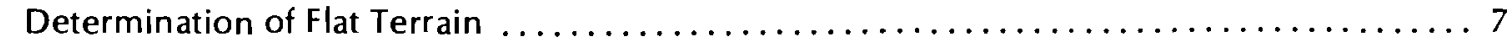

Formation of a New Wind Profile Above Ground Level $\ldots \ldots \ldots \ldots \ldots \ldots \ldots \ldots \ldots$

The Effects of Roughness Changes on the Vertical Wind Profile $\ldots \ldots \ldots \ldots \ldots \ldots \ldots \ldots 9$

Transition and Equilibrium Heights Downwind of a Change in Roughness $\ldots \ldots \ldots \ldots \ldots 9$

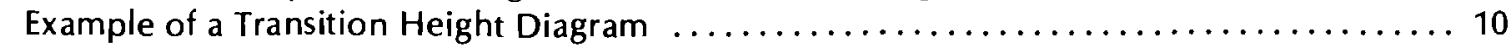

9 Comparison of the Effects of Different Surface Roughness on

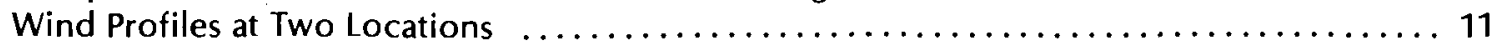

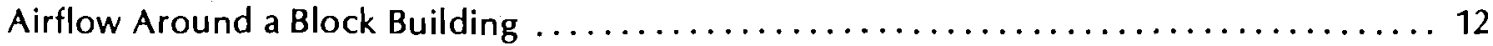

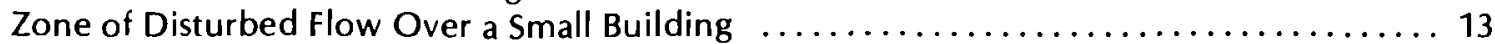

The Effects of an Undisturbed Airflow Encountering an Obstruction $\ldots \ldots \ldots \ldots \ldots \ldots \ldots$

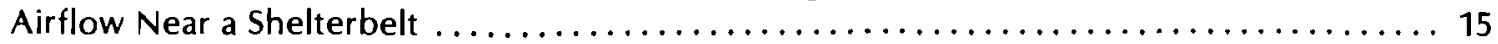

Percent Wind Speed at Different Levels Above the Surface Behind a

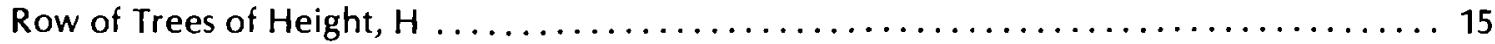

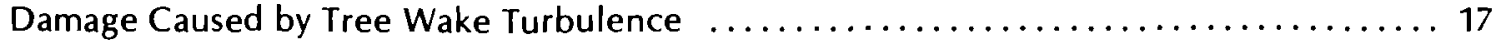

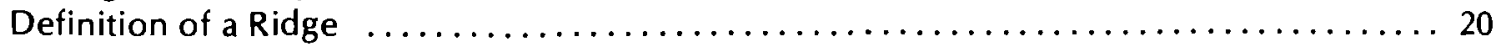

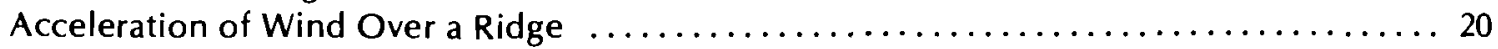

The Effects of Ridge Orientation and Shape on WECS Site Suitability $\ldots \ldots \ldots \ldots \ldots \ldots \ldots \ldots \ldots \ldots$

Ranking of Ridge Shape by Amount of Wind Acceleration . . . . . . . . . . . . . . . . . 21

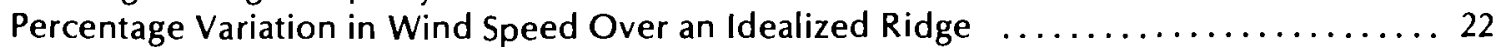

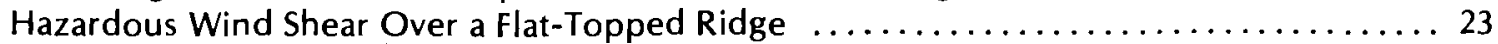

Effect of Surface Roughness on Wind Flow Over a Low Sharp-Crested Ridge .......... 23

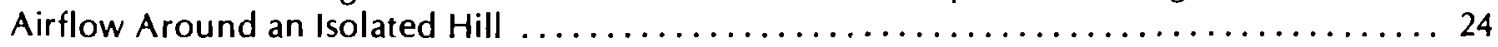

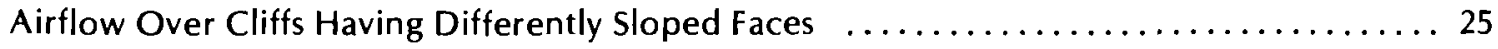

Top View of Airflow Over Concave and Convex Portions of a Cliff Face $\ldots \ldots \ldots \ldots \ldots 25$

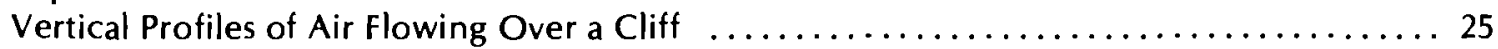

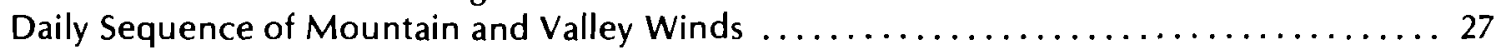

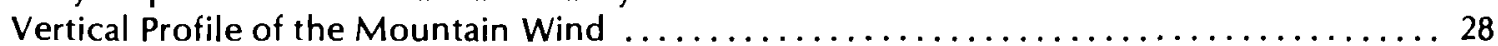

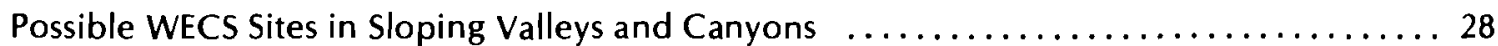

Possible WECS Sites Where Prevailing Winds are Channeled by Valleys ............. 29

A Schematic Illustration of Flow Patterns That May Be Observed

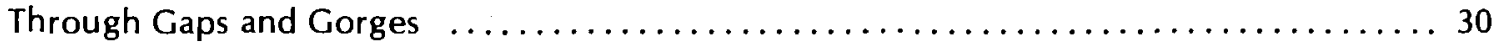

32 A Schematic of the Wind Pattern and Velocity Profile Through a Mountain Pass ....... 31

33 Wind Speed Rating Scale Based on the Shape of the Crown and

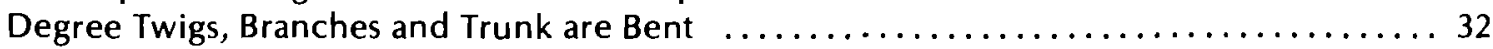

34 Deformation Ratio Computed as a Measure of the Degree of

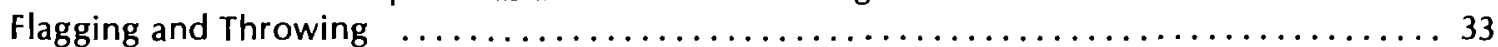

35 Increases in Accuracy of Long-Term Average Wind Speed Estimates with

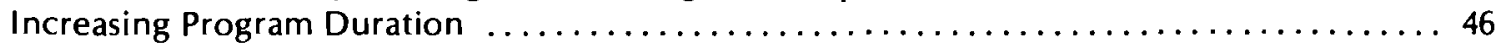

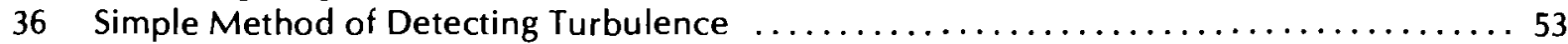

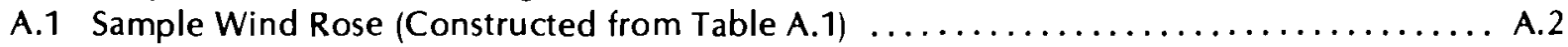

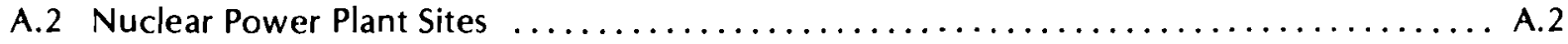

A.3 Sample Wind Power Rose (Constructed from Table A.1) $\ldots \ldots \ldots \ldots \ldots \ldots \ldots \ldots \ldots$ A.3

B.1 Annual-Average Wind Power at $50 \mathrm{~m}$ Above Higher Elevations, $\mathrm{W} / \mathrm{m}^{2} \ldots \ldots \ldots \ldots \ldots$ B.1

C.1 Estimate of Expected Average Output Power for Wind Turbines $\ldots \ldots \ldots \ldots \ldots \ldots \ldots \ldots$ C.1

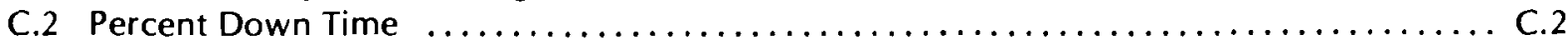

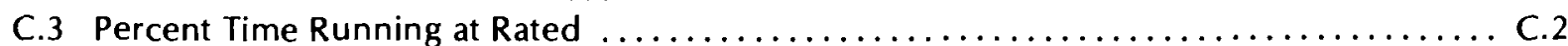

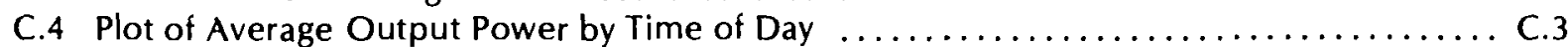

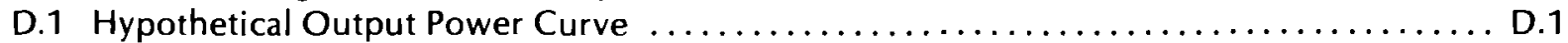




\section{List of Tables}

1 Wind Speed Extrapolation from $30 \mathrm{ft}$ to Other Heights Over Flat Terrain

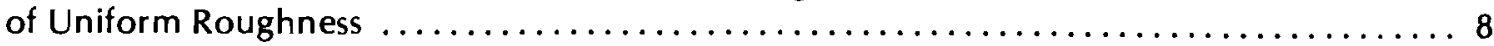

2 Wind Speed Extrapolation Factors for Sites in Areas of Different

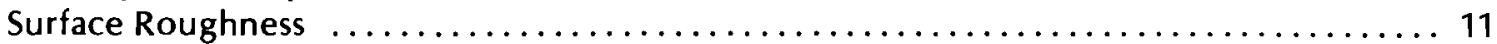

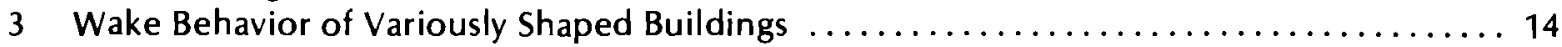

4 Available Power Loss and Turbulence Increase Downwind from Shelterbelts of Various Porosities .................................... 16

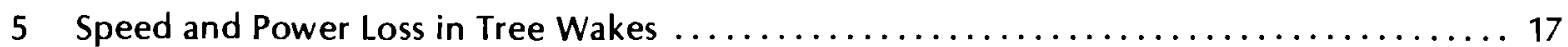

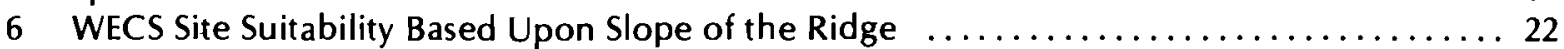

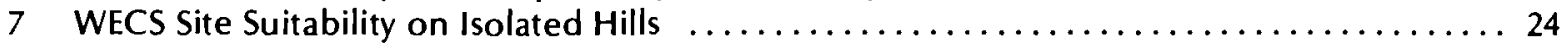

8 Mean Annual Wind Speed Versus the Griggs-Putnam Index $\ldots \ldots \ldots \ldots \ldots \ldots \ldots \ldots \ldots$

9 Mean Annual Wind Speed Versus the Deformation Ratio $\ldots \ldots \ldots \ldots \ldots \ldots \ldots \ldots \ldots$

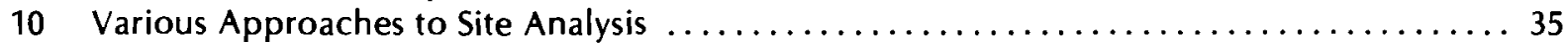

11 Example of Local Climatological Data Summarized by Hour of Day . . . . . . . . . . . 36

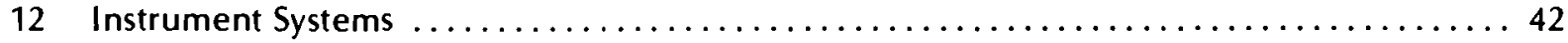

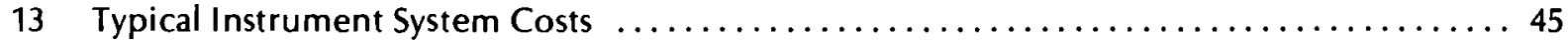

14 Uncertainty in Estimating the Long-Term Average Wind Speed, \% . . . . . . . . . . . 47

A.1 Sample Wind Summary with Percentage Frequencies of Wind

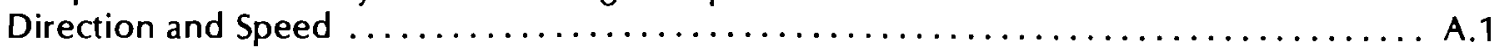

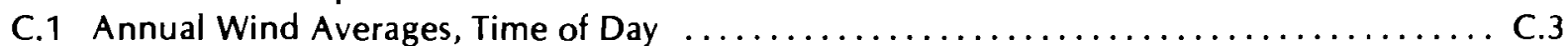

C.2 Values for Average Output Power/Rated Power $\ldots \ldots \ldots \ldots \ldots \ldots \ldots \ldots \ldots \ldots \ldots \ldots \ldots \ldots \ldots$

D.1 Hypothetical Wind Summary(\% Frequency of Occurrence) $\ldots \ldots \ldots \ldots \ldots \ldots \ldots \ldots \ldots .2$

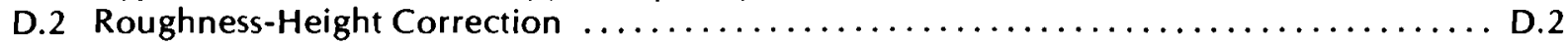

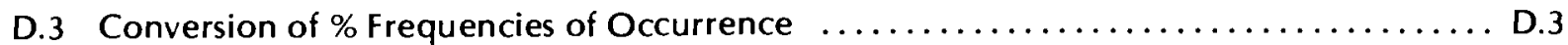




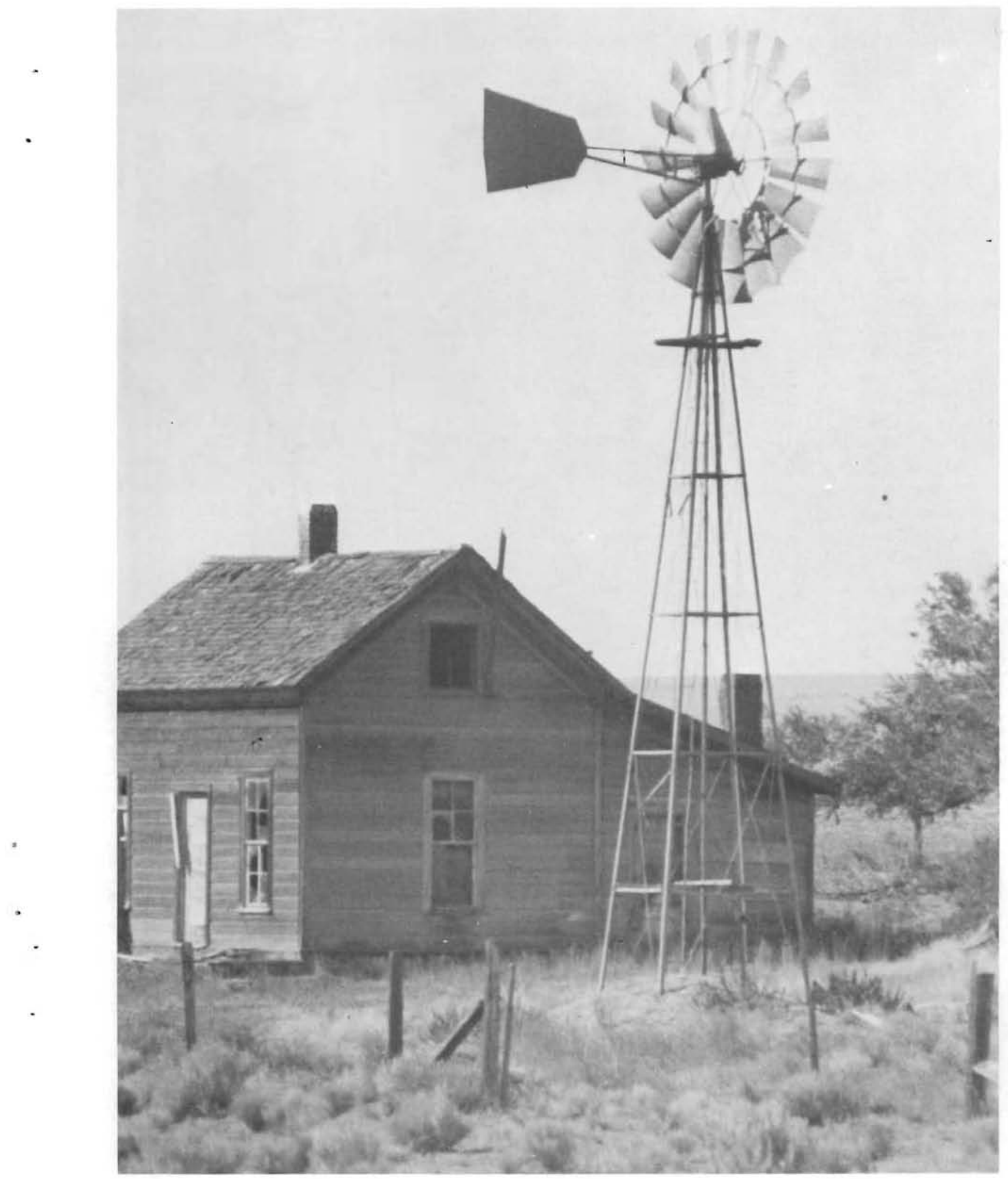





\section{Chapter 1}

\section{Introduction}

According to manufacturers of small wind energy conversion systems (WECS), improper siting has been a common cause of dissatisfaction among WECS owners (AWEA, 1977). However, a potential owner of a small WECS should realize that a relatively small investment for locating the best available site can easily yield savings of several thousand dollars over the lifetime of the system.

This handbook was written to serve as a siting guide for individuals wishing to install small wind energy conversion systems (WECS); that is, machines having a rated capacity of less than 100 kilowatts. It incorporates half a century of siting experience gained by WECS owners and manufacturers, as well as recently developed siting techniques. The user needs no technical background in meteorology or engineering to understand and apply the siting principles discussed; he needs only a knowledge of basic arithmetic and the ability to understand simple graphs and tables. By properly using the siting techniques, an owner can select a site that will yield the most power at the least installation cost, the least maintenance cost, and the least risk of damage or accidental injury.

The siting of small WECS should be viewed as an integral part of an overall plan for potential WECS users. A suggested plan is presented in the following outline:

A. Preliminary Feasibility Study

1. Initial wind resource assessment

a. Survey available WECS

*b. Estimate power output

c. Estimate power needs

2. Economic analysis

a. Analyze cost of WECS

b. Consider institutional factors, such as building codes or utility rates

c. Formulate working budget

* Since this handbook deals primarily with site selection, only asterisked topics are covered in detail; however, references are provided for all other topics.
B. Site and System Selection

1. Final wind resource assessment

*a. Select candidate site

*b. Determine available power at candidate site

2. Selection of WECS

a. Estimate power needs quantitatively

*b. Estimate power output quantitatively

c. Choose WECS (and storage/backup system, if applicable).

The following step-by-step procedure is suggested as a method of integrating the siting handbook and other references to accomplish the steps in the planning outline.

\section{A. Preliminary Feasibility Study}

To make the initial wind resource assessment, take the following steps:

1. Obtain information on costs and operating characteristics of available WECS. The American Wind Energy Association can provide lists of manufacturers and distributors from whom this information can be obtained. The address is:

\section{American Wind Energy Association 1621 Connecticut Avenue, N.W. \\ Washington, D.C. 20009}

2. Use the information in Appendix $B$ of this handbook to make a rough estimate of wind power potential. If there is little potential, wind energy will probably not be competitive with other energy sources.

3. Consult a copy of Wind Power for Farms, Home, and Small Industry by J. Park and D. Schwind (1978). This booklet contains practical information that complements the siting handbook and may be purchased from:

National Technical Information Service (NTIS)

United States Department of Commerce

5285 Port Royal Road

Springfield, Virginia 22151 
4. Estimate roughly the energy needs (both average load and peak load). Consult a WECS dealer and/or Chapter 4 of Park and Schwind (1978) for assistance.

5. Estimate power output for several available WECS, using Appendix $\mathrm{C}$ of this handbook. Will any of the WECS produce sufficient power? If not, can energy conservation make up the energy deficit?

To analyze the economics of the WECS, take the following steps:

1. If a WECS appears to meet power requirements, compare estimated WECS costs (over the life expectancy of the WECS) to the projected costs of conventional power for the same period. Chapter 6 of Park and Schwind (1978) gives instructions for a thorough economic analysis.

2. Consider the impact of all economic restraints, such as available funds, legal, environmental, utility interface and other concerns (see Chapter 7 of Park and Schwind, 1978).

3. Formulate a working budget from this information.

\section{B. Site and System Selection}

To make the final wind resource assessment, follow the general siting strategy depicted in Figure 1 . The following steps will help guide the user through the strategy shown in Figure 1.

1. Read Chapters 2 and 7 of the siting handbook for essential information on the nature of wind, wind power and WECS hazards.

2. Read the introduction to Chapter 3 and classify terrain as flat or non-flat.

a. If terrain is non-flat:

(1) Read Sections 3.1 and 3.2 of Chapter 3 for background.

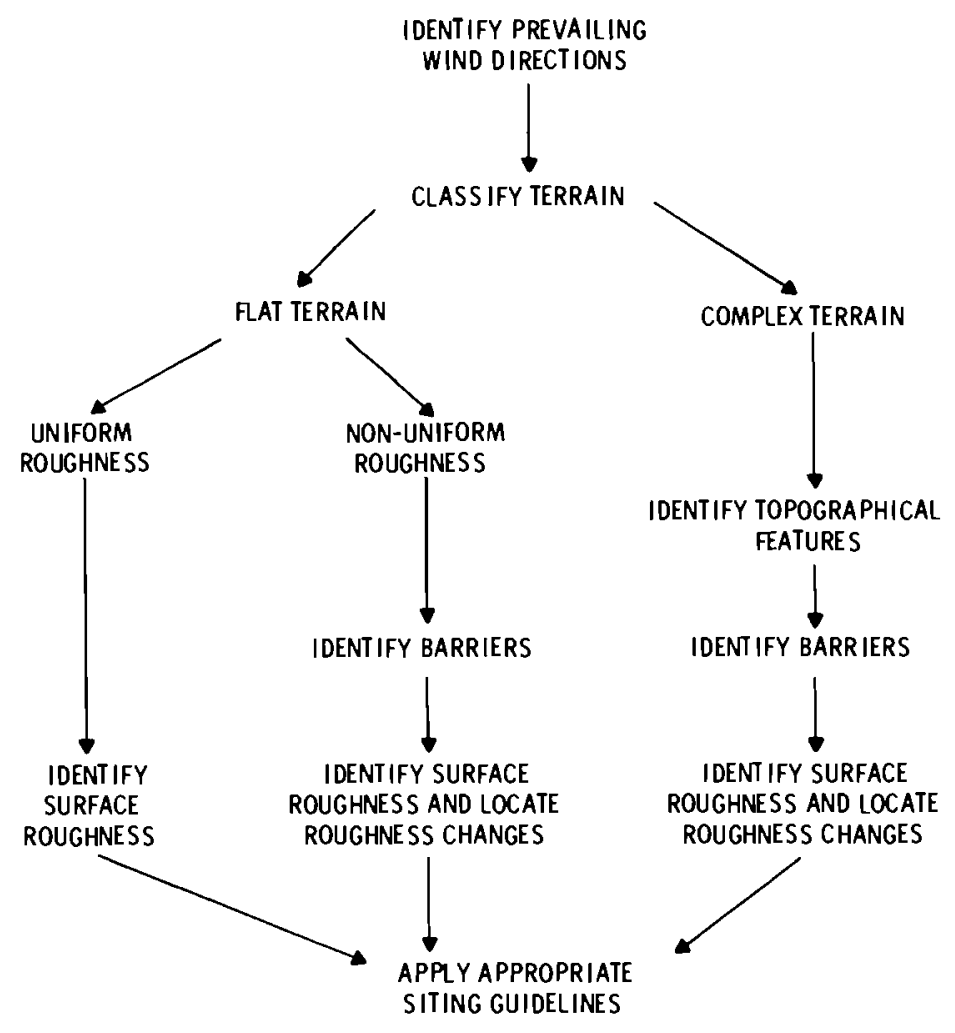

FIGURE 1. Development of a Siting Strategy Based on Terrain Classification 


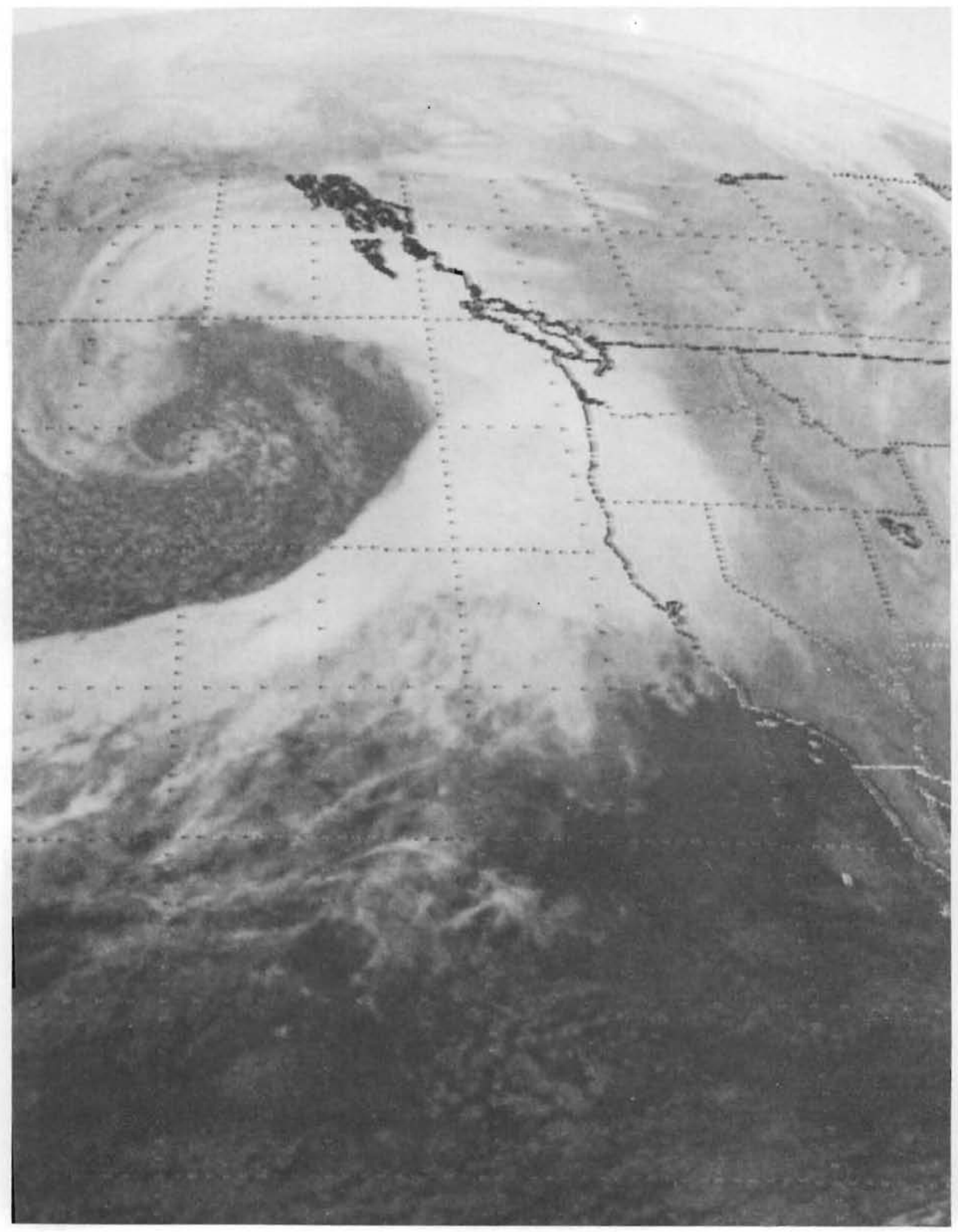




\section{Chapter 2}

\section{General Description of the Wind}

The sun is the ultimate energy source that drives the wind. Incoming solar energy, which generally decreases from the equator to the poles, is absorbed and reflected differently by various parts of the atmosphere and by the various types of surfaces (i.e., oceans, snow, ice, sandy deserts, forests, etc.). The redistribution of incoming solar energy produces low and high pressure areas. These pressure differences in the atmosphere force the air to move toward lower pressure. Once the air begins to move, other factors modify its speed and direction.

\subsection{Influences on Airflow}

Pressure systems (frequently 500 to $\mathbf{1 0 0 0}$ miles or more in diameter), which are associated with large-scale wind patterns, migrate from west to east across North America. As the air in the large-scale wind pattern moves through local areas, its speed and direction may be changed by the local topography and by local heating or cooling. At a particular WECS site, trees, buildings or other small-scale influences may further disturb the wind flow. The combined effects of these three scales of influence produce highly variable winds.

\subsection{Effects of Surface Roughness}

The surface over which the wind flows affects wind speed near that surface. A rough surface (such as trees and buildings) will produce more friction than a smooth surface (such as a lake). The greater the friction the more the wind speed is reduced near the surface.

Figure 2 illustrates how surface roughness affects wind speed by means of a vertical wind speed profile-simply a picture of the change in wind speed with height. Within $10 \mathrm{ft}$ of the surface, wind speed is greatly reduced by friction. Wind speed increases with height as the effects of surface roughness are overcome. Knowing how the surface roughness affects the vertical wind speed profile is extremely valuable when determining the most beneficial WECS tower height.

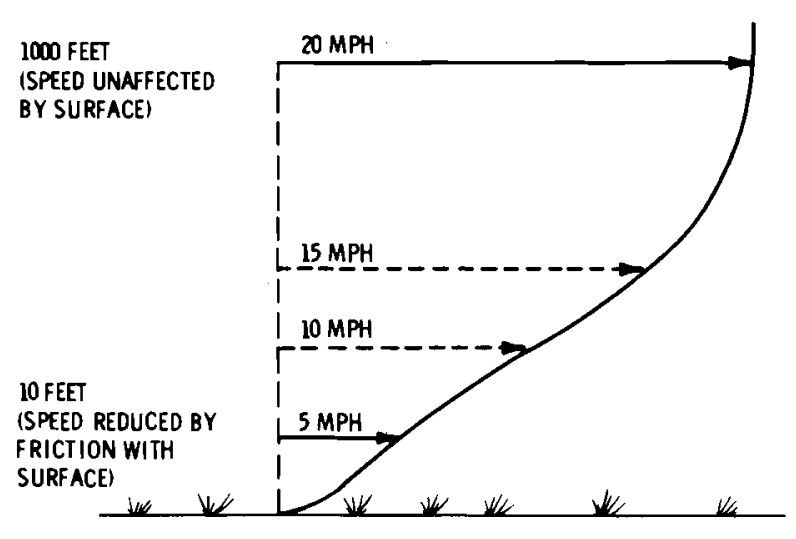

FIGURE 2. Effect of Surface Friction on Low-Level Wind

\subsection{Available Power in the Wind}

A clear understanding of the variation of power with wind speed is essential to finding a site with the most available wind power. The following equation defines the relationship between available power and wind speed:

$$
\text { Available Power }=0.5 \times \mathrm{D} \times \mathrm{A} \times \mathrm{S}^{3}
$$

where

$$
\begin{aligned}
& D=\text { air density } \\
& A=\text { area of the rotor disc } \\
& S=\text { the wind speed }\left(S^{3}=S \times S \times S\right. \text {, cube of wind } \\
& \text { speed }) .
\end{aligned}
$$

Rotor discs (mentioned in the above equation) are illustrated in Figure 3 for three different types of WECS. Since air density (D) at a site normally varies only $10 \%$ or less during the year, the available power depends primarily on the area (A) of the rotor disc and the wind speed (S). Increasing the diameter of the rotor disc (by increasing the blade length) will allow the WECS to intercept more of the wind and thereby harness more power. (a) Since the available power varies with cube of the wind speed, choosing a site where wind speed is

(a) The choice of WECS size should not be made solely on this basis, but in conjunction with the WECS dealer and/or Chapter 5 of this handbook. 
(2) Read the portions of Section 3.3 and Chapter 4 that deal with barriers and terrain features in, or near, the siting area.

(3) Follow siting guidelines given to select the best candidate site(s).

b. If terrain is flat:

(1) Read Sections 3.1 and 3.2 for background.

(2) If the surface roughness $(a)$ is uniform, select candidate sites by reading applicable portions of Section 3.3.

(3) If there are changes in roughness, consider Section 3.2 in conjunction with the applicable portions of Section 3.3 to select candidate site(s).
3. Read Chapter 5 of this handbook and select a method of site evaluation. If onsite data are to be collected, read Chapter 6 of this handbook before beginning.

To select a WECS, take the following steps:

1. When all site evaluation data have been collected, use guidelines in Chapter 5 and Appendices $C$ and $D$ of this handbook to make final estimates of output power for various WECS.

2. Make a detailed estimate of energy needs if this was not done in the feasibility study (a WECS dealer and/or Chapter 4 of Park and Schwind, 1978, can provide guidance).

3. Select the WECS that meets energy requirements at the lowest cost.

(a) Surface roughness is explained in Chapter 2. 
(HORIZONTAL AXIS ROTOR)
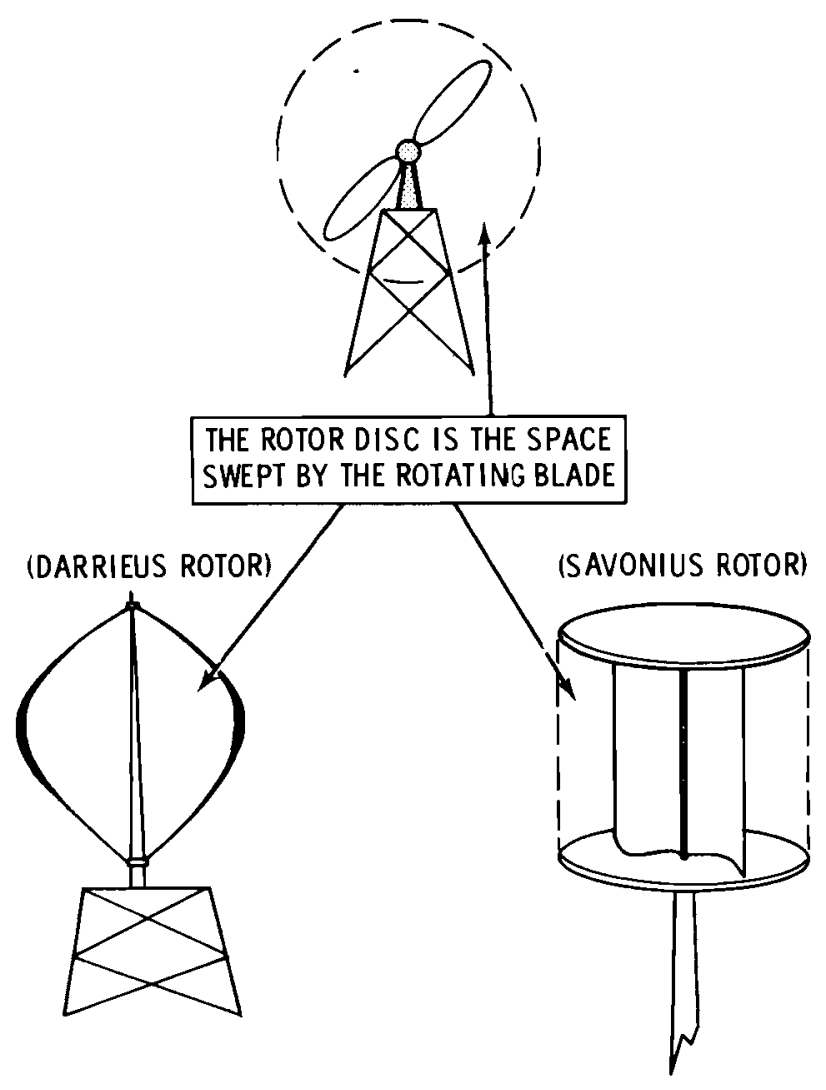

FIGURE 3. Definition of the Rotor Disc greatest is desirable. Even a small change in wind speed results in a large change in available power. Suppose that one computation of available power at a site has been based on a wind speed estimate of $10 \mathrm{mph}$ when the actual speed was $9 \mathrm{mph}$. The actual available power would be almost $30 \%$ less than the estimated power as a result of only a one$\mathrm{mph}$ error in the estimated wind speed.

To estimate the available power in the entire year, it is necessary to estimate how frequently each wind speed occurs. The value that the user places on accurate estimates of available power will ultimately determine the time and money he is willing to spend to estimate the annual frequencies of wind speeds at his site. Various approaches to wind data collection and analysis are discussed in Chapters 5 and 6.

Before a site is chosen, the user should know how available power and wind direction vary in the area. A convenient way of expressing the relationship between the two is through the use of a wind power rose, a graphic representation of the amount of wind power associated with each wind direction. If a potential WECS user has lived at a location for a long period of time, he may intuitively know the principal power direction (i.e., which wind direction will contain most of the available power). However, if data from a nearby observing station are available, a wind power rose can be constructed from the summarized data (see Appendix A for definition, methods of construction, and use of wind power roses). 


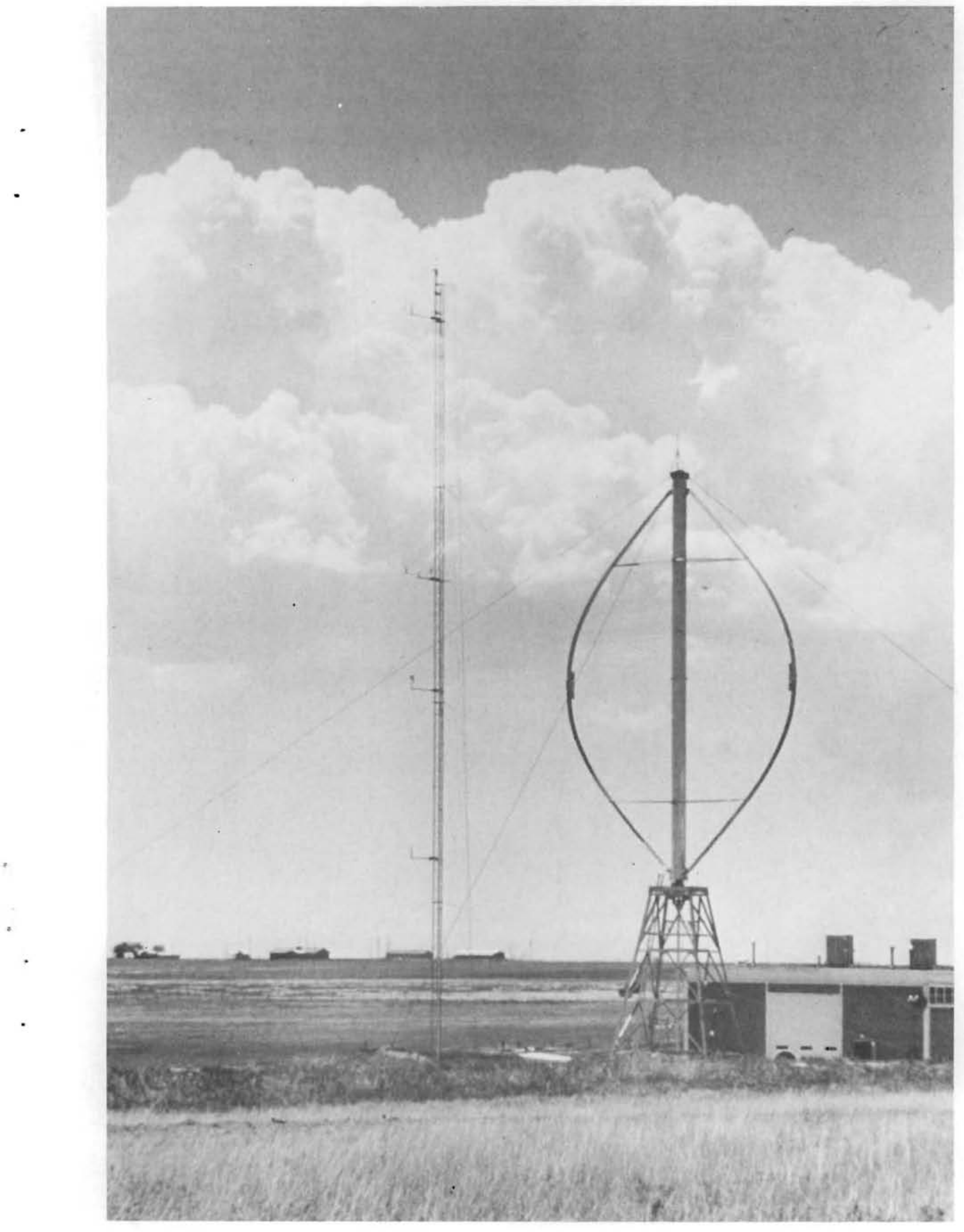




\section{Chapter 3}

\section{Siting in Flat Terrain}

Choosing a site in flat terrain is not as complicated as choosing a site in hilly or mountainous areas. When siting in flat terrain, only two primary questions need to be considered:

- What surface roughnesses affect the wind profile in the area?

- What barriers might affect the free flow of the wind?

Terrain can be considered flat if it meets the following conditions; however, these conditions are very conservative (see Figure 4, Frost and Nowak, 1977):

1. the elevation difference between the site and the surrounding terrain is less than $200 \mathrm{ft}$ for 2 to 3 miles in any direction;

2. the ratio of $h \div \ell$ in Figure 4 is less than 0.03 (that is, a $3 \%$ grade).

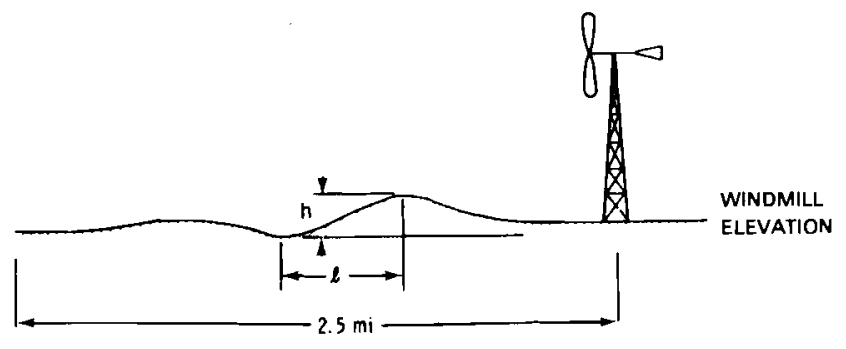

h - LARGEST DIFFERENCE OF TERRAIN

$\ell$ - LENGTH OVER WHICH LARGEST DIFFERENCE OF TERRAIN OCCURS

FIGURE 4. Determination of Flat Terrain (Frost and Nowak, 1977)

If there are no large topographical features within a mile or so of the proposed WECS site, Chapter 3 can be used for siting. However, if nearby terrain features might influence the choice of a site, the user should read the portion(s) of Chapter 4 dealing with these features to better understand the local airflow.

Wind rose information (see Appendix A) can also guide the user in determining the influence of nearby terrain. For example, suppose a 400 -ft-high hill lies $1 / 2$ mile northeast of the proposed site (this classifies the terrain as non-flat). Also, assume the wind rose indicates that winds blow from the northeast quadrant only $5 \%$ of the time with an average speed of $5 \mathrm{mph}$. Obviously, so little power is associated with winds blowing from the hill to the site that the hill can be disregarded. If there are no terrain features upwind of the site along the principal wind power direction(s), the terrain can be considered flat.

\subsection{Uniform Roughness}

Surface roughness describes the texture of the terrain. The rougher the surface, the more the wind flowing over it is impeded. Flat terrain with uniform surface roughness is the simplest type of terrain for selecting a WECS site. A large area of flat, open grassland is a good example of uniform terrain. If there are no obstacles (i.e., buildings, trees, or hills), the wind speed at a given height is nearly the same over the entire area.

The only way to increase the available power in uniform terrain is to raise the machine higher above the ground. A measurement or estimate of the average wind speed at one level can be used to estimate wind speed (thus the available power) at other levels. Table 1 provides estimates of wind speed changes for several surface roughnesses at various tower heights. The numbers in the table are based on wind speeds measured at $30 \mathrm{ft}$ because National Weather Service wind data are frequently measured near that height. To estimate the wind speed at another level, multiply the $30-\mathrm{ft}$ speed by the factor for the appropriate surface roughness and height. For example, if the average wind speed at $30 \mathrm{ft}$ over an area of low grass cover is $10 \mathrm{mph}$, use the multiplication factor from Table 1 (which in this case is 1.17) to determine the wind speed at $80 \mathrm{ft}$ : $1.17 \times 10 \mathrm{mph}=11.7 \mathrm{mph}$.

If the height of the known wind speed is not $30 \mathrm{ft}$, wind speed can be estimated using the following equation:

Estimated wind speed $=\frac{E}{K} \times S$

where

$E=$ the table value for the height of the wind speed to be estimated

$K=$ the table value for the height of the known wind

$S=$ the known wind speed. 
TABLE 1. Wind Speed Extrapolation from $30 \mathrm{ft}$ to Other Heights Over Flat Terrain of Uniform Roughness(a)

\begin{tabular}{|c|c|c|c|c|c|c|c|c|c|c|}
\hline $\begin{array}{l}\text { Roughness } \\
\text { Characteristic }\end{array}$ & & & & & Abo & Grour & & & & \\
\hline & 20 & 40 & 60 & 80 & 100 & 120 & 140 & $160^{(b)}$ & $180^{(b)}$ & $200^{(b)}$ \\
\hline $\begin{array}{l}\text { Smooth surface } \\
\text { ocean, sand }\end{array}$ & 0.96 & 1.03 & 1.07 & 1.10 & 1.12 & 1.14 & 1.16 & 1.17 & 1.18 & 1.19 \\
\hline $\begin{array}{l}\text { Low grass or } \\
\text { fallow ground }\end{array}$ & 0.93 & 1.05 & 1.12 & 1.17 & 1.21 & 1.24 & 1.27 & 1.29 & 1.31 & 1.33 \\
\hline $\begin{array}{l}\text { High grass or } \\
\text { low row crops }\end{array}$ & 0.92 & 1.06 & 1.14 & 1.20 & 1.25 & 1.28 & 1.32 & 1.34 & 1.37 & 1.39 \\
\hline $\begin{array}{l}\text { Tall row crops } \\
\text { or low woods }\end{array}$ & 0.91 & 1.06 & 1.15 & 1.21 & 1.26 & 1.30 & 1.33 & 1.36 & 1.39 & 1.41 \\
\hline $\begin{array}{l}\text { High woods } \\
\text { with many trees }\end{array}$ & 0.86 & 1.10 & 1.24 & 1.34 & 1.41 & 1.48 & 1.53 & 1.58 & 1.62 & 1.65 \\
\hline $\begin{array}{l}\text { Suburbs, small } \\
\text { towns }\end{array}$ & 0.78 & 1.16 & 1.38 & 1.54 & 1.67 & 1.77 & 1.85 & 1.93 & 1.99 & 2.05 \\
\hline
\end{tabular}

Suppose the $10 \mathrm{mph}$ in the previous example had been measured at $20 \mathrm{ft}$ instead of $30 \mathrm{ft}$. To estimate the speed at $80 \mathrm{ft}$, divide the factor for $80 \mathrm{ft}(1.17)$ by the factor for $20 \mathrm{ft}(0.93)$ to obtain the corrected factor (1.26); then multiply this corrected factor by the known wind speed (10 $\mathrm{mph}$ ) to estimate the $80-\mathrm{ft}$ wind speed (12.6 $\mathrm{mph})$. This calculation is shown in equation form below:

$\frac{\mathrm{E}}{\mathrm{K}} \times \mathrm{S}=\frac{1.17}{0.93} \times 10 \mathrm{mph}=1.26 \times 10 \mathrm{mph}=12.6 \mathrm{mph}$

The heights in Table 1 should not always be thought of as heights above ground. Over areas of dense vegetation (such as an orchard or forest) a new "effective ground level" is established at approximately the height where branches of adjacent trees touch. Below this level there is little wind; consequently, it is called the level of zero wind, or the zero displacement height. In a dense cornfield, the level of zero wind would be the average corn height; in a wheat field, the average height of the wheat, etc. The height at which this level occurs is labeled " $d$ " in Figure 5. If " $d$ " is less than $10 \mathrm{ft}$, it can usually be disregarded in estimating speed and power changes. However, if ground level is used when " $d$ " is actually $10 \mathrm{ft}$ or more, changes in speed and power from one level to another will be underestimated. Table 1 expresses all heights above the " $d$ " height, rather than above ground.

\subsection{Changes in Roughness}

In many locations, the surface roughness may change upwind of the WECS site; for example, a forest may change to open grassland. Such a sharp, or clearly defined, change may affect the vertical wind profile. Figure 6 shows how the wind profile changes as the surface roughness changes from rough to smooth or from smooth to rough. In part $A$ of Figure 6 , the wind profile in the lowest region (zone 1) is in equilibrium with the downwind surface roughness; that is, the forces acting on the wind are in balance. Because the wind profile is in equilibrium, a known wind at one height in the zone can be extrapolated upward or downward within the zone using the extrapolation factors for 


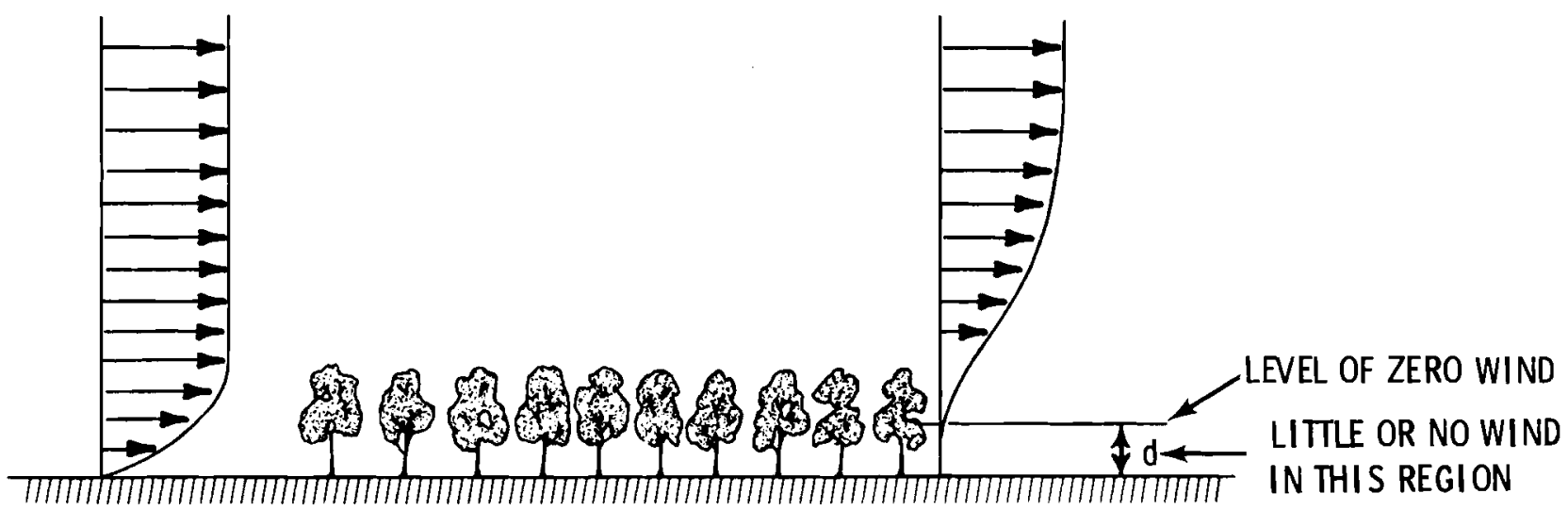

FIGURE 5. Formation of a New Wind Profile Above Ground Level

(A)

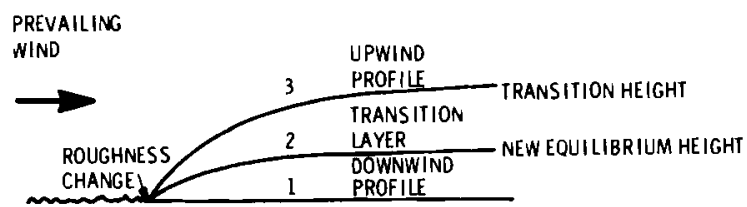

(B)

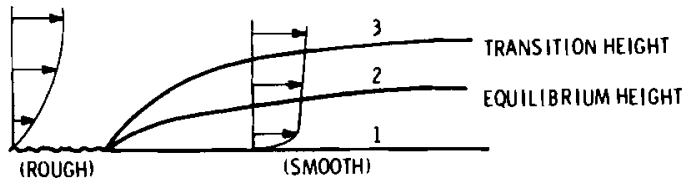

(C)

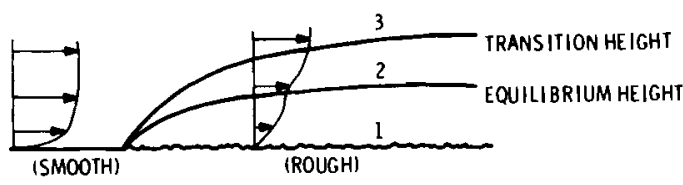

FIGURE 6. The Effects of Roughness Changes on the Vertical Wind Profile

the appropriate surface roughness (see Table 1). Similarly, the wind speed can be extrapolated upward or downward in the highest region (zone 3) where the wind profile is in equilibrium with the upwind surface roughness.

A transition layer (zone 2) exists between zones 1 and 3 . In this zone, the wind changes from one type of profile to another, so it is not possible to predict the precise nature of the wind speed change. However, it is possible to make some qualitative estimates of how the wind speed changes with height in the transition layer and to estimate the height and thickness of the transition layer.

A WECS owner must have some knowledge of the height and thickness of the transition layer before he can make a decision concerning the height of a WECS tower (see Figure 7). Notice that the top of the transition layer depends primarily on the distance downwind from the roughness change, but that the new equilibrium height depends on the type of roughness change.

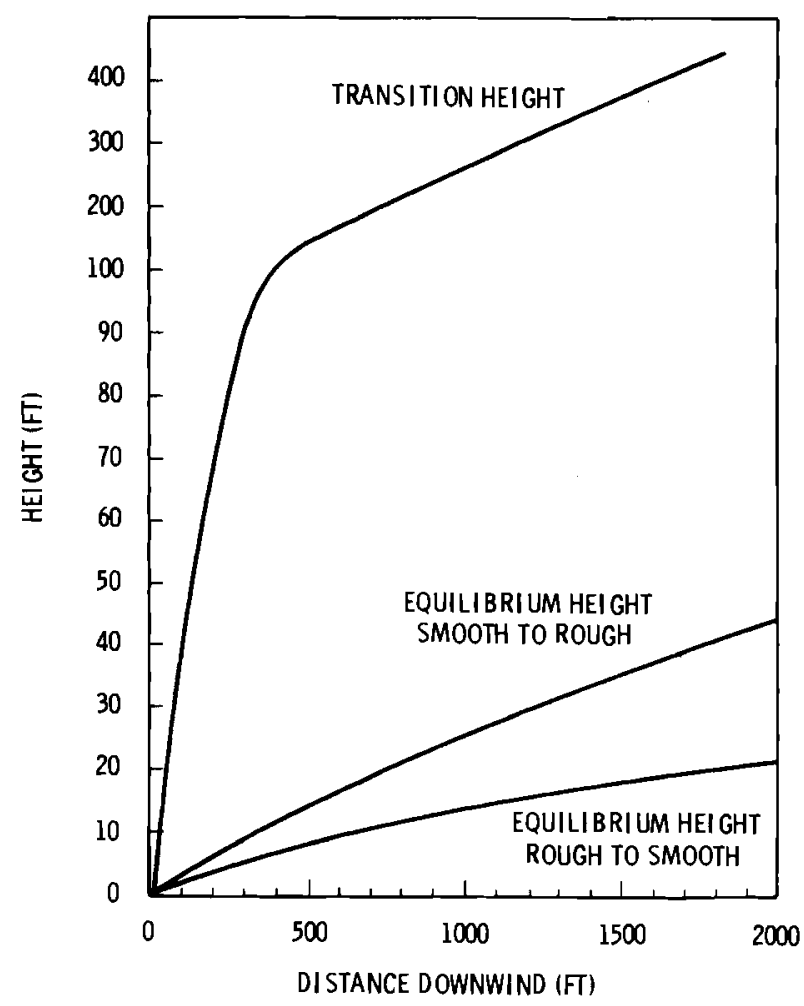

FIGURE 7. Transition and Equilibrium Heights Downwind of a Change in Roughness (Rao, Wyngaard and Coté, 1973) 
Part B of Figure 6 shows what the wind speed profile might look like if the surface is rougher upwind of the WECS site along the prevailing wind power direction(s). In this case, the rate of increase of wind with height is reduced which means that increasing the WECS tower height in this situation may be less beneficial. On the other hand, part $C$ of the figure shows that a substantial increase in wind speed occurs in the transition layer if the smoother surface is upwind. Here it may be very beneficial to increase the WECS tower height.

Figure 8 illustrates how data from Figure 7 can sometimes be used to take advantage of transition heights downwind of roughness changes. In this example, the roughness changes from relatively smooth (low grass) to fairly rough (low forest) at about $200 \mathrm{ft}$ upwind of the WECS site. Notice that the " $d$ " height shown in Figure 5 was taken into account for the forested land. In this case, a WECS tower height of about $90 \mathrm{ft}$ would allow the user to place the WECS up in the airflow influenced by the low grassland, rather than in the slower flow caused by the forest below. However, the information in this section should only be used to make estimates of the wind profile.

One approach to estimating the wind profile is to use wind data from a nearby weather station. Logically, monthly or annual averages at the height of the weather station anemometer would be used and the average speed(s) simply extrapolated to the WECS height (using Table 1) to estimate the average speed at the WECS site. However, this approach may give erroneous results if the WECS rotor is located in an area that is affected by a surface roughness appreciably different from the roughness at the weather station. Figure 9 illustrates this problem.

In Figure 9, the weather station is assumed to be a typical airport site having a surface roughness characteristic of tall grass. The long-term average wind measured at the airport at the anemometer height is represented by the length of the lower arrow (arrow 1). Because the surface at the WECS site is very rough, the wind speed is much lower for the WECS site at the same height as the airport anemometer. After extrapolating to the proposed WECS height, the figure shows that the site wind speed is still lower than the airport wind speed.

By using Table 2, the user can extrapolate average wind speeds from a weather station of known anemometer height and surface roughness to that of the proposed WECS height at the WECS site. If the weather station has a high grass roughness and the wind was measured near the $30-\mathrm{ft}$ level ( 25 to $35 \mathrm{ft}$ ), the average wind at the WECS site can be estimated for a proposed tower height by simply multiplying the weather station speed by the appropriate WECS site roughness and height factor given in Table 2. For example, a user wants to estimate the annual average wind speed of a WECS at $80 \mathrm{ft}$ in a suburban area, but the annual average wind speed at the nearest weather station, measured at $28 \mathrm{ft}$, is $10 \mathrm{mph}$. To estimate the annual average wind speed for his proposed site, the user would multiply the multiplication factor given in Table 2 for $80 \mathrm{ft}$ over suburbs and small towns $(0.74)$

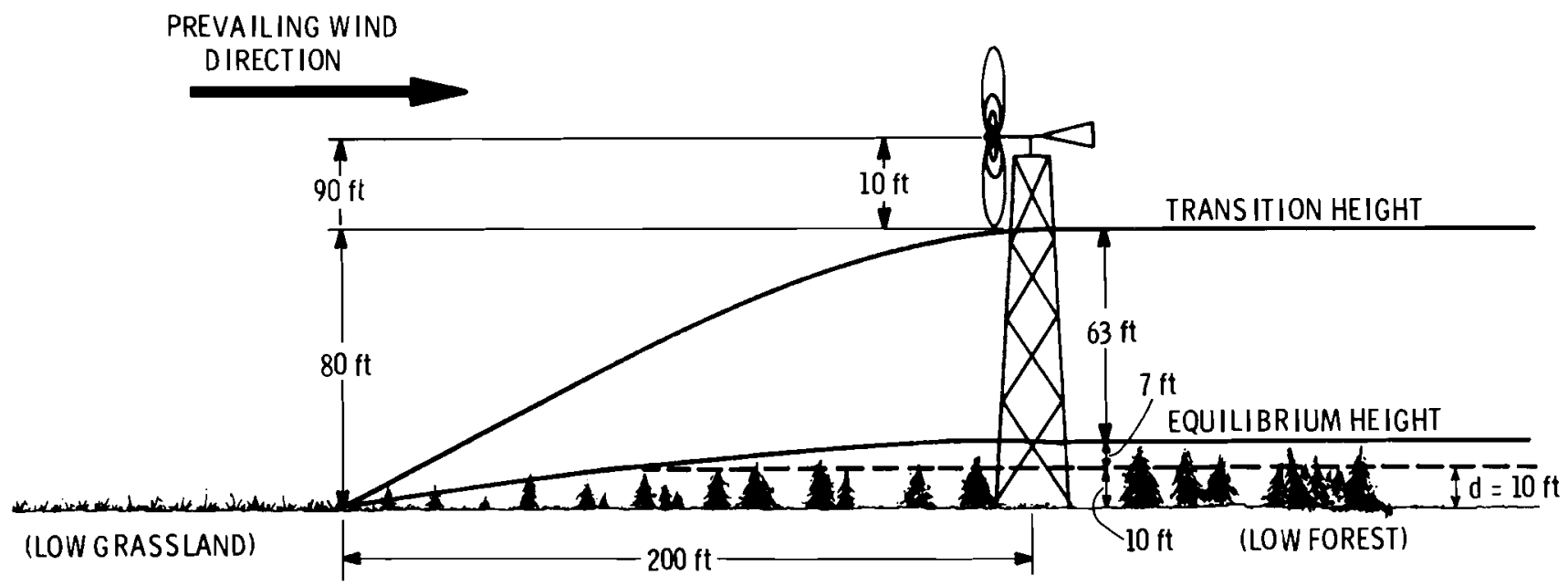

FIGURE 8. Example of a Transition Height Diagram 


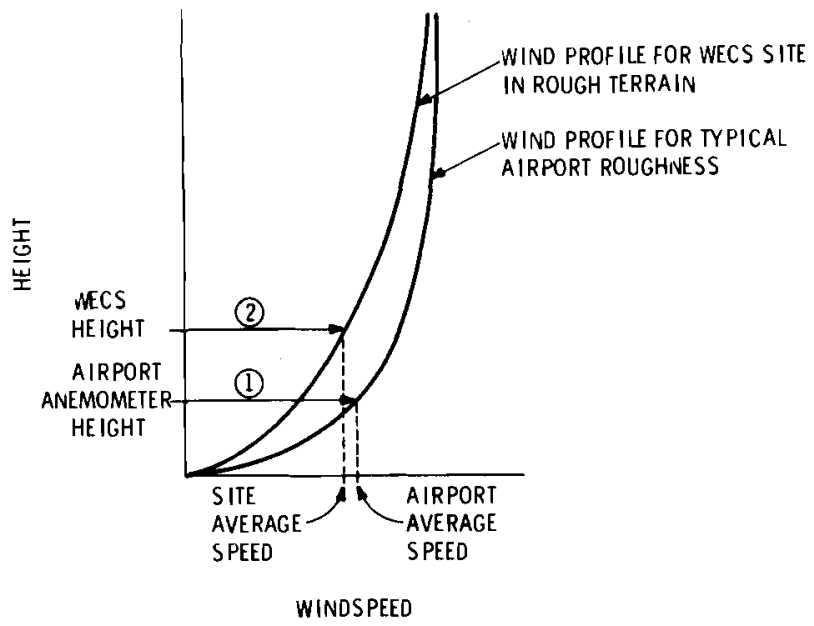

FIGURE 9. Comparison of the Effects of Different Surface Roughness on Wind Profiles at Two Locations

by the annual average wind speed at the weather station $(10 \mathrm{mph})$. The product would be an estimated annual average wind speed of $7.4 \mathrm{mph}$.

For cases where the weather station anemometer is not near $30 \mathrm{ft}$ and/or where the rough- ness is other than that of high grass, a ratio of factors must be considered. The multiplication factor for the WECS site should be divided by the multiplication factor for the weather station to obtain the proper correction factor. This correction factor should then be multiplied by the weather station average wind speed to estimate the WECS site wind speed. Consider the following example: the WECS is to be located in an area of high woods at a height of $80 \mathrm{ft}$. The user is interested in the June average wind speed at his site. The weather station anemometer is located in an area of low grass at $20 \mathrm{ft}$ above ground, where the long-term wind speed average for June is $9 \mathrm{mph}$. The proper correction factor is the WECS site factor (0.93) divided by the weather station factor (1.02), which equals 0.91 . The estimated wind speed for June at the WECS site is $0.91 \times 9 \mathrm{mph}=8.2$ mph.

This method of extrapolating wind speeds from one height to another in areas of different roughness is limited in its application. First, this method only provides a rough estimate of the average wind speed at the WECS site, although the information can be used to select the WECS tower height. (It

TABLE 2. Wind Speed Extrapolation Factors for Sites in Areas of Different Surface Roughness ${ }^{(a)}$

\begin{tabular}{|c|c|c|c|c|c|c|c|c|c|c|c|}
\hline \multirow[t]{2}{*}{$\begin{array}{l}\text { Roughness } \\
\text { Characteristic }\end{array}$} & \multicolumn{11}{|c|}{ Height Above Ground, ft } \\
\hline & 20 & 30 & 40 & 60 & 80 & 100 & 120 & 140 & 160 & 180 & 200 \\
\hline $\begin{array}{l}\text { Smooth surface } \\
\text { ocean, sand }\end{array}$ & 1.40 & 1.45 & 1.50 & 1.56 & 1.60 & 1.63 & 1.66 & 1.68 & 1.70 & 1.72 & 1.74 \\
\hline $\begin{array}{l}\text { Low grass or } \\
\text { fallow ground }\end{array}$ & 1.02 & 1.10 & 1.16 & 1.24 & 1.29 & 1.34 & 1.37 & 1.40 & 1.43 & 1,45 & 1.47 \\
\hline $\begin{array}{l}\text { High grass or } \\
\text { low row crops }\end{array}$ & 0.92 & 1.00 & 1.06 & 1.14 & 1.20 & 1.25 & 1.28 & 1.32 & 1.34 & 1.37 & 1.39 \\
\hline $\begin{array}{l}\text { Tall row crops } \\
\text { or low woods }\end{array}$ & 0.88 & 0.97 & 1.05 & 1.11 & 1.17 & 1.22 & 1.26 & 1.29 & 1.32 & 1.34 & 1.36 \\
\hline $\begin{array}{l}\text { High woods } \\
\text { with many trees }\end{array}$ & 0.60 & 0.70 & 0.77 & 0.86 & 0.93 & 0.99 & 1.03 & 1.07 & 1.10 & 1.13 & 1.15 \\
\hline $\begin{array}{l}\text { Suburbs, small } \\
\text { towns }\end{array}$ & 0.37 & 0.48 & 0.55 & 0.66 & 0.74 & 0.80 & 0.84 & 0.89 & 0.92 & 0.95 & 0.98 \\
\hline
\end{tabular}

(a) This table was developed by Tom Hiester of PNL using log profiles. 
emphasizes the need for increased tower height in rough terrain.) Second, it should not be applied in mountainous or hilly terrain. Third, the method should not be applied to the sites that are more than about 60 miles from the weather station. Finally, this extrapolation method is only valid if the wind at the WECS site is in balance with the surface roughness at the WECS site.

Although estimates of the wind profile can be used to select WECS sites and identify acceptable tower heights, the wind profile should be verified. The best way to verify the wind profile is to make a few onsite wind measurements during prevailing wind conditions, given the siting considerations presented in this chapter. When using the extrapolation method the user should:

- consult Figure 7 if the roughness changes sharply upwind of the WECS site

- use the upwind surface roughness to characterize the site if the proposed height is above the transition height

- not use Table 2 if the WECS is in the transition layer.

\subsection{Barriers in Flat Terrain}

Barriers produce disturbed areas of airflow downwind, called wakes. In barrier wakes, wind speed is reduced and rapid changes in wind speed and direction, called turbulence, are increased. Because most wind generators have relatively thin blades that rotate at high speeds, barrier wakes should be avoided whenever possible, not only to maximize power, but also to minimize turbulence. Exposure to turbulence may greatly shorten the lifespan of small WECS. (See Chapter 7 for a discussion of turbulence as a hazard.)

In the following discussion several figures and tables are presented that describe wind power and turbulence variations in barrier wakes. To make this information useful, all lengths are expressed as the number of heights or widths of a particular barrier. By knowing the dimensions of a barrier, the user can apply the siting guidelines to his particular problem.

\subsubsection{Buildings}

Since it is likely that buildings will be located near a WECS candidate site, it is important to know how they affect airflow and available power.
Figure 10 illustrates the complexity of airflow around a block-shaped building.

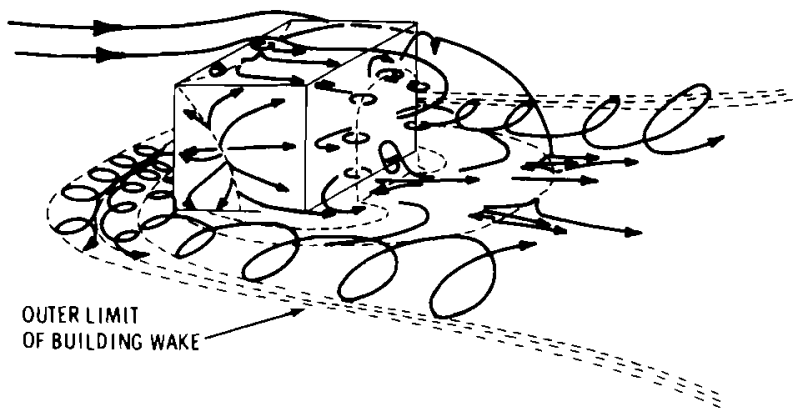

FIGURE 10. Airflow Around a Block Building (Sandborn, 1977)

As with roughness changes, building wakes increase in height immediately downstream. As the figure illustrates, the wind flows around the building forming a horseshoe-shaped wake (indicated by the dashed lines), beginning just upsteam of the building and extending some distance downstream.

A general rule of thumb for avoiding most of the adverse effects of building wakes is to site a WECS:

- upwind(a) a distance of more than two times the height of the building;

- downwind $(\mathrm{a})$ a minimum distance of ten (preferably 20) times the building height; or

- at least twice the building height above ground if the WECS is immediately downwind of the building.

Figure 11 illustrates this rule with a cross-sectional view of the flow wake of a small building.

The above rule of thumb is not foolproof, because the size of the wake also depends upon the building's shape and orientation to the wind. Figure 12 estimates changes in available power and turbulence in the wake of a sloped-roof building. All of these estimates apply at a level equal to one building height above the ground. Downwind from the building, available power losses become small at a distance equal to 15 building heights.

(a) Upwind and downwind indicate directions along the principal power direction. 


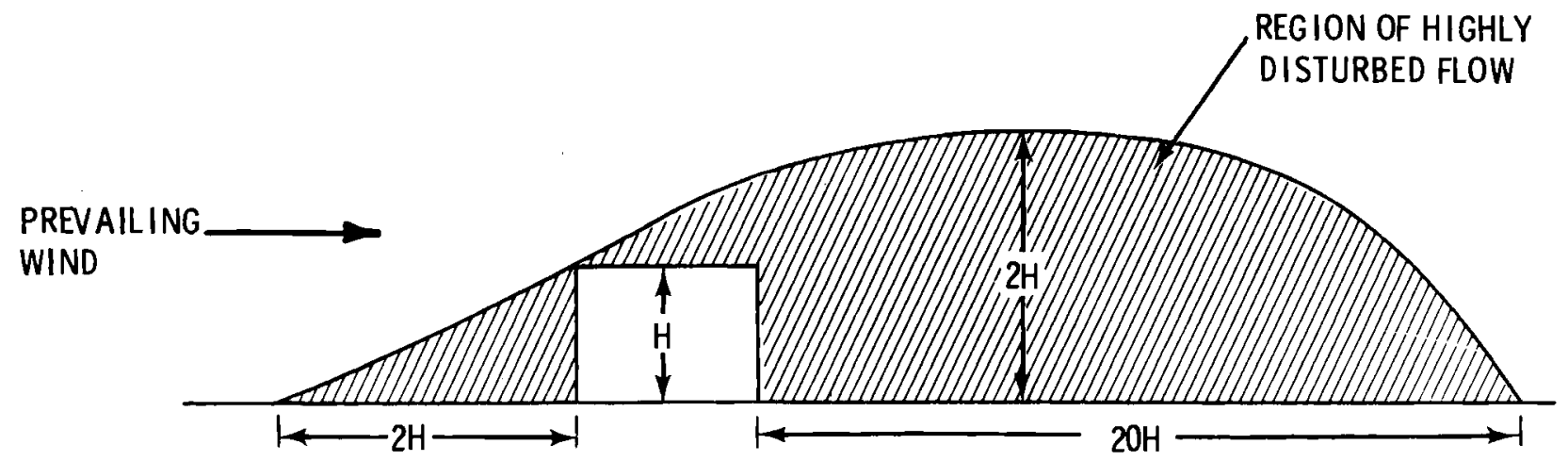

FIGURE 11. Zone of Disturbed Flow Over a Small Building (Frost and Nowak, 1977; Van Eimern et al., 1964)

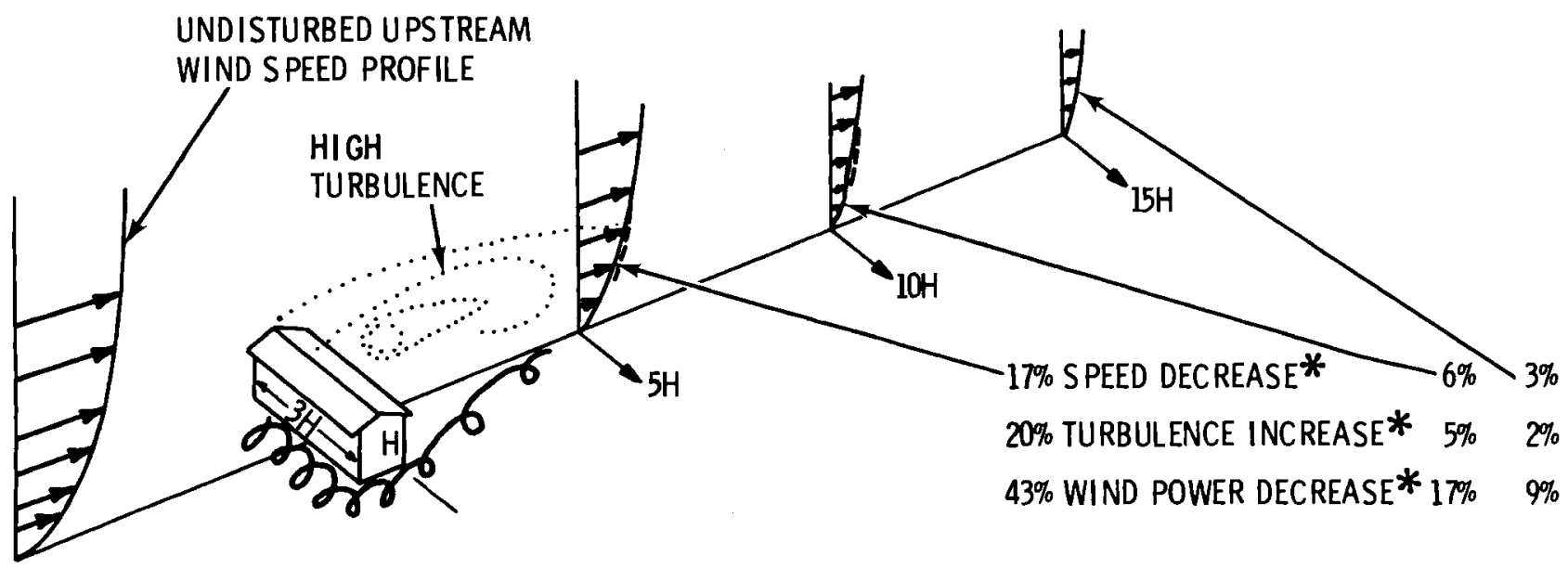

\section{* APPROXIMATE MAXIMUM VALUES DEPEND UPON BUILDING SHAPE, TERRAIN, OTHER NEARBY OBSTACLES}

FIGURE 12. The Effects of an Undisturbed Airflow Encountering an Obstruction (Meroney, 1977)

Table 3 summarizes the effects of building shape on wind speed, available power, and turbulence for buildings oriented perpendicular to the wind flow. Building shape is given by the ratio "width divided by height." As might be expected, power reduction is felt farther downstream for wider buildings. At twenty times the height downwind, only very wide buildings (those in which width $\div$ height $=3$ or more) produce more than a $10 \%$ power reduction. The speed, power, and turbulence changes reflected in Table 3 occur only when the WECS lies in the building wake. Wind rose information (see Appendix A) will indicate how often this actually occurs. Annual percentage time of occurrence multiplied by the percentage power decrease in the table will give the net power loss. An example of such a calculation is given on page 16 .

\subsubsection{Shelterbelts}

Shelterbelts are windbreaks usually consisting of a row of trees. When selecting a site near a shelterbelt, the user should either

- choose a site far enough upwind, downwind, or to the side of the shelterbelt to avoid the disturbed flow; 
TABLE 3. Wake Behavior of Variously Shaped Buildings (Meroney, 1977)

Downwind Distances (In Terms of Building Heights)

\begin{tabular}{|c|c|c|c|c|c|c|c|c|c|}
\hline \multirow[b]{2}{*}{$\begin{array}{l}\text { Building Shape } \\
\text { (Width } \div \text { Height }\end{array}$} & \multicolumn{3}{|c|}{$5 \mathrm{H}$} & \multicolumn{3}{|c|}{$10 \mathrm{H}$} & \multicolumn{3}{|c|}{$20 \mathrm{H}$} \\
\hline & $\begin{array}{l}\text { Percent } \\
\text { Speed } \\
\text { Decrease }\end{array}$ & $\begin{array}{l}\text { Percent } \\
\text { Power } \\
\text { Decrease }\end{array}$ & $\begin{array}{c}\text { Percent } \\
\text { Turbulence } \\
\text { Increase }\end{array}$ & $\begin{array}{l}\text { Percent } \\
\text { Speed } \\
\text { Decrease }\end{array}$ & $\begin{array}{l}\text { Percent } \\
\text { Power } \\
\text { Decrease }\end{array}$ & $\begin{array}{c}\text { Percent } \\
\text { Turbulence } \\
\text { Increase }\end{array}$ & $\begin{array}{l}\text { Percent } \\
\text { Speed } \\
\text { Decrease }\end{array}$ & $\begin{array}{l}\text { Percent } \\
\text { Power } \\
\text { Decrease }\end{array}$ & $\begin{array}{l}\text { Percent } \\
\text { Turbulence } \\
\text { Increase }\end{array}$ \\
\hline 4 & 36 & 74 & 25 & 14 & 36 & 7 & 5 & 14 & 1 \\
\hline 3 & 24 & 56 & 15 & 11 & 29 & 5 & 4 & 12 & 1 \\
\hline 1 & 11 & 29 & 4 & 5 & 14 & 1 & 2 & 6 & - \\
\hline 0.33 & 3 & 7 & 3 & 1 & 4 & 1 & - & - & - \\
\hline 0.25 & 2 & 6 & 3 & 1 & 3 & 1 & - & - & - \\
\hline
\end{tabular}

Height of the 1.5 2.0

3.0 wake flow region (in building heights)

- use a tower of sufficient height to avoid the disturbed flow; or

- if the disturbed flow at the shelterbelt cannot be entirely avoided, minimize power loss and turbulence by examining the nature of the windflow near the shelterbelt and choose a site accordingly.

The degree to which the wind flow is disturbed depends on the height, length, and porosity of the shelterbelt. Porosity can be thought of as the percentage of open area one would see when looking through a shelterbelt.

Figure 13 locates the region of greatest turbulence and wind speed reduction near a thick windbreak. How far upwind and downwind this area of disturbed flow extends varies with the height of the windbreak. Generally, the taller the windbreak is, the farther the region upwind and downwind that will experience a disturbed airflow.

Figure 14 illustrates the effect of a row of trees on the wind speed at various heights and distances from the windbreak. The wind speeds are expressed as percentages of undisturbed upwind flow for several selected heights. All heights and distances are expressed in terms of the height of the shelterbelt to facilitate application to a particular siting problem.

When examining this figure, note that loose foliage actually reduces winds behind the windbreak more than dense foliage. Furthermore, medium-density foliage reduces wind speeds farther downwind than either loose or dense foliage.

For levels $1-1 / 2 \mathrm{H}$ or less, the wind speed begins to decrease at 5 or $6 \mathrm{H}$ upstream of the shelterbelt. Therefore, if the shelterbelt is $30 \mathrm{ft} \mathrm{high}$ and the WECS tower is only $45 \mathrm{ft}$ high, the WECS site should be at least $150 \mathrm{ft}(5 \mathrm{H})$ upstream of the windbreak to avoid entirely the speed decrease and turbulence on the windward side.

At the distance of $2-1 / 2 \mathrm{H}$ downwind, the wind speed at the 2-1/2 $\mathrm{H}$ level (for both dense and loose foliage) increases approximately $5 \%$. At first glance this appears to be a good WECS site. However, there is a turbulent zone downwind from the shelterbelt that may make this site undesirable, particularly if the tower is too short.

To capitalize on the acceleration of the wind over a shelterbelt, the entire rotor disc must be located above the turbulent zone. To determine where this turbulent zone is located, the user should study turbulence patterns during prevailing wind conditions. (Chapter 7 provides 


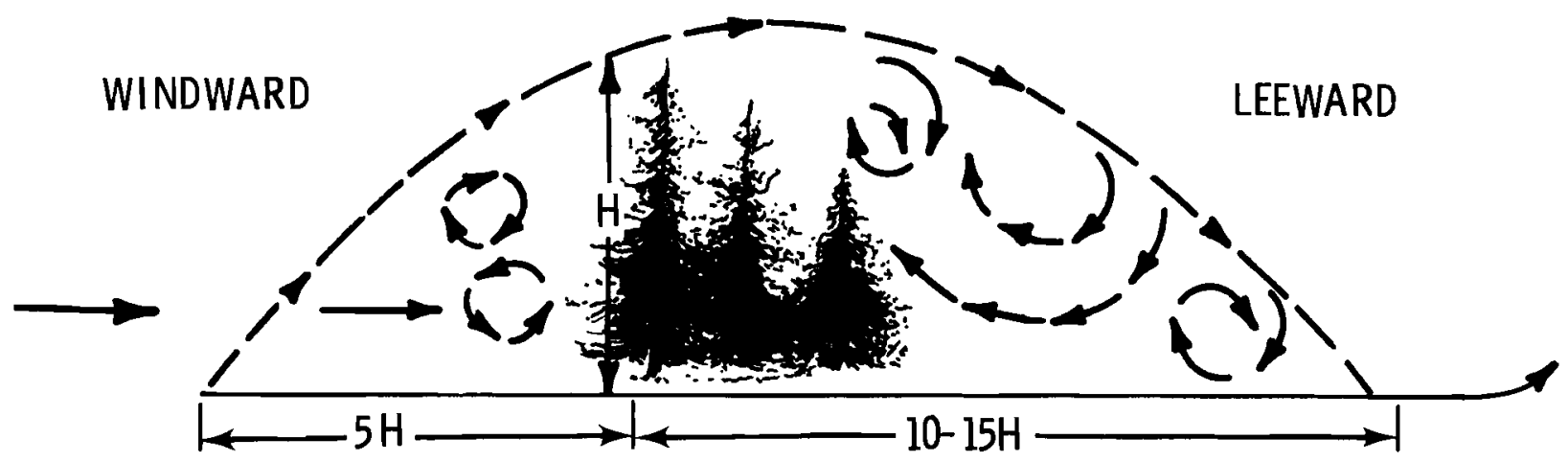

FIGURE 13. Airflow Near a Shelterbelt (Van Eimern et al., 1964)

simple methods of turbulence detection.) He should also study other frequently occurring wind directions. If significant turbulence or power loss appears possible when the wind blows from any of these directions, another site should be selected.

Table 4 provides information on the wind speed, power reductions and turbulence increases for sites in the lee of a shelterbelt. Speed, power, and turbulence changes are expressed as percentages of the upwind flow. The porosity of the windbreak can be estimated visually; then, Table 3 can be used to determine how far downwind the site should be located to minimize power loss and turbulence. Speed, power, and turbulence changes expressed in the table occur only when the WECS lies in the shelterbelt wake. Wind rose information (see Appendix A) will indicate how often this actually occurs. Annual percentage time of occurrence multiplied by the table percentage will give the net change. An example of this type of calculation is given in the following section.

\subsubsection{Individual Trees}

The trees near a prospective WECS site may not be organized into a shelterbelt. In such cases, the effect of an individual tree or of several trees scattered over the surrounding area may be a problem.

The wake of disturbed airflow behind individual trees grows larger (but weaker) with distance, much like a building wake. However, the highly disturbed portion of a tree wake extends farther

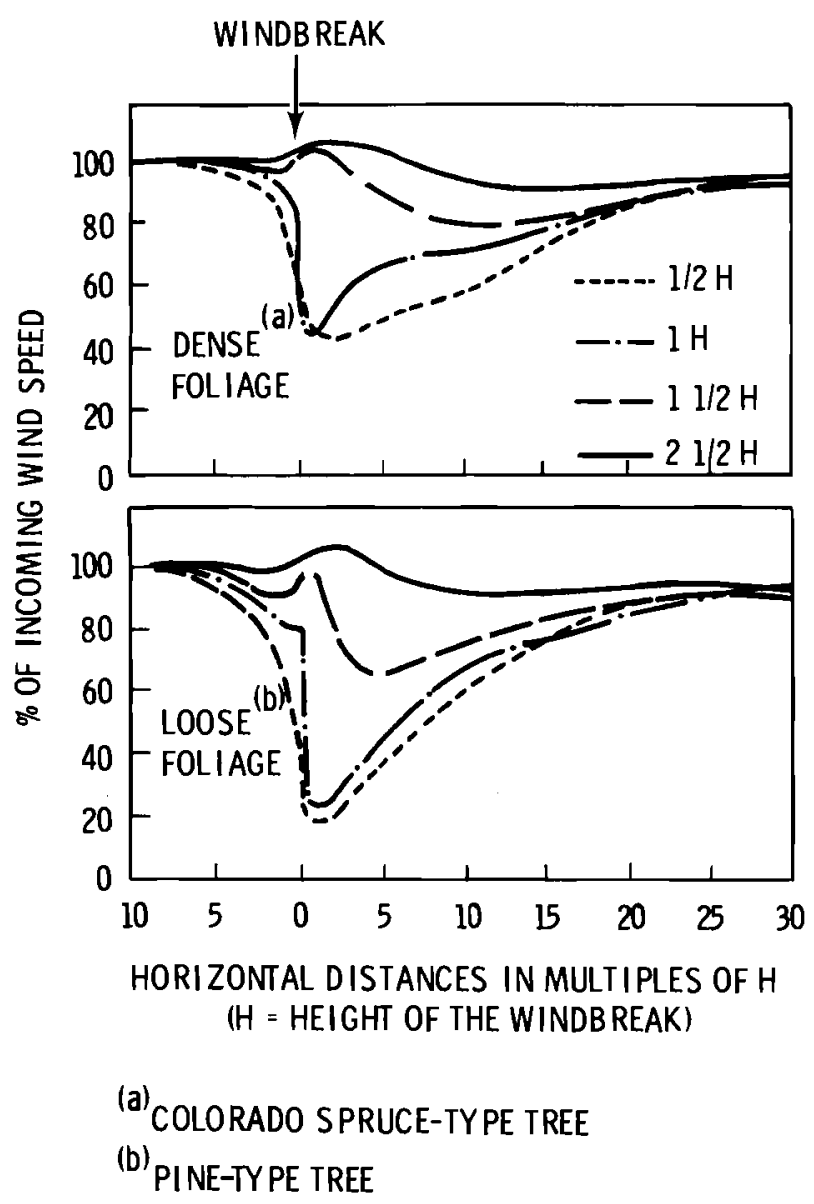

FIGURE 14. Percent Wind Speed at Different Levels Above the Surface Behind a Row of Trees of Height, H (Van Eimern et al., 1964) 
TABLE 4. Available Power Loss and Turbulence Increase Downwind from Shelterbelts of Various Porosities (Meroney, 1977)

\begin{tabular}{|c|c|c|c|c|c|c|c|c|c|}
\hline \multirow{3}{*}{$\begin{array}{c}\text { Porosity } \\
\text { (O) } \\
\text { (Open Area } \\
\div \\
\text { Total Area) }\end{array}$} & \multicolumn{9}{|c|}{ Downwind Distances (In Terms of Shelterbelt Heights) } \\
\hline & \multicolumn{3}{|c|}{$5 \mathrm{H}$} & \multicolumn{3}{|c|}{$10 \mathrm{H}$} & \multicolumn{3}{|c|}{$20 \mathrm{H}$} \\
\hline & $\begin{array}{l}\text { Percent } \\
\text { Speed } \\
\text { Decrease }\end{array}$ & $\begin{array}{l}\text { Percent } \\
\text { Power } \\
\text { Decrease }\end{array}$ & $\begin{array}{c}\text { Percent } \\
\text { Turbulence } \\
\text { Increase }\end{array}$ & $\begin{array}{l}\text { Percent } \\
\text { Speed } \\
\text { Decrease }\end{array}$ & $\begin{array}{l}\text { Percent } \\
\text { Power } \\
\text { Decrease }\end{array}$ & $\begin{array}{c}\text { Percent } \\
\text { Turbulence } \\
\text { Increase }\end{array}$ & $\begin{array}{l}\text { Percent } \\
\text { Speed } \\
\text { Decrease }\end{array}$ & $\begin{array}{l}\text { Percent } \\
\text { Power } \\
\text { Decrease }\end{array}$ & $\begin{array}{c}\text { Percent } \\
\text { Turbulence } \\
\text { Increase }\end{array}$ \\
\hline $\begin{array}{l}0 \% \\
\text { (no space } \\
\text { between trees) }\end{array}$ & 40 & 78 & 18 & 15 & 39 & 18 & 3 & 9 & 15 \\
\hline $\begin{array}{l}20 \% \\
\text { (with loose } \\
\text { foliage such as } \\
\text { pine or broadleaf } \\
\text { trees) }\end{array}$ & 80 & 99 & 9 & 40 & 78 & - & 12 & 32 & - \\
\hline $\begin{array}{l}40 \% \\
\text { (with dense } \\
\text { foliage such as } \\
\text { Colorado Spruce) }\end{array}$ & 70 & 97 & 34 & 55 & 90 & - & 20 & 49 & - \\
\hline $\begin{array}{l}\text { Top of Turbulent } \\
\text { Zone (b) } \\
\text { (in terms of } \\
\text { shelterbelt } \\
\text { height) }\end{array}$ & & 2.5 & & & 3.0 & & & 3.5 & \\
\hline
\end{tabular}

$\overline{(a)}$ Determine the porosity category of the shelterbelt by estimating the percentage of open area and by associating the foliage with the sample tree type.

(b) Though the top of the turbulent zone continues to grow in height downwind, the intensity of the turbulence decreases.

downstream than does that of a solid object. Table 5 may be used to estimate available power loss downstream. For example, consider a $30-\mathrm{ft}$ wide tree having fairly dense foliage. At 30-tree widths (or $900 \mathrm{ft}$ ) downstream, the table indicates a $9 \%$ loss of available power whenever the WECS is in the tree wake. The numbers in the bottom two rows of the table provide estimates of the width and height of the tree wake. The velocity and power losses expressed in the table occur only when the WECS lies in the tree wake.

If available, wind rose information (Appendix $A$ ) can be used to estimate the percentage of time a site will be in the tree wake and thereby the total power loss as a result of the tree. For instance, suppose that $50 \%$ of the time the wind direction places the site in the tree wake. In the example above, the tree produced a $9 \%$ loss of available power. If the loss occurred $50 \%$ of the time, $4.5 \%$ $(50 \% \times 9 \%)$ of the available power would be lost annually.

Perhaps more important than power loss is: the WECS will be exposed to tree wake turbulence $50 \%$ of the time. This will certainly reduce the life of the machine. Figure 15 shows how tree wake turbulence can damage even a sturdy water pumper.

\subsubsection{Scattered Barriers}

When considering the barrier wakes discussed, the advantages of increasing tower height in areas of scattered barriers are evident. Since choosing 
TABLE 5. Speed and Power Loss in Tree Wakes (Meroney, 1977)

\begin{abstract}
Dense-foliage tree (such as a Colorado spruce)
\end{abstract}

Thin-foliage tree (such as a pine)
Maximum percent loss of velocity

Maximum percent loss of power

Maximum percent loss of velocity

Maximum percent loss of power

Height of the turbulent flow region

(in tree heights)

Width of turbulent flow region (in tree widths)

a site not located in any barrier wake will probably be impossible, the WECS should be raised above the most highly disturbed airflow. To avoid most of the undesirable effects of scattered barriers, a conservative rule of thumb is to locate the rotor disc on the tower at a minimum height of three times that of the tallest upwind
Downwind Distances (In Terms of Tree Widths)

\begin{tabular}{lllll}
\hline 5 & 10 & 15 & 20 & 30 \\
\hline
\end{tabular}

20

9

6

4

3

49

25

17

13

9

16

7

4

3

2

41

18

12

8

6

1.5

2.0

2.5

3.0

3.5

1.5

2.0

2.5

3.0

3.5

barrier. If this rule is impractical (for economic or other reasons), the user can 1) find the minimum height required to clear the region of highest turbulence by using the turbulence detection techniques outlined in Chapter 7 , or 2) choose the site so the WECS will clear the highest obstruction within a $500-\mathrm{ft}$ radius by at least $25 \mathrm{ft}$ (AWEA, 1977).

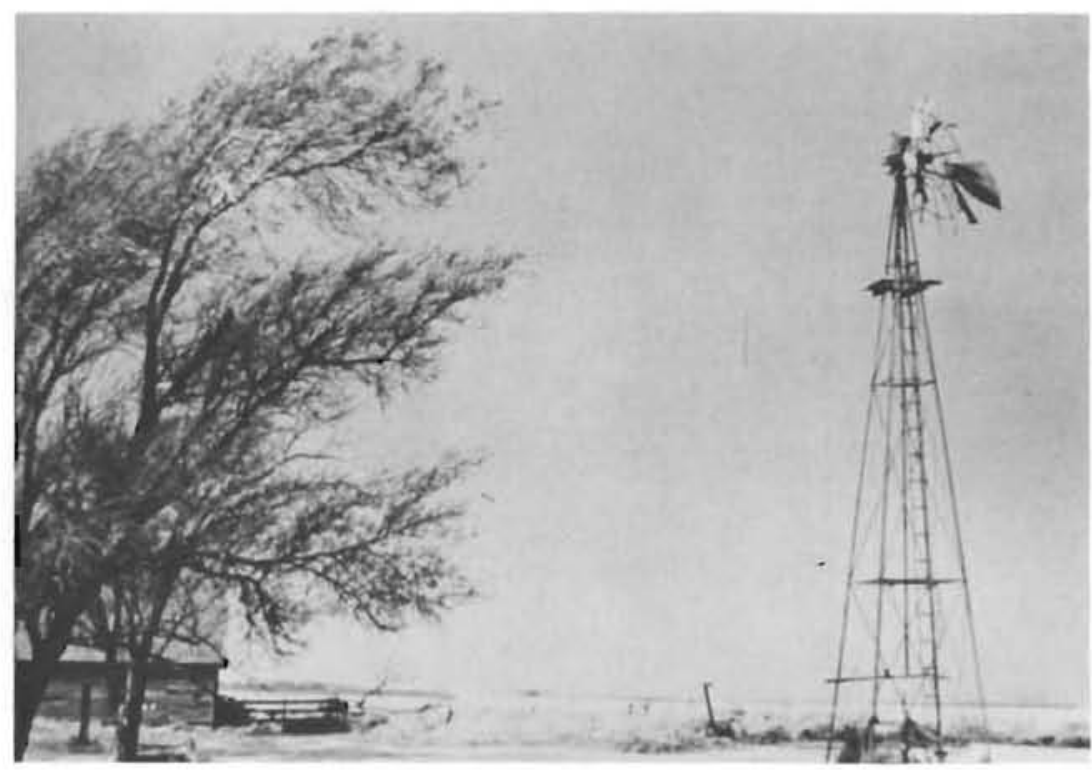

FIGURE 15. Damage Caused by Tree Wake Turbulence 


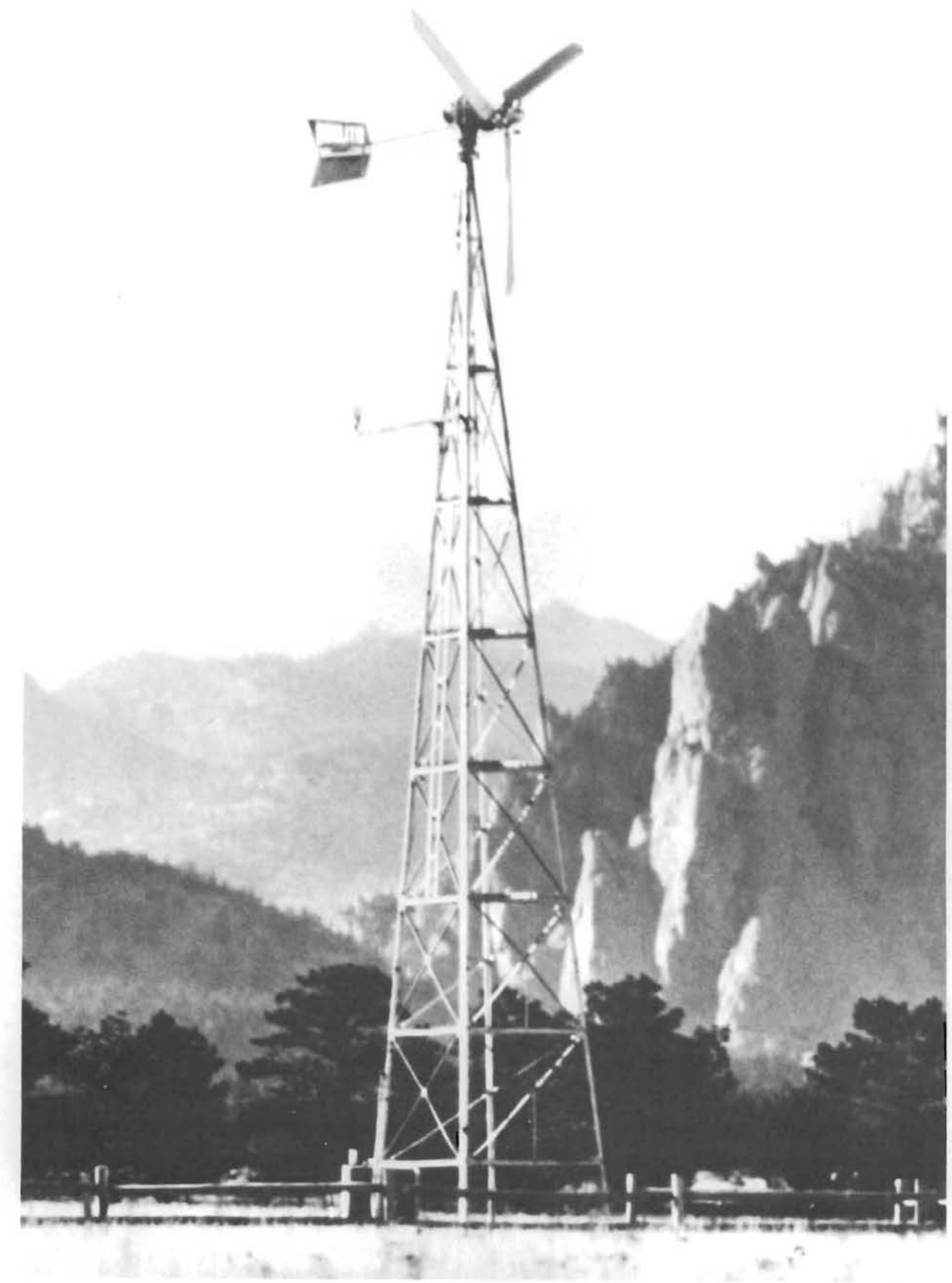




\section{Chapter 4}

\section{Siting in Non-Flat Terrain}

Any terrain that does not meet the criteria listed in Figure 4 is considered to be non-flat or complex. To select candidate sites in such terrain, the potential user should identify the terrain features (i.e., hills, ridges, cliffs, valleys) located in or near the siting area and then read the applicable portions of this chapter.

In complex terrain, landforms affect the airflow to some height above the ground in many of the same ways as surface roughness does. However, topographical features affect airflow on a much larger scale, overshadowing the effects of roughness. When weighing various siting factors according to their effects on wind power, topographical features should be considered first, barriers second, and roughness third. For example, if a particular section of a ridge is selected as a good candidate site, the location of barriers and surface roughness should only be considered to pinpoint the best site on that section of the ridge.

Complex terrain can be divided into two categories: elevated terrain such as hills, ridges and cliffs, and depressions, which include valleys, basins, passes and gorges. Since each category of feature has different effects on airflow and thus on WECS siting, elevated terrain and depressions are discussed separately.

\subsection{Elevated Terrain}

As Chapter 2 points out, winds generally increase with height, and elevated terrain (like a tower) raises a WECS into a region of higher winds. In addition, daily temperature changes affect the wind profile. At night as the earth's surface cools, the air near the surface cools. The cool, heavy air drains from the hillsides into the valleys and may accumulate into a layer several hundred feet deep by early morning. This dome of cool air separates from the general wind flow above it to produce the calm morning air that lowlands often experience. Because of this phenomenon, a WECS located on a hill or ridge may produce power all night, but one located at a lower elevation may not.

A similar, but more persistent, situation may occur in the winter when cold air moves into an area. Much like flowing water, cold air tends to fill all the low spots. This may cause extended periods of calm in the lowlands while the surrounding hills experience winds capable of driving a WECS.
By siting at higher elevations, one can often take advantage of more persistent winds. This will generally increase the WECS power production, and for some WECS applications it will reduce the amount of energy storage capacity (or backup power), thereby providing a more dependable and economical power source.

\subsubsection{Ridges}

Ridges are defined as elongated hills that reach less than or equal to $2000 \mathrm{ft}$ above surrounding terrain and have little or no flat area on the summit (see Figure 16). There are three advantages to locating a WECS on a ridge: 1) the ridge acts as a tower; 2) the undesirable effects of cooling near the ground are partially avoided; and 3) the ridge may accelerate the airflow over it, thereby increasing the available power. The first two advantages are not unique to ridges, but apply to all topographical features having high relief (hills, mountains, etc.).

Figure 17 shows how air approaching the ridge is squeezed into a thinner layer that causes it to speed up as it crosses the summit (advantage 3). The orientation of the ridge relative to the prevailing wind direction is an important factor in determining the amount of wind acceleration over the ridge. Figure 18 depicts various ridge orientations and ranks their suitability as WECS sites. However, when comparing ridges, it is important to remember that a ridge several hundred feet or more higher than another should have significantly stronger winds simply because the wind increases with height. This is true even if the higher ridge is slightly less perpendicular to the prevailing wind than the lower ridge.

Part A of Figure 18 shows the ideal orientation of a ridge to the prevailing wind. The maximum acceleration at the ridge summit occurs when the prevailing wind blows perpendicular to the ridge line. The acceleration lessens if the ridge line is not perpendicular, as in Part B of the figure. When the ridge line is parallel to the prevailing wind, as in Part $\mathrm{C}$, there is little acceleration over the ridge top; however, the ridge may still be a fair-to-good wind site because it acts like an isolated hill or peak (see discussion on siting on hills or mountains).

The orientation of concave or convex ridges (or such portions of a ridge) can further modify the wind flow. Part D of Figure 18 shows how concavity on the windward side may enhance 


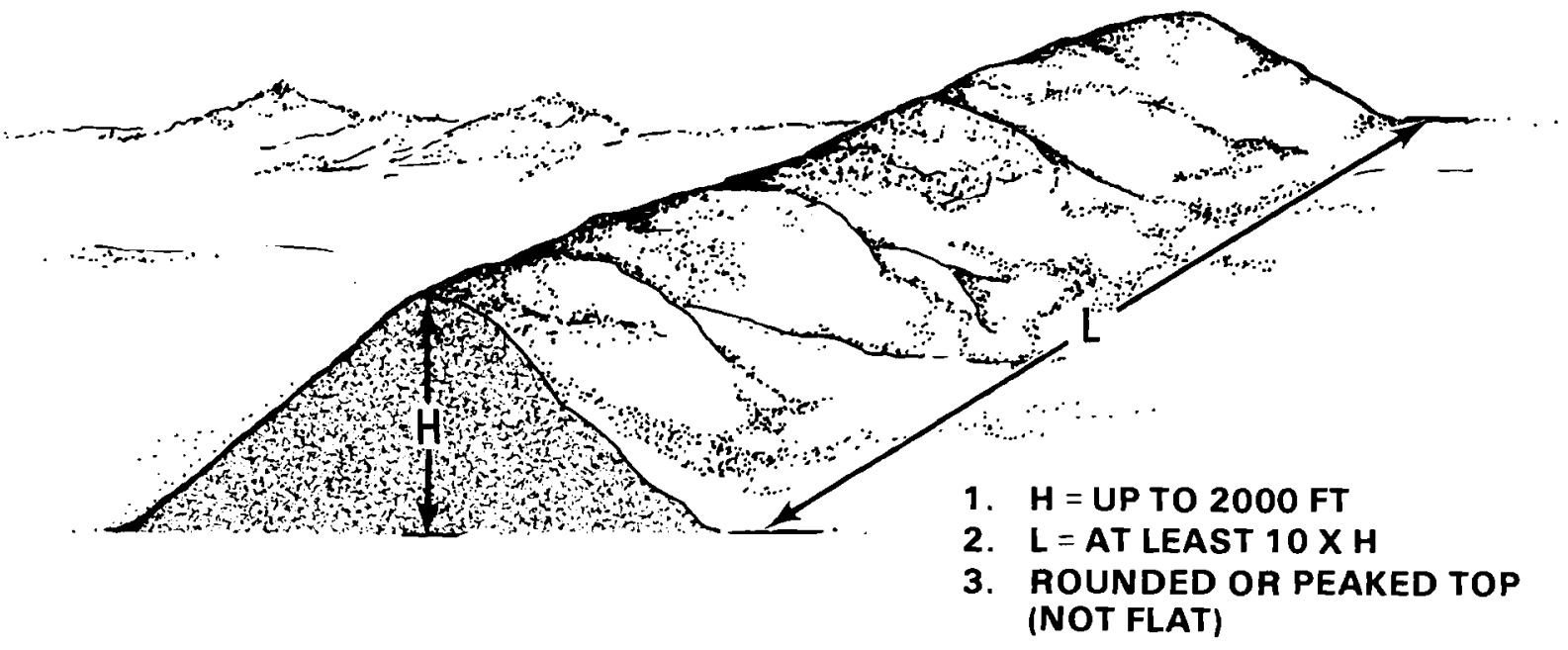

FIGURE 16. Definition of a Ridge

CREST OF WINDFLOW

(ALSO REGION OF MAXIMUM WIND ACCELERATION)

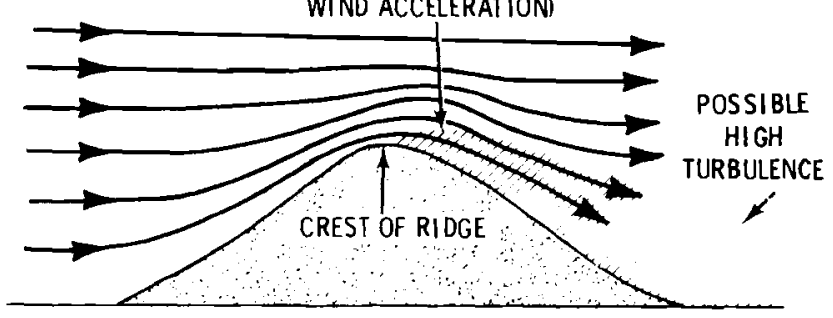

FIGURE 17. Acceleration of Wind Over a Ridge (Eldridge, 1975)

acceleration over the ridge by funneling the wind. On the other hand, convexity on the windward side (Part E) reduces acceleration by deflecting the wind flow around the ridge.

Figure 19 shows the cross-sectional shapes of several ridges and ranks them by the amount of acceleration they produce. Notice that a triangularshaped ridge causes the greatest acceleration and that the rounded ridge is a close second. The data used in ranking these shapes were collected in laboratory experiments using wind tunnels to simulate real ridges. Though few wind experiments have been conducted over actual ridges, the results are similar to wind tunnel simulations. Both indicate that certain slopes, primarily in the nearest few hundred yards to the summit, (a) increase the

(a) This portion of the ridge has the greatest influence on the wind profile immediately above the summit. wind more effectively than others. Table 6 classifies smooth, regular ridge slopes according to their value as wind power sites.

Figure 20 gives percentage variations in wind speed for an ideally shaped ridge. Since these numbers are taken from wind tunnel experiments, they should not be taken too literally; nevertheless, the user should expect similar windspeed trends along the path of flow. Generally, wind speed decreases significantly at the foot of the ridge, then accelerates to a maximum at the ridge crest. It only exceeds the upwind speed on the upper half of the ridge.

Another consideration in choosing a site on a ridge is the turbulent zone that often forms in the lee of ridges (Figure 17). The steeper the ridge slope and the stronger the wind flow, the more likely turbulence will form in the lee of the ridge. Thus, it is safest to site at the summit of the ridge, both to maximize power and to avoid lee turbulence.

Shoulders (ends) of ridges are often good WECS sites. Even for a very long ridge, as much as onethird of the air approaching at low levels may flow around, rather than over, the ridge (Park and Schwind, 1978). To move such a volume of air around the ridge, the wind must accelerate as it flows around the ends. No quantitative estimates of this acceleration are available at this time, but it appears that from the standpoint of available wind power the ends of ridges may rank second behind the ridge crest as the best potential WECS sites. 


\section{ORIENTATION}

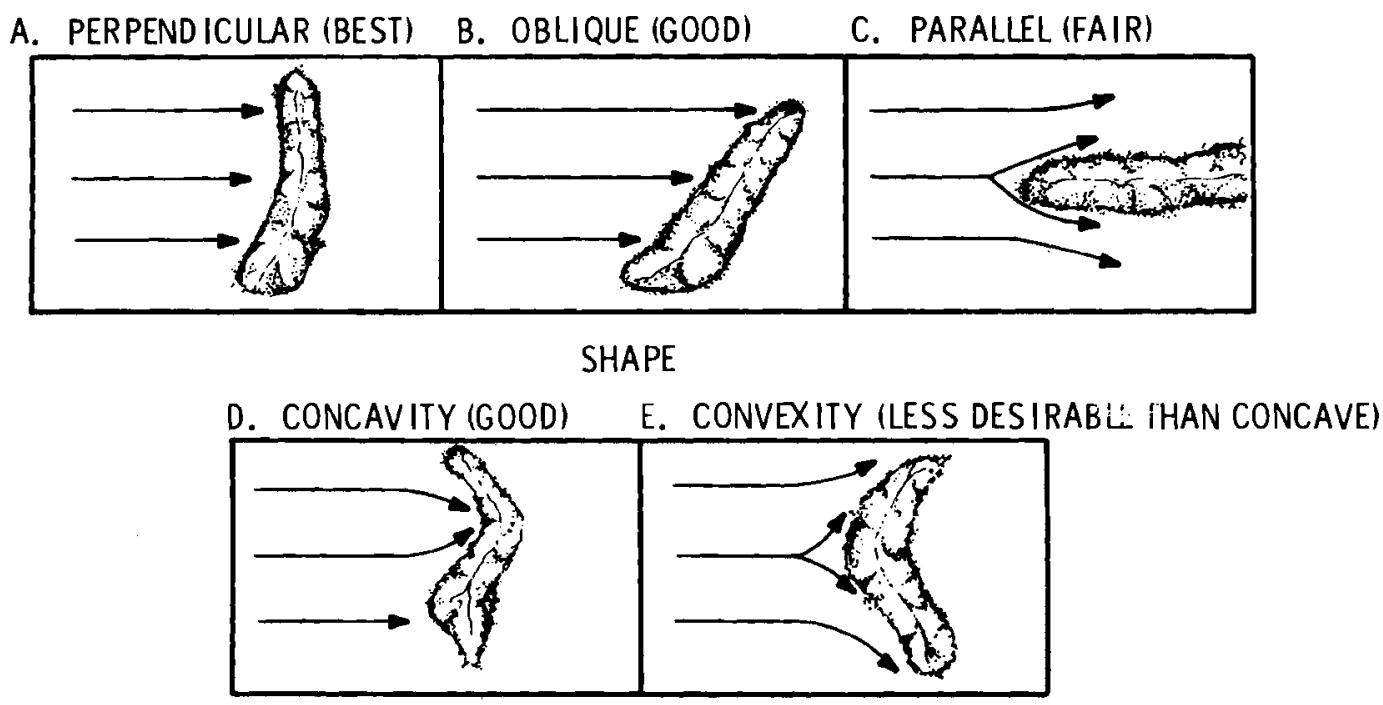

FIGURE 18. The Effects of Ridge Orientation and Shape on WECS Site Suitability

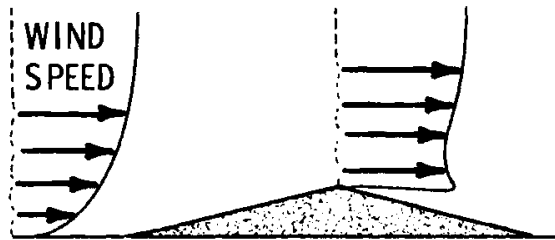

1. TRIANGULAR (MOST ACCELERATION)

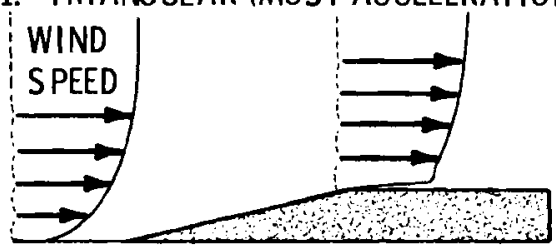

3. FLAT TOP
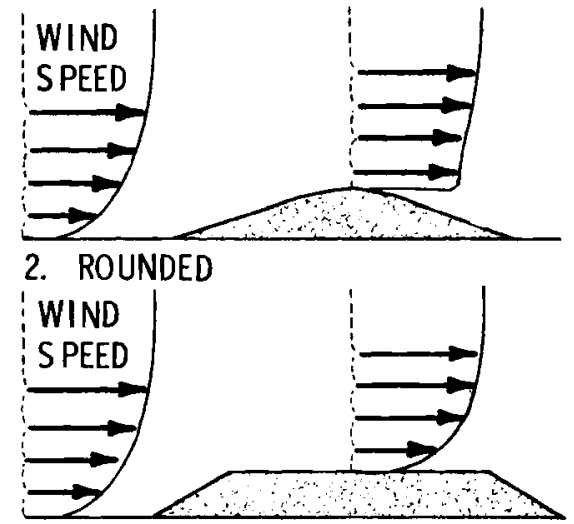

4. STEEP SLOPE

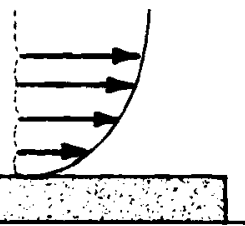

5. BLUFF (LEAST ACCELERATION)

FIGURE 19. Ranking of Ridge Shape by Amount of Wind Acceleration (Sandborn, 1977) 
TABLE 6. WECS Site Suitability Based Upon Slope of the Ridge (Frenkeil, 1962)

\begin{tabular}{|c|c|c|}
\hline \multirow[b]{2}{*}{$\begin{array}{l}\text { WECS Site } \\
\text { Suitability }\end{array}$} & \multicolumn{2}{|c|}{ Slope of the Hill Near the Summit } \\
\hline & $\begin{array}{l}\text { Percent } \\
\text { Grade }^{(a)} \\
\end{array}$ & $\begin{array}{l}\text { Slope } \\
\text { Angle } \\
\end{array}$ \\
\hline Ideal & 29 & $16^{\circ}$ \\
\hline Very good & 17 & $10^{\circ}$ \\
\hline Good & 10 & $6^{\circ}$ \\
\hline Fair & 5 & $3^{\circ}$ \\
\hline Avoid & $\begin{array}{l}\text { less than } 5 \\
\text { greater than } 50\end{array}$ & $\begin{array}{l}\text { less than } 3^{\circ} \\
\text { greater than } 27^{\circ}\end{array}$ \\
\hline
\end{tabular}

(a) Percent grade as used above is the number of feet of rise per $100 \mathrm{ft}$ horizontal distance.

Flat-topped ridges present special problems because they can actually create hazardous wind shear at low levels, as Figure 21 illustrates. Consequently, the slope classifications used in Table 6 do not apply to these ridges. The hatched area at the top of the flat ridge indicates a region of reduced wind speed caused by the "separation" of the flow from the surface. Immediately above the separation zone is a zone of high wind shear. This shear zone is located just at the top of the shaded area in the figure. Siting a WECS in this region will cause unequal loads on the blade as it rotates through areas of different wind speeds, will create rapid fluctuations in direction, and could decrease performance and the life of the blades. These problems can be avoided by increasing the tower height to allow the blade to clear the shear zone.

As in the case of flat terrain, the effects of barriers and roughness should not be overlooked. Figure 22 shows how a rough surface upwind of a ridge can greatly decrease the wind speed. After selecting the best section of a ridge based upon its geometry, the potential user should consider the barriers, then the upwind surface roughness.

The most important considerations in siting WECS on or near ridges are summarized below:

1. The best ridges or sections of a single ridge are those most nearly perpendicular to the prevailing wind. (However, a ridge several hundred feet higher than another and only slightly less perpendicular to the wind is preferable.)

2. Ridges or sections of a single ridge having the most ideal slopes within several hundred yards of the crest should be selected (use Table 6). Ridge sites meriting special consideration are those with features such as gaps, passes, or saddles.

3. Sites where turbulence or excessive wind shear cannot be avoided should not be considered.

4. Roughness and barriers must be considered.

5. If siting on the ridge crest is not possible, the site should be either on the ends or as high as possible on the windward slope of the ridge. The foot of the ridge and the leeward side should be avoided.

6. Vegetation may indicate the ridge section having the strongest winds (see Section 4.3).

\subsubsection{Isolated Hills and Mountains}

An isolated hill is 500 to $2000 \mathrm{ft}$ high, is detached from any ridges and has a length of less than 10 times its height. Hills greater than $2000 \mathrm{ft}$ high will

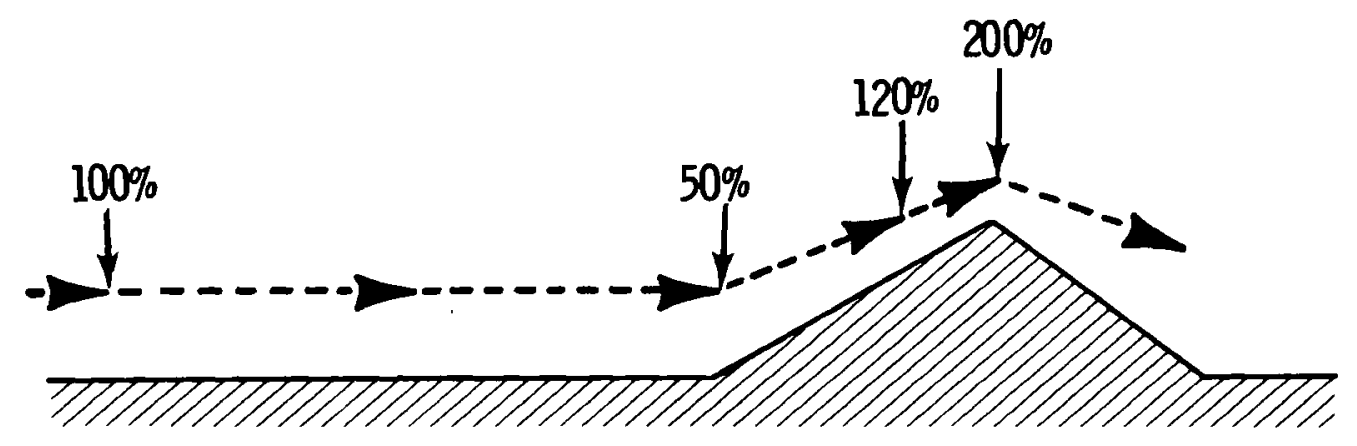

FIGURE 20. Percentage Variation in Wind Speed Over an Idealized Ridge (Park and Schwind, 1978) 


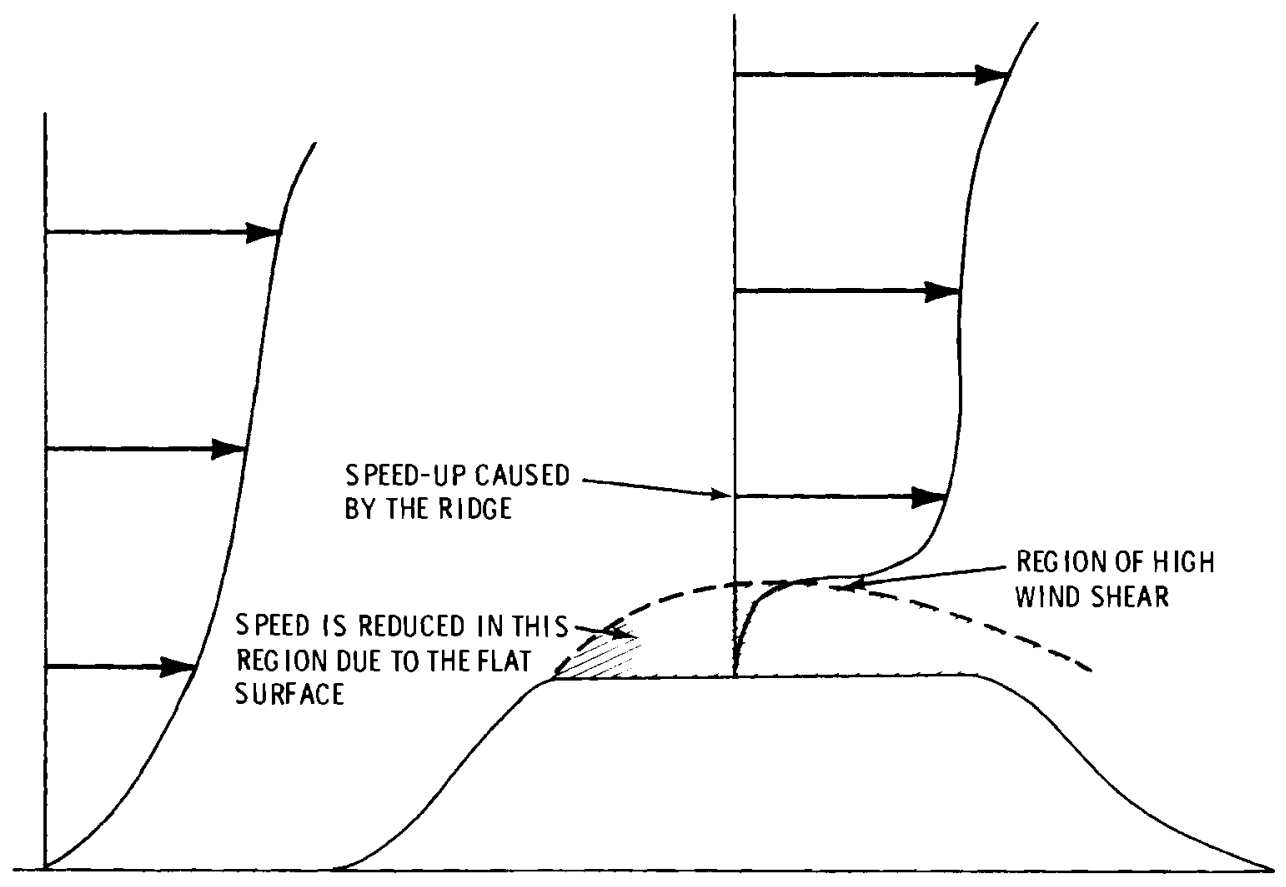

FIGURE 21. Hazardous Wind Shear Over a Flat-Topped Ridge

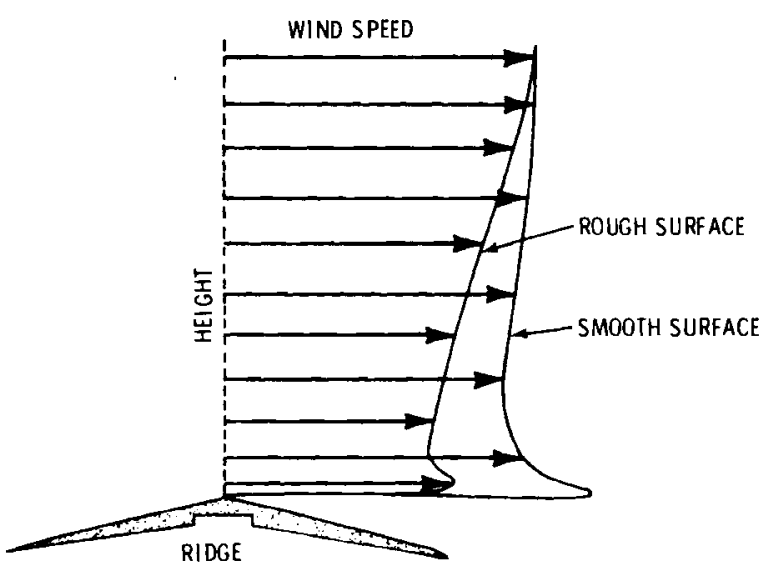

FIGURE 22. Effect of Surface Roughness on Wind Flow Over a Low Sharp-Crested Ridge (Sandborn, 1977)

be referred to as mountains. Hills, like ridges, may accelerate the wind flowing over them but not as much as ridges, since more of the air tends to flow around the hill (Figure 23). Not enough information is currently available to make quantitative estimates of wind accelerations either over or around isolated hills. However, Table 6 can be used to rank hills according to their slope.
Two benefits are gained by siting on hills: 1) airflow can be accelerated, and 2) the hill acts as a huge tower, raising the WECS into a stronger airflow aloft and above part of the nocturnal cooling and resulting calm periods. The best WECS sites on an isolated hill may be along the sides of the hill tangent to the prevailing wind provided the sides are smoothly rounded (Sandborn, 1977). These sites are shown as areas of accelerated flow in Figure 23. However, further research is required to verify this supposition. Currently, simultaneous wind recordings are the surest method of comparing hillside and hilltop sites.

Table 7 ranks the suit ability of WECS sites on hills. But the effects of a surface roughness and barriers should also be weighed before a WECS site is selected.

When choosing a site on isolated mountains, the potential user should consider all the factors discussed for hills. However, because of the greater size, greater relief, and more complex terrain configurations of mountains, other factors must be considered. Inaccessibility may create logistical problems, and thunderstorms, hail, snow, and icing hazards will occur more frequently than at lower elevations. 


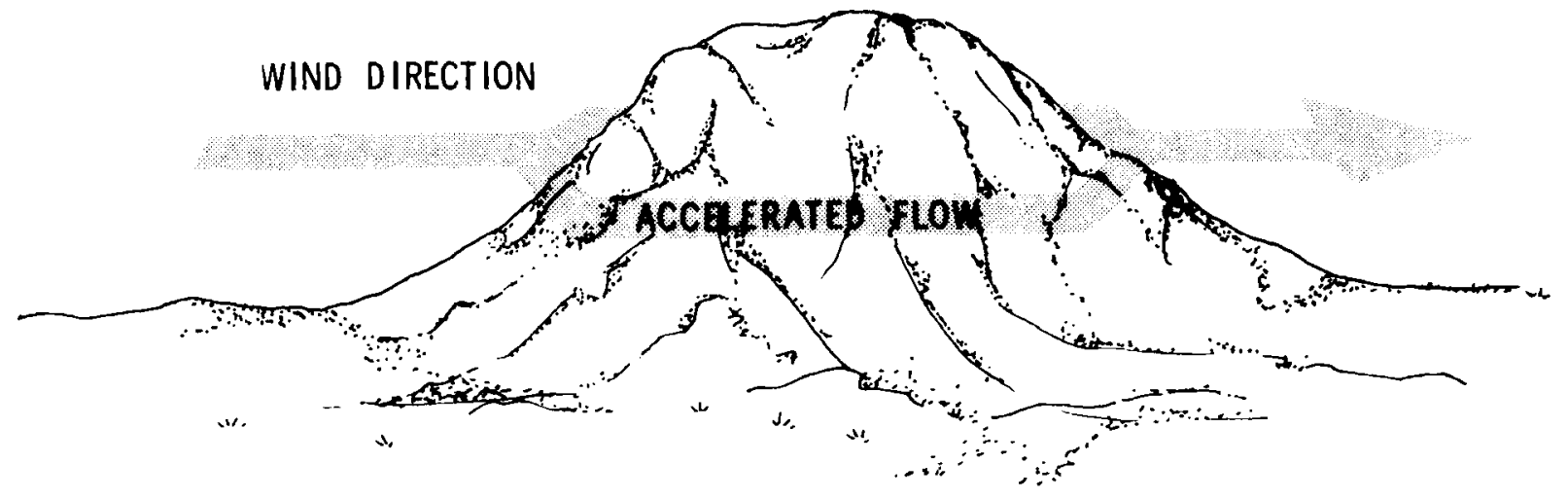

FIGURE 23. Airflow Around an Isolated Hill

In spite of the drawbacks, an isolated mountain may still be the most promising WECS site in an area. To select the best site(s) in the favorable areas of the mountain, use the criteria for hills in Table 7. For mountains, these favorable areas may be very large, containing many different terrain features, barriers, and surface roughnesses. To pinpoint the best site(s), consider the largest terrain features first; then, evaluate the barriers and surface roughness. Vegetation may provide additional information for site comparison (see Section 4.3).

\subsubsection{Cliffs}

A cliff, as discussed in this handbook, is any escarpment (mesa, butte, etc.) of sufficient length
(10 or more times its height) to force the airflow over rather than around its face. The factors affecting the airflow over cliffs are the slope (both on the windward and leeward sides), the height of the cliff, the curvature along the face, and the surface roughness upwind.

Figure 24 shows how the air flows over cliffs of different slopes. The swirls in the flow near the base and downwind from the cliff edge are turbulent regions that must be avoided. Turbulent swirls, called areas of flow separation, increase with cliff height and with the leaning of the cliff more into the wind. When the cliff slopes downward on the lee side, as in Part $\mathrm{C}$ of the figure, the zone of turbulence moves more downwind from the face.

TABLE 7. WECS Site Suitability on Isolated Hills

Suitability

Good

Good

Fair

Avoid

\section{Location}

Upper half of hills where prevailing wind is tangent

Top of hills

Upper half of the windward face of the hill

Entire leeward half of hills $(a)$

The foot and lower portions of hills
Flow Characteristics

The point of maximum acceleration around the hill

The point of maximum acceleration over the hill

A slight acceleration of flow up the hill

Reduced wind speeds and high turbulence

Reduced wind speeds

(a) Under certain conditions the strongest winds may occur on the leeward slopes of larger hills and mountains (such as on the east slopes of the Rocky Mountains). However, these winds are usually gusty, localized, and generally represent more of a hazard than a wind resource. 
(A)

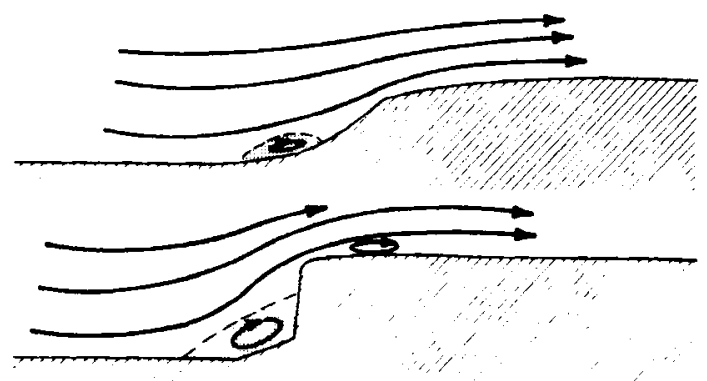

(B)

(C)

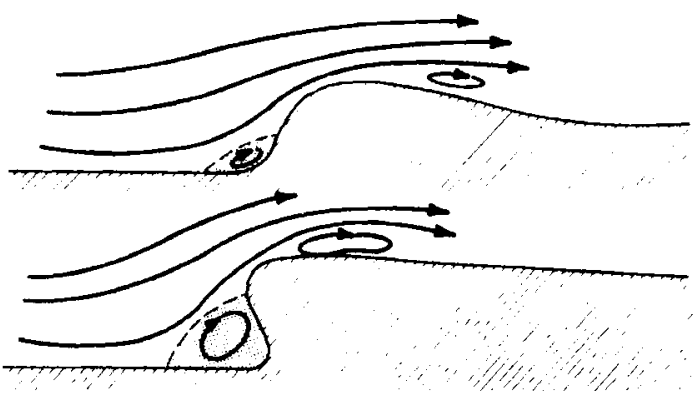

(D)

FIGURE 24. Airflow over Cliffs Having Differently Sloped Faces
Although no estimates are available of how much wind speed is enhanced in these concave areas, they are probably better WECS sites than convex areas because more air may be forced through them.

Laboratory and field experiments both indicate that cliffs do enhance the wind speed (much like ridges discussed on pages 26-31). Figure 26 shows the vertical wind profile of air flowing over a cliff. The longer arrows in wind profile 3 compared to those in profile 1 illustrate how wind speed is enhanced. The dotted regions show turbulent areas of flow separation. Wind speed rapidly increases near the top of the flow separation. This region of shear should be avoided, either by choosing a new site or by raising the WECS so the rotor disc is above the shear zone.

Since this turbulent zone continually changes size and shape, it is wise to choose as high a tower as is practical (this will also increase available power). To estimate the size of the zone, follow the procedures for turbulence detection discussed in Chapter 7. Measurements should be made on several

Part of the turbulence can be avoided by siting a WECS very close to the face of such hill-shaped cliffs. Selecting a section of the cliff having a more gradual slope (as in Part A) is sometimes advantageous because the tower height required to clear the turbulent zone is reduced.

Any curvature along the face of a cliff should also be considered. Figure 25 illustrates a top view of a curved cliff section. The curvature of the face channels the winds into the concave portions.

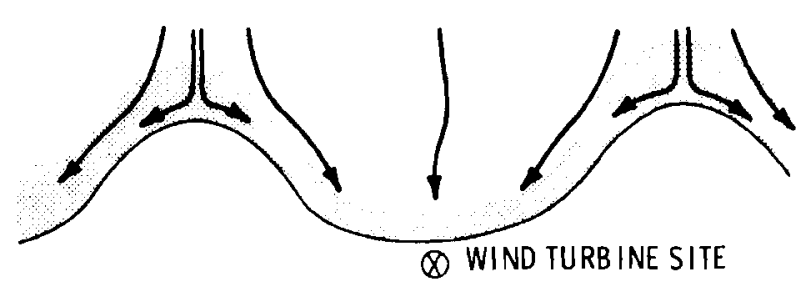

FIGURE 25. Top View of Airflow Over Concave and Convex Portions of a Cliff Face

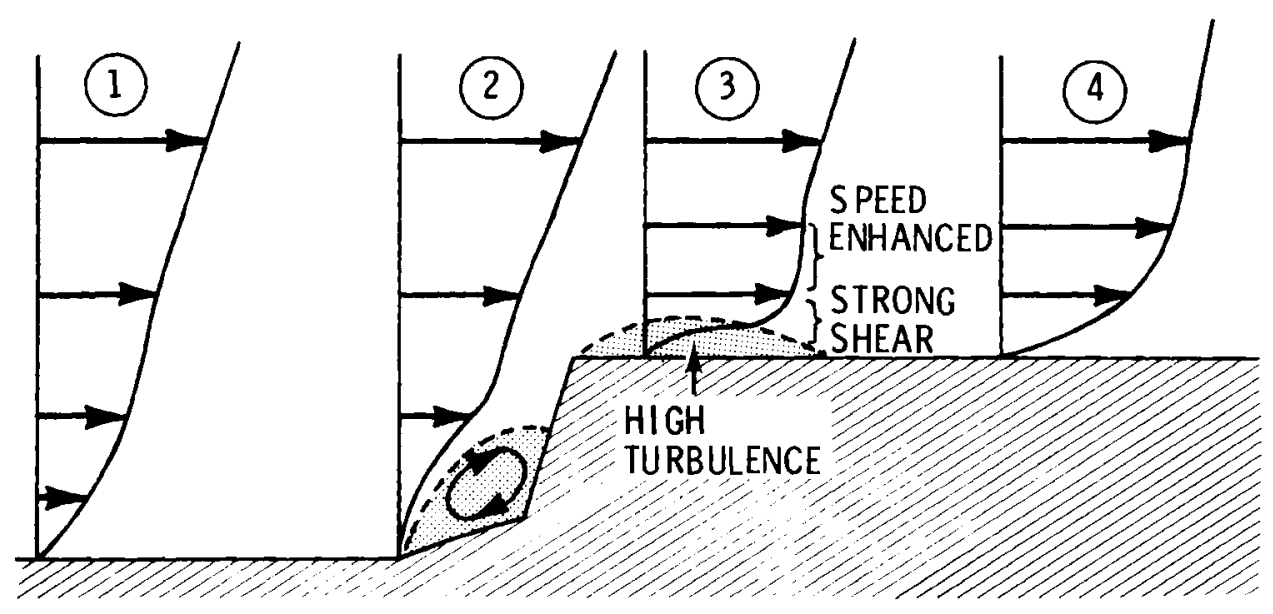

FIGURE 26. Vertical Profiles of Air Flowing Over a Cliff 
different days when the prevailing wind is blowing. In general, sunny days will produce larger turbulent zones. If the turbulence extends too far upward, as may be the case for high cliffs, the cliff may not be a suitable site.

Other factors to consider when siting on cliffs are the surface roughness upstream and the prevailing wind direction. For maximum enhancement of the wind speed, the prevailing wind direction should be perpendicular to the cliff section on which the WECS will be located.

Studies of airflow over cliffs made in wind tunnels and with theoretical models show that the location of the zone of strongest winds depends on the height of the cliff. For smaller cliffs ( $100 \mathrm{ft}$ or less in height) the user can usually site above the separation zone. The best location on such cliffs appears to lie between 0.25 and 2.5 times the cliff height downwind. For very rough surfaces upwind of the cliff, the best site would be at about 0.25 times the cliff height downwind from the edge. Considering progressively smoother surfaces upwind, the best site would be farther downwind from the cliff.

Since the suitability of a cliff site depends on a complex combination of local influences, the best strategy is to make wind measurements during several strong wind situations to determine the site suitability. The following major points should be considered when choosing a site on a cliff:

1. the best cliffs (or portions of a single cliff) are well exposed to the wind (i.e., they are not sheltered by tall trees);

2. the best cliffs (or portions of a single cliff) are oriented perpendicular to the prevailing winds;

3. caution should be used when siting on cliffs greater than $100 \mathrm{ft}$ high, as the turbulent zone may be very large;

4. sites very close to the base of a cliff should always be avoided;

5. if the face of the cliff is curved, a concave portion is better than a convex portion of the cliff (Figure 25);

6. because cliff-induced turbulence can be extremely hazardous to WECS, the shape and slope of the cliff (or section of a cliff) that cause the least turbulence should be selected (Figure 24);

7. general wind patterns near cliffs may be revealed by the deformation of trees and vegetation; and

8. the best sites will usually be between 0.25 and 2.5 times the cliff height downwind from the cliff, providing the region of high turbulence can be cleared during all wind conditions.

\subsection{Depressions}

Depressions include such terrain features as valleys, basins, gorges, and passes. Since depressions are at least partially surrounded by higher terrain, exposure to the prevailing wind is a prime factor in determining WECS site suitability. If, for example, a valley is sheltered from the prevailing wind by mountains, it will probably be a poor area for WECS.

A second concern is the existence of any local wind circulations, such as the sea breeze, or mountain-valley winds. If depressions can effectively channel the prevailing wind, or any local wind flow, they may provide good WECS sites. However, the power is more likely to vary by timeof-day or by season than it is for elevated terrain. Consequently, the feasibility of WECS use in depressions may depend upon how well the available wind matches power needs.

\subsubsection{Valleys and Canyons}

The airflow pattern in a particular valley or canyon depends on such factors as the orientation of the valley to the prevailing wind; slope of the valley floor; height, length, and width of the surrounding ridges; irregularities in the width; and surface roughness of the valley.

Valleys and canyons that do not slope downward from mountains are not usually good sites. Perhaps the only benefit to siting in non-sloping valleys is the possible funneling effect when the large-scale prevailing wind blows parallel to the valley. Funneling occurs only if the valley or canyon is constricted at some point. Unless the valley is constricted, the surrounding ridges will provide better WECS sites than the valley floor.

Three types of flow patterns occur in valleymountain systems. The first, known as valley (mountain)-slope winds, occurs when the largescale wind over the area is weak, and the diurnal 
heating and cooling cycle dominates. This happens most often during the warmer months (May to September). Part of the daily sequence of valley (mountain)-slope winds is shown in Figure 27. During the afternoon the valley wind is fully developed. Shortly after sunset the valley winds weaken. In the middle of the night, the mountains are colder than the lowlands, and the mountain wind is fully developed. The mountain winds frequently continue until shortly after sunrise.

Figure 28 illustrates a wind profile observed for mountain winds in Vermont. The wind accelerates down the valley, with the strongest mountain winds occurring at the mouth (lower end) of the valley, and the lightest winds at the head (upper end). In the vertical direction, the wind speed increases upward from the valley floor reaching a maximum in the center of the valley at about twothirds the height of the surrounding ridges. The mountain wind speed may reach as high as $25 \mathrm{mph}$. The mountain wind is generally well developed for valleys between high ridges and/or rather steeply sloping valley floors. The upper half of the wind profile is very smooth while the lower half occasionally reflects gusty and turbulent conditions.

The daytime wind blowing up the valley is more sensitive to factors such as heating by the sun (the driving force for this wind) and the winds blowing high overhead. As a result, the valley winds are more variable and often weaker, than mountain winds. Unlike the mountain wind, which is strongest near the center of the valley, valley winds are normally greatest along the side slope that most directly faces the sun. Figure 29 shows WECS sites selected to take advantage of mountain and valley winds.

The second type of flow pattern in mountainvalley systems occurs when moderate to strong prevailing winds are parallel to (or within about $35^{\circ}$ of) the valley. In this case, broad valleys surrounded by mountains can effectively channel and accelerate the large-scale wind.

Figure 30 shows possible wind sites where valley channeling enhances the wind flow. Part A presents a funnel-shaped valley on the windward side of a mountain range. The constriction (or narrowing) near the mouth produces a zone of accelerated flow. In this example, the valley is large (approximately 60 miles wide) and open to the prevailing wind. Part $B$ shows a narrow valley in the lee of a mountain range. It is parallel to the prevailing wind and is constricted slightly near its mouth.

A valley that is both parallel to the prevailing wind and experiences mountain-valley winds will provide sites that are dependable sources of power. Moderate to strong prevailing winds in winter and spring will drive the WECS. During the warmer months, mountain-valley winds can be utilized.

The third type of valley flow occurs when the prevailing wind is perpendicular to the valley (or crosses it at an angle greater than $35^{\circ}$ ). A valley eddy may be set up by a combination of solar heating and cross-valley winds. Though there may be times when this eddy could be exploited by a WECS located on either side slope of the valley, it is not a dependable power source because it only occurs on sunny days and is very turbulent.
VALLEY WIND

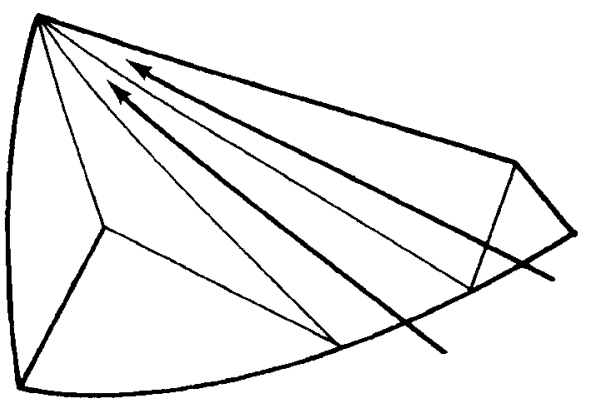

NOON TO SUNSET
MOUNTAIN WIND

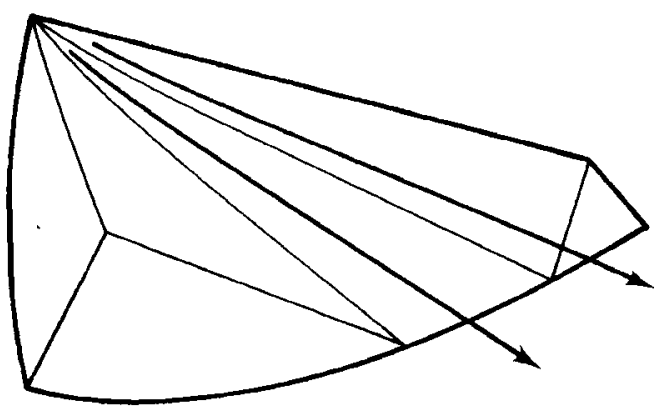

EVENING TO SUNRISE

FIGURE 27. Daily Sequence of Mountain and Valley Winds 


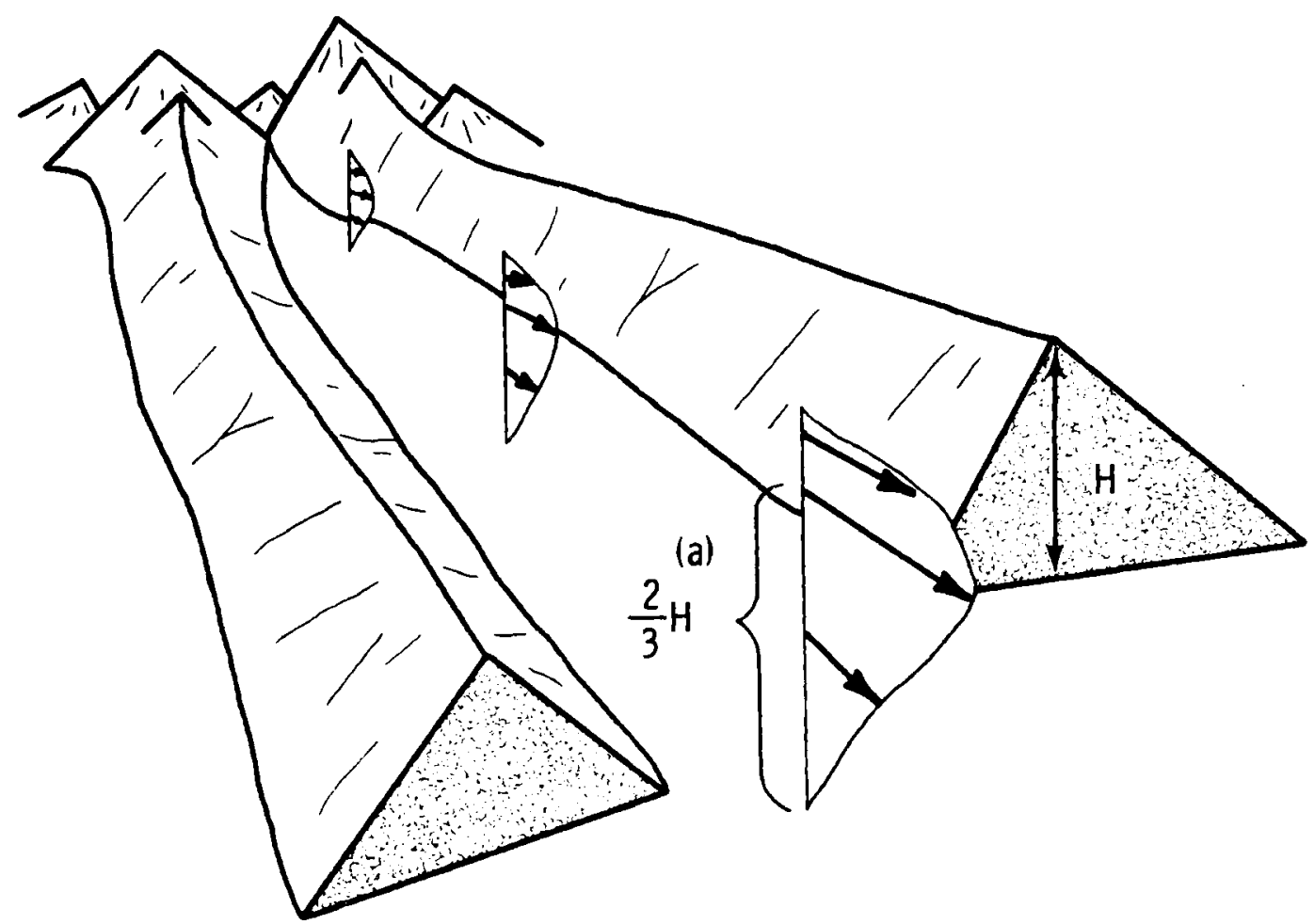

(a)THIS PROFILE IS BASED UPON A LIMITED NUMBER OF OBSERVATIONS

FIGURE 28. Vertical Profile of the Mountain Wind (Park and Schwind, 1978)

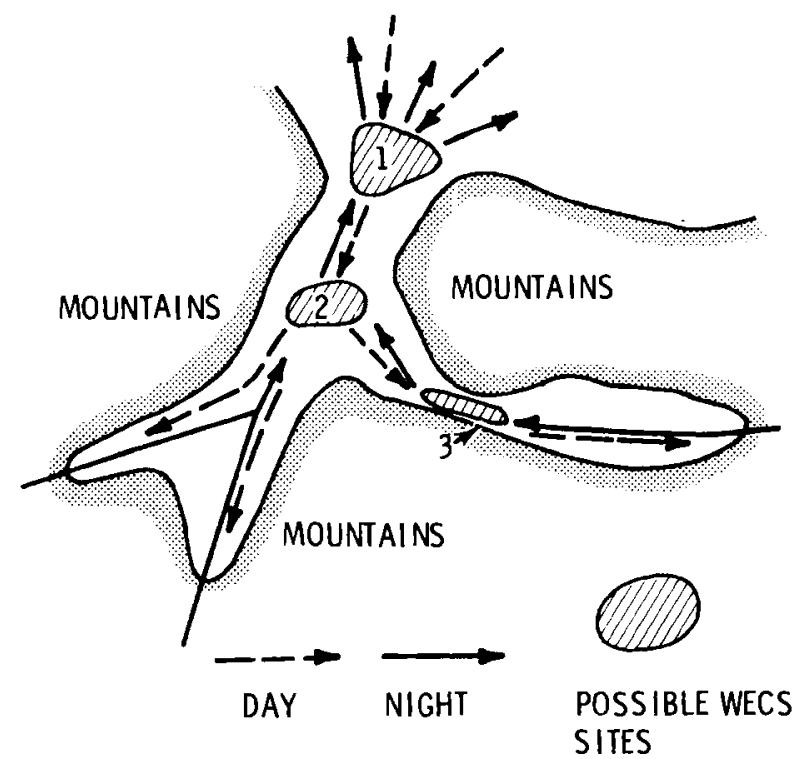

1. MOUTH OF THE VALLEY

2. JUNCTION OF TWO VALLEYS

3. CONSTRICTION IN THE VALLEY

FIGURE 29. Possible WECS Sites in Sloping Valleys and Canyons
To site WECS in valleys and canyons, the potential user should:

1. select wide valleys parallel to the prevailing wind or long valleys extending down from mountain ranges;

2. choose sites in possible constrictions in the valley or canyon where the wind flow might be enhanced;

3. avoid extremely short and/or narrow valleys and canyons, as well as those perpendicular to the prevailing winds;

4. choose sites near the mouth of valleys where mountain-valley winds occur;

5. ensure that the tower is high enough to place the WECS as near to the level of maximum wind as is practical;

6. use vegetation to indicate high wind areas; and 
PREVAILING WIND

(A)

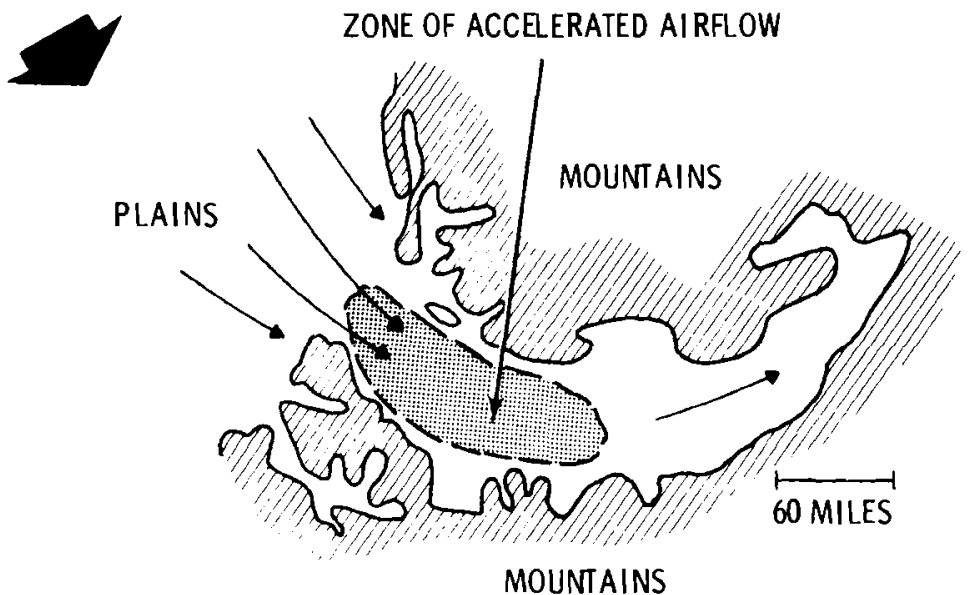

MOUNTAINS

(B)

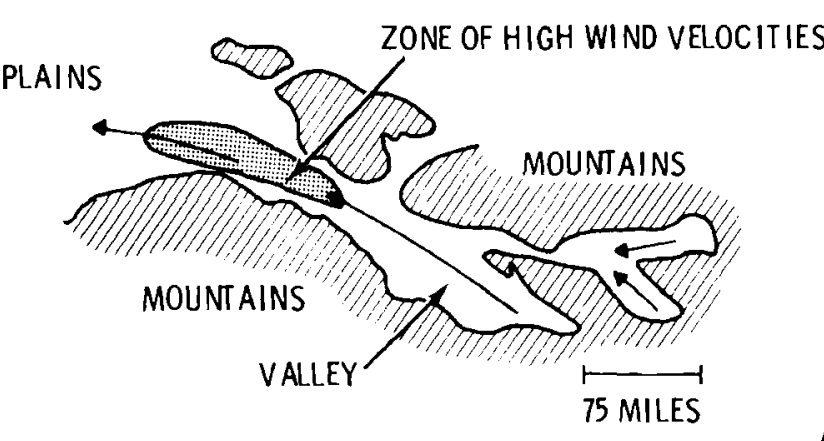

PREVAILING WINDS

FIGURE 30. Possible WECS Sites Where Prevailing Winds are Channeled by Valleys

7. consider nearby topographical features, barriers, and surface roughness (after favorable areas in the valley or canyon are located).

\subsubsection{Basins}

Basins are depressions surrounded by higher terrain. Large, shallow inland basins (such as the Columbia Basin in southeastern Washington) may have daily wind cycles during the warmer months of the year that can be used to drive small WECS. The flow into and out of a basin is similar to the mountain-valley cycle in Figure 27. In fact, valleys sloping down into basins may provide sufficient channeling to warrant consideration as WECS sites.

The flow of cool air from surrounding mountains and hills into the basin during the night is usually stronger than the flow out of the basin caused by daytime heating. Well-developed nighttime flow into a basin may average from 10 to $20 \mathrm{mph}$ for several hours during the night and occasionally more than $25 \mathrm{mph}$ for periods of one or two hours. Afternoon flow out of the basin is generally lighter, averaging 5 to $15 \mathrm{mph}$.

Winter and spring storms combined with the summer wind cycles may provide sufficient wind power in basins for most of the year. However, in the fall and portions of the winter, basins frequently fill with cold air. During these periods the air in the basin may be stagnant for days or even weeks. Consequently, WECS in basins may not be possible for some applications.

The following guidelines are helpful when siting WECS in basins:

1. consider only large, shallow inland basins; 
2. use vegetation indicators of wind to locate areas of enhanced winds in basins (see Section 4.3); and

3. consider all topographical features, barriers, and surface roughness effects.

\subsubsection{Gaps and Gorges}

In some areas rivers and streams have eroded deep gaps or gorges through mountain chains and ridges. The Columbia River Gorge in Oregon and Washington is an example. Since these gaps are frequently the only low-level paths through mountain barriers, much air is forced through them (Figure 31).
The problem of siting WECS in gaps and gorges is much like that of siting in passes and saddles. However, there are a few important differences. On the positive side, gaps and gorges are generally deeper than passes and can significantly enhance even relatively light winds. A river gorge can augment mountain-valley or land-sea breezes providing a reliable source of power. The chief drawback to sites in gaps and gorges is: because they are narrow, there is often much turbulence and wind shear. In addition, since streams usually flow through them, there may be no land near the center on which to locate a WECS.

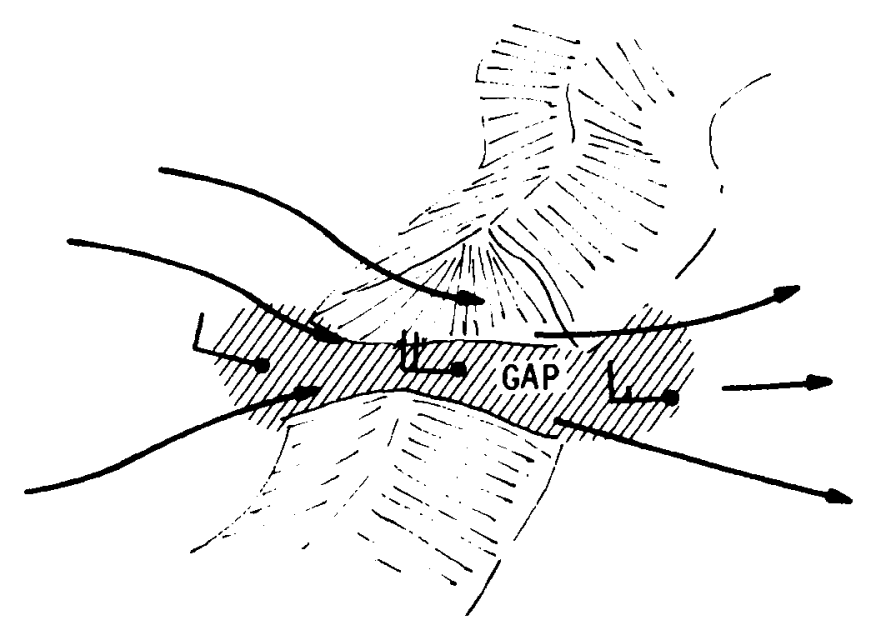

(A)

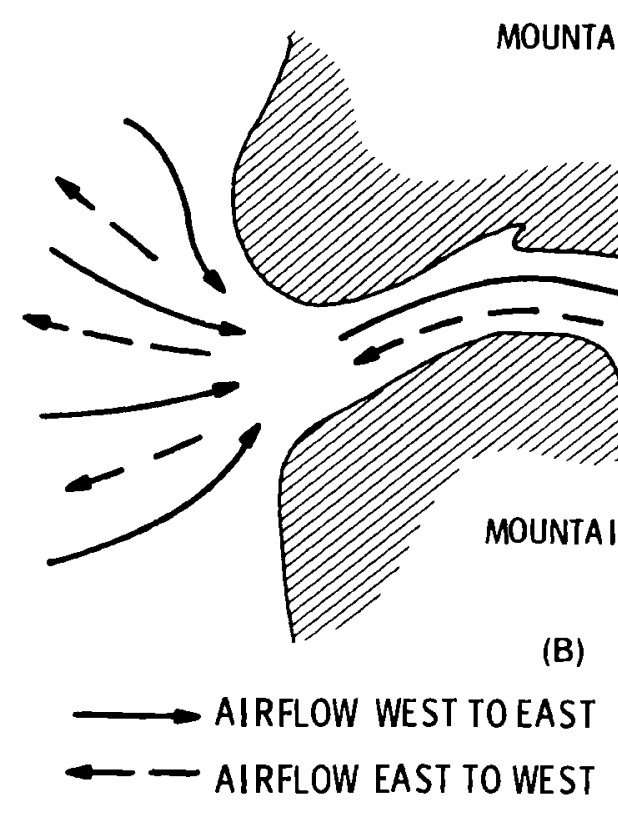

FIGURE 31. A Schematic Illustration of Flow Patterns That May Be Observed Through Gaps and Gorges 


\subsubsection{Passes and Saddles}

Passes and saddles are low spots or notches in mountain barriers. Such sites offer three advantages to WECS operations. First, since they are often the lowest spots in a mountain chain, they are more accessible than other mountain locations. Second, because they are flanked by much higher terrain, the air is funneled as it is forced through the passes. Third, depending upon the steepness of the slope near the summit, wind may accelerate over the crest as it does over a ridge.

Factors affecting airflow through passes are: orientation to the prevailing wind, width and length of the pass, elevation differences between the pass and adjacent mountains, the slope of the pass near the crest, and the surface roughness. At this time, there has not been sufficient research to allow classification of WECS site suitability in terms of these factors. However, some desirable characteristics of passes are listed below:

1. the pass should be open to the prevailing wind (preferably parallel to the prevailing wind);
2. the pass should have high hills or mountains on both sides (the higher the better);

3. the slope (grade) of the pass near the summit should be sufficient to further accelerate the wind like a ridge (see Table 6 for slope suitability); and

4. the surface should be smooth (the smoother the better). (If the pass is very narrow, the user should consider the roughness of the sides of the pass.)

Figure 32 shows two views of the wind profiles in a pass. Part $A$ is a view through the pass. A core of maximum wind (denoted by the innermost circle) is located in the center of the pass, well above the surface. Part B is looking across the pass. In this view, a strong increase in wind from the ground up to the wind maximum is clearly shown. The WECS should be sited near the center of the pass at a level as near the core of maximum winds as possible. Near the ground there may be very strong vertical wind shear and much turbulence. Since vertical

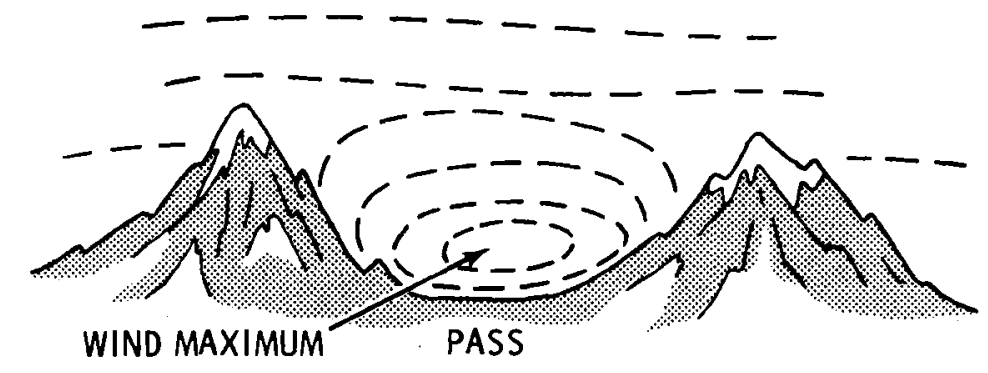

(A)

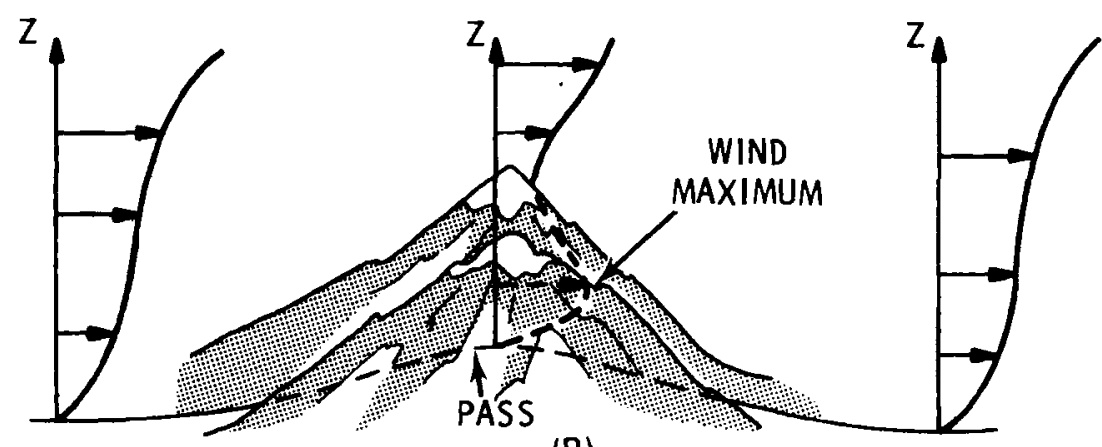

(B)

FIGURE 32. A Schematic of the Wind Pattern and Velocity Profile Through a Mountain Pass 
wind profiles will vary from pass to pass, wind measurements are recommended before a final decision on WECS placement is made.

Passes to avoid are those not open to the prevailing wind (because there will be much less flow through them) and passes, or portions of passes, which are extremely narrow and canyon-like (because these may have turbulence and strong horizontal wind shear).

\subsection{Ecological Indicators of Site Suitability}

Vegetation deformed by high average winds can be used both to estimate the average speed (thus power) and to compare candidate sites. This technique works best in three regions: 1) along coasts, 2) in river valleys and gorges exhibiting strong channeling of the wind, and 3) in mountainous terrain. Ecological indicators are especially useful in remote mountainous terrain not only because there are little wind data, but also because the winds are often highly variable over small areas and difficult to characterize. The most easily observed deformities of trees (illustrated in Figure 33) are listed and defined below:

- Brushing - Branches and twigs bend downwind like the hair of a pelt that has been brushed in one direction only. This deformity can be observed in deciduous trees after their leaves have fallen. It is the most sensitive indicator of light winds.

- Flagging - Branches stream downwind, and the upwind branches are short or have been stripped away.

- Throwing - A tree is wind thrown when the main trunk and the branches bend away from the prevailing wind.

- Carpeting - This deformity occurs because the winds are so strong that every twig reaching more than several inches above the ground is killed, allowing the carpet to extend far downwind.

Figure 33 is one of the best guides to ranking tree deformities by wind speed. Both a top view and a side view of the tree are shown to demonstrate the brushing of individual twigs and branches and the shape of the tree trunk and crown. The figure uses the Griggs-Putnam classification of tree deformi-

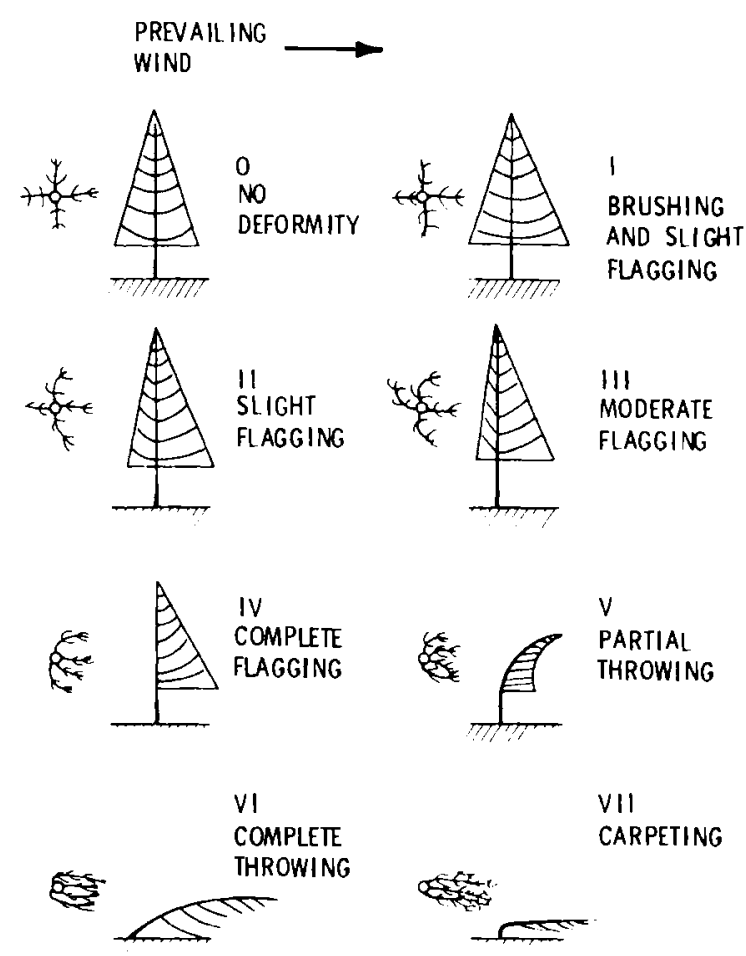

FIGURE 33. Wind Speed Rating Scale Based on the Shape of the Crown and Degree Twigs, Branches, and Trunk are Bent (Griggs-Putnam Index; Hewson, Wade and Baker, 1977)

ties described by indices from 0 to VII. When WECS sites are ranked by this scheme, only like species of trees should be compared, because different types of trees may not be deformed to the same degree.

Another good indicator of relative wind speeds is the deformation ratio (Hewson, Wade and Baker, 1977). It also measures how much the tree crown has been flagged and thrown. Figure 34 shows the tree angles, A, B, and C, that must be measured to compute the deformation ratio " $D$ ". To measure these angles, the trees can either be photographed or sketched to scale. (The user might sketch the tree on clear acetate while he looks at it through the acetate.) He should draw or take the tree pictures while viewing the tree perpendicular to the prevailing wind direction so that he can see the full effects of flagging and throwing.

To compute $D$, the three angles shown in the figure ( $A$ on the downwind side, $B$ on the upwind side and $C$, the angle of deflection) should be measured in degrees using a protractor. The larger the value of $D$, the stronger the average wind speed. 


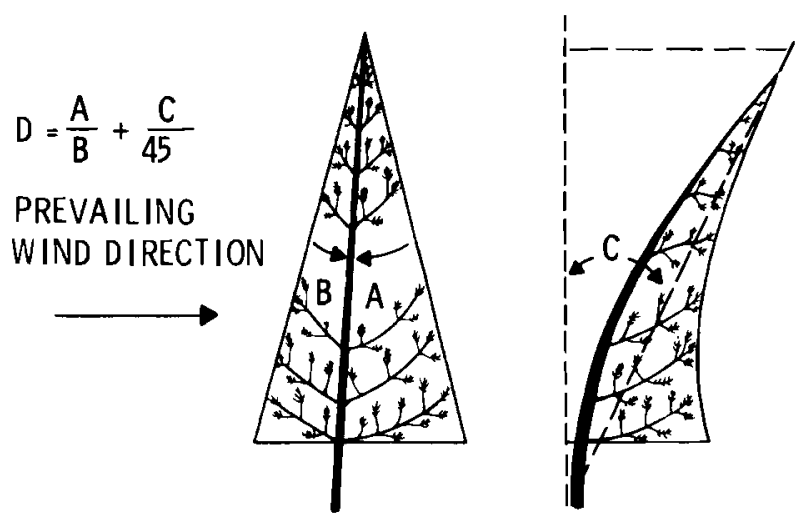

FIGURE 34. Deformation Ratio Computed as a Measure of the Degree of Flagging and Throwing (Hewson, Wade and Baker, 1977)

Mean annual wind speed is correlated with the Griggs-Putnam Index (Figure 33) in Table 8, and with the deformation ratio (Figure 34) in Table 9. These reflect only preliminary research results based on studies of two species of conifers, the Douglas Fir and the Ponderosa Pine. Further studies are examining these and other tree species to improve predictions of mean annual winds with ecological indicators. However, these tables do agree well with similar research conducted by Griggs and Putnam on Balsam and Fir trees in the Northeast (Frost and Nowak, 1977).

Estimates of mean annual wind speed using vegetation can be improved if several trees in a siting area are sampled, using the Griggs-Putnam Index and the deformation ratio. The results of all the sampling should then be averaged. However, ecological indicators should be used primarily to identify possible high wind areas, to locate candidate sites, and to estimate roughly the annual average wind speed. Selection of a WECS should not be based solely on ecological indicators. WECS economics and performance analysis should include either a wind measurement program or available wind data in addition to ecological indicators.

Though the presence of one type of deformity (or a combination) may indicate an area of high average winds and the degree of deformity may give estimates of the relative strengths of the winds, there are still pitfalls to rating sites according to tree deformity. Because past or present growing conditions can greatly affect the size and shape of trees, only isolated trees appearing to have grown under similar conditions should be compared. For example, a tree in or near a dense stand of timber should not be compared to an isolated tree. In addition, trees being compared should be of nearly the same height (preferably $30 \mathrm{ft}$ or more). Another fact to be aware of is: limbs are stripped from trees not only by strong flagging. They can be damaged by man, disease, other trees that once grew nearby, or possibly ice storms. Misinterpreting such signs could lead to the wrong assumptions about the prevailing wind direction and the average speed. Common sense, however, should reveal whether or not all the deformities observed in an area fit together into a consistent pattern.

TABLE 8. Mean Annual Wind Speed Versus the Griggs-Putnam Index (a)

Griggs-Putnam Index (as in Figure 33)

Probable Mean Annual Wind Speed Range (mph)

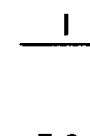

7-9

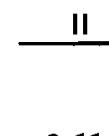

$9-11$

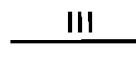

$11-13$
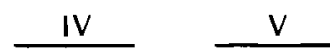

15-18

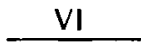

$16-21$

TABLE 9. Mean Annual Wind Speed Versus the Deformation Ratio (a)

Deformation Ratio

(as in Figure 34 Wind Speed Range (mph)

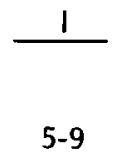

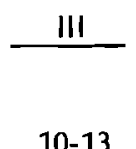

10-13

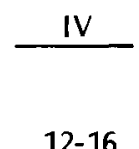

12-16

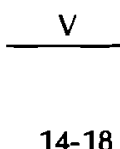

14-18
VI

15-21

(a) These data were prepared by E. W. Hewson, J. E. Wade, and R. W. Baker of Oregon State University. 
The following guidelines summarize this section and suggest how to use ecological indicators effectively:

1. detect ecological indicators of strong wind;

2. compare isolated trees of the same species and height within the strong wind areas to select candidate sites;

3. consider flow patterns over barriers, terrain features, and surface roughness in the final selection;

4. measure the wind in complex terrain to ensure that a suitable site is selected; and

5. base selection of a particular WECS and any detailed estimation of its power output on wind measurements, not on ecological indicators alone. 


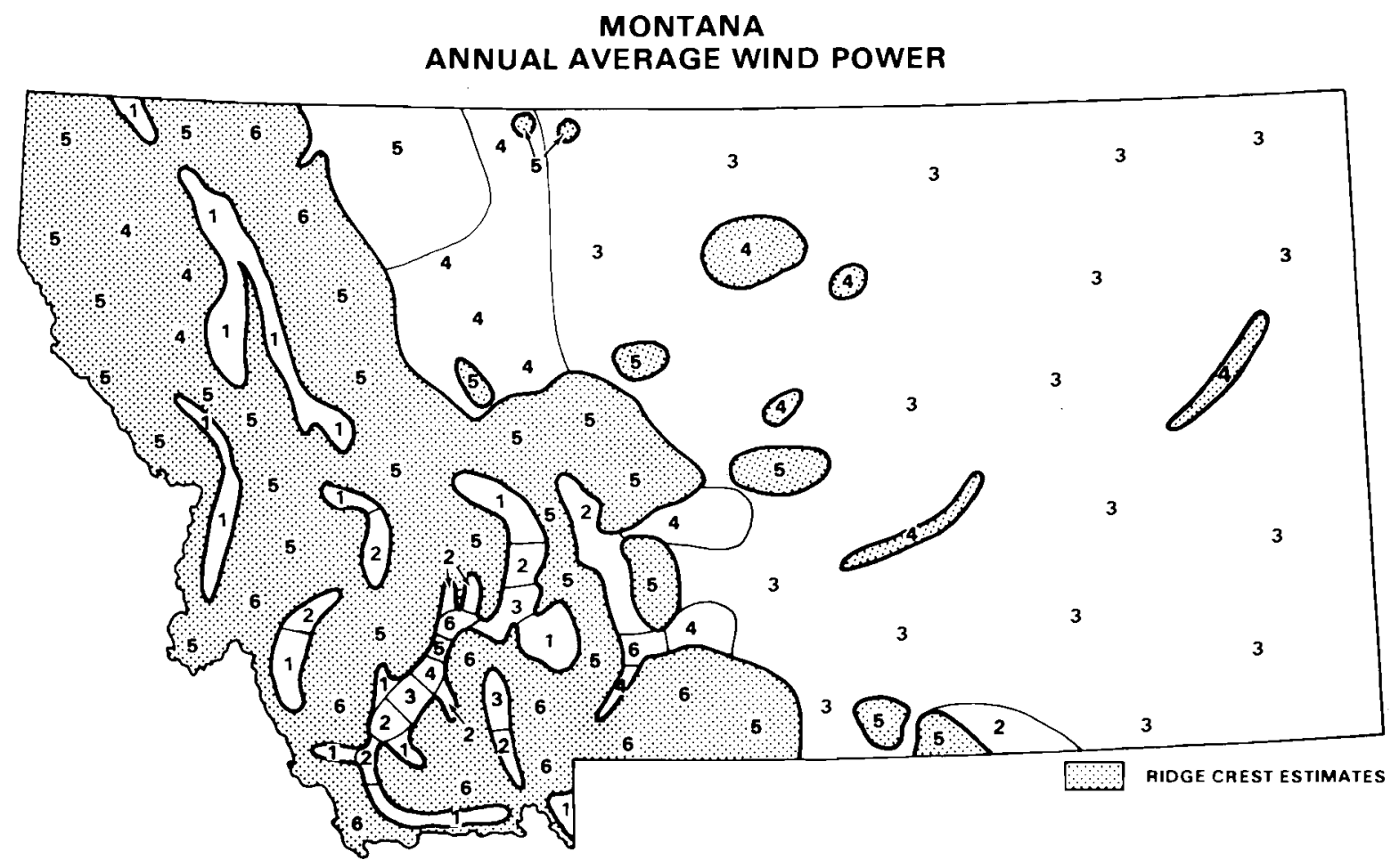

\begin{tabular}{|ccc|}
\hline \multicolumn{3}{|c|}{ WIND POWER } \\
(WATTS/M \\
\multicolumn{3}{c}{ (W) } \\
\cline { 2 - 2 } & $10 M$ & $50 M$ \\
\hline 1 & $<100$ & $<200$ \\
2 & $100-150$ & $200-300$ \\
3 & $150-200$ & $300-400$ \\
4 & $200-250$ & $400-500$ \\
5 & $250-300$ & $500-600$ \\
6 & $300-400$ & $600-800$ \\
7 & $>400$ & $>800$ \\
& & \\
\hline
\end{tabular}




\section{Chapter 5}

\section{Methods of Site Analysis}

If only the annual average output power is important, the site evaluation process for WECS applications is completed once the feasibility is established and the best site chosen. If WECS have been used in the immediate vicinity, little analysis is required since experience will be the best guide. However, if more precise economic or performance information is needed, additional analysis of wind data should be performed.

Table 10 presents three general approaches to site analysis and the respective advantages and disadvantages of each. These methods of site analysis range from expending a few dollars and a few hours analyzing existing data to collecting and analyzing onsite data for an entire year. Each approach has different levels of analysis that can be performed depending upon the user's needs for information, his budget, and the format of the available or collected wind data.

\subsection{Use of Available Wind Data}

Method one uses only wind data collected at a representative weather station. (A representative station is a station that can be expected to have wind characteristics similar to the WECS site because of similar exposure to prevailing winds.)
Determining whether a nearby weather station is representative is not simple; even in areas such as the Great Plains, wind conditions can vary significantly over short distances. The relationship of the site and the weather station to local terrain is very important when using data from a nearby weather station. For example, a shallow river valley will usually have lower average wind speeds than the surrounding higher elevations. Lower winds are particularly prevalent in depressions during the night and early morning, because cold, heavy air drains into the depressions and isolates them from the regional winds. Therefore, a weather station located in such an area could have lower average wind speeds than a site located at a higher elevation.

As a very general rule, sites within 10 to 20 miles of one another in large regions of relatively flat terrain should have similar wind characteristics, provided they have similar exposures to the prevailing winds. In very flat areas, this distance may be extended to 60 miles. In rugged, hilly or mountainous terrain, the winds from a nearby station are usually not applicable for a site analysis.

The amount of information that can be gleaned from available wind data depends upon the form in which the data are summarized. Summaries that give wind speed versus direction (see Appendix A, Table A.1) can be used to estimate annual output

TABLE 10. Various Approaches to Site Analysis

\section{Approach}

1

Use wind data from a nearby station; determine output power characteristics.

Make limited onsite wind measurements; establish rough correlation with nearby station; compute output power using adjusted wind data.

3 Collect wind data for the site and analyze it to obtain output power characteristics.
Advantages

Little time or expense required for collecting and analyzing summarized data. If used properly, can be acceptably accurate.

If there is a high correlation between the site and the station, this method should be more accurate than first method.

Most reliable method. Works in all types of terrain.
Disadvantage

Only works well in large areas of flat terrain where average annual wind speeds are $10 \mathrm{mph}$ or greater. Unsummarized data requires much time to analyze.

Of questionable accuracy, particularly where there is seasonal variation in the correlation between the WECS site and the nearby station.

Requires at least a year of data collection. Added costs of wind recorders. Data period should represent typical wind conditions. 
power and to identify potential wind barriers. If monthly average wind speeds or averages by time of day are listed (see Table 11), ot her valuable statistics can easily be computed. For example, if monthly average wind speeds are given, each monthly average can be used to obtain an estimate of the average monthly output power of a WECS (see Appendix C). If power needs to be available during certain seasons, such as for crop irrigation, then the summarized monthly average windspeeds can be used to estimate how well the WECS output power will match the seasonal demand for power.

For some WECS applications, the time-of-day (diurnal) variations in WECS output power must match the diurnal power load, such as when a WECS is used to reduce the amount of electrical energy purchased from a utility. In this situation, WECS economics may be greatly affected by utility rate structures. A utility might charge WECSowning customers time-of-day rates; that is, the cost of electricity will be higher during the utility's peak demand time(s) than during other times. Likewise the price of excess power produced by the WECS and sold back to the utility could vary with time of day. Under these conditions the economic viability of WECS might depend upon how much of the WECS power is produced during the "high cost" hours of the day rather than on annual average output power. If diurnal wind speed averages are summarized, as in Table 11, this type of analysis can be performed.

If wind data are only available in an unsummarized form, (i.e., the original wind logs) the needed diurnal or monthly wind summaries can usually be produced, but more time will be required to organ- ize the data into the proper format. The user should weigh the time and money needed to properly summarize such data against his need for answering questions concerning monthly or hourly load-matching.

Caution should be used whenever long-term average wind speeds from weather stations are used. At most weather stations the wind instruments have been moved to different heights having different exposures (therefore different surface roughnesses) over the period of record. However, when the long-term averages are computed, anemometer location changes are disregarded. For example, the anemometer may have been mounted on a roof, $80 \mathrm{ft}$ above ground for $20 \mathrm{yr}$, then moved to a tower near the airport runway at $20 \mathrm{ft}$ above ground for the next $10 \mathrm{yr}$. When the average wind speed was computed, all of the observations were lumped together, even though the winds at $80 \mathrm{ft}$ were probably stronger than at $20 \mathrm{ft}$.

As discussed in Chapter 3, when nearby weather station data are used to estimate the WECS site winds, the effects of height-roughness changes should be considered. This means that periods of constant anemometer height and exposure should be separated and a new average wind speed calculated for a period of known anemometer height and surface roughness. If one is using data from a primary National Weather Service station, "Local Climatological Data" (LCDs) annual summaries contain anemometer histories. These summaries are available through the National Climatic Center (NCC) for a few cents per copy (see Appendix A for the address).

TABLE 11. Example of Local Climatological Data Summarized by Hour of Day

\begin{tabular}{|c|c|c|c|c|c|c|c|c|c|}
\hline \multirow[b]{2}{*}{$\begin{array}{c}\text { Local } \\
\text { Time }\end{array}$} & \multicolumn{7}{|c|}{ Averages } & \multicolumn{2}{|c|}{ Resultant Wind } \\
\hline & $\begin{array}{l}\text { Sky Cover } \\
\text { in Tenths }\end{array}$ & $\begin{array}{c}\text { Station } \\
\text { Pressure, } \\
\text { In. }\end{array}$ & $\begin{array}{c}\text { Dry } \\
\text { Bulb, } \\
{ }^{\circ} \mathrm{F}\end{array}$ & $\begin{array}{c}\text { Wet } \\
\text { Bulb, } \\
{ }^{\circ} \mathrm{F}\end{array}$ & $\begin{array}{c}\text { Relative } \\
\text { Humidity, } \\
\%\end{array}$ & $\begin{array}{l}\text { Dew } \\
\text { Point, } \\
{ }^{\circ} \mathrm{F} \\
\end{array}$ & $\begin{array}{c}\text { Wind } \\
\text { Speed, } \\
\text { mph }\end{array}$ & Direction & $\begin{array}{c}\text { Speed, } \\
\text { mph }\end{array}$ \\
\hline 01 & 8 & 29.59 & 42 & 40 & 84 & 38 & 9.1 & 17 & 8.1 \\
\hline 04 & 8 & 29.59 & 41 & 40 & 88 & 38 & 9.1 & 18 & 7.2 \\
\hline 07 & 8 & 29.61 & 42 & 40 & 89 & 38 & 9.0 & 18 & 7.5 \\
\hline 10 & 8 & 29.62 & 46 & 43 & 80 & 39 & 11.0 & 21 & 7.4 \\
\hline 13 & 7 & 29.61 & 50 & 45 & 68 & 39 & 11.3 & 22 & 7.9 \\
\hline 16 & 8 & 29.59 & 51 & 45 & 66 & 38 & 10.4 & 24 & 3.5 \\
\hline 19 & 7 & 29.59 & 48 & 43 & 71 & 38 & 9.4 & 24 & 3.5 \\
\hline 22 & 7 & 29.60 & 45 & 42 & 79 & 38 & 8.8 & 18 & 4.6 \\
\hline
\end{tabular}

(a) Averages are given for every third hour of the day. 
If the available data being used are not from a station for which an LCD is produced, the National Wind Data Index (Changery, 1977) contains all known anemometer histories for all stations in the United States at which wind data have been collected.

For stations having annually summarized wind data, computing a representative average wind speed is an easy process. Simply order the annual LCD summaries from NCC for the years of constant anemometer location and compute the average wind speed for that period (a minimum of $5 \mathrm{yr}$ is suggested for establishing a long-term average). If no summaries are available for the period of constant anemometer location, one would have to obtain the available weather logs and expend a great deal of time (a week or more) to compute a representative wind speed average. In this case a screening process is suggested in which the user simply scans the weather logs and makes rough estimates of the average wind speed for each month. For cases in which the change in anemometer height and exposure are not great (10 ft or less and not more than two categories of roughness) the long-term average can be used, if available, without correction.

\subsection{Limited Onsite Data Collection}

The second method of site analysis might be considered whenever nearby weather stations may not adequately represent the WECS site. Weather stations may not be representative,

- if they have slightly different exposures to the prevailing winds than the WECS site, or

- if they are too far away to ensure adequate representation of the WECS site.

In this approach, the site is first instrumented and wind data are collected over a specified time interval. The anemometer should be sited using the same guidelines as for an actual WECS. It should be at, or as near as possible to, the actual WECS height. The minimum suggested time interval for data collection is three months.

Data must be obtained for the weather station that corresponds to the same collection period as that of the onsite data. Ideally, wind data should be collected hourly (or three hourly) to give an indication of the diurnal variation in the wind. If this is not possible, daily averages can be collected at the
WECS site using even a simple wind-run anemometer (see Chapter 6).

After the daily (or hourly) average data at both locations have been obtained, anyone with a handheld scientific calculator and a background in math or statistics can perform the needed analysis, i.e., a regression analysis on the daily or hourly averages. (Local science and math teachers or meteorologists can give assistance.) This technique will give an indication of how well the winds at the weather station represent the winds at the WECS site. It will also provide a simple equation (for daily average winds) or a set of equations (for hourly average winds) that will help predict the wind average at the WECS site, providing the winds at the weather station are known.

The equation(s) will allow an estimate of an entire year of wind at the site using weather station data. There are drawbacks to the short-term data collection method. First, the regression analysis may indicate that the weather station is a very poor indicator of WECS site winds. In this case, the user has gained very little knowledge of his wind resource. Second, the correlation between the two sites may vary from season to season. In this case, one has gained only a knowledge of the wind resource for the three months of data collection and he may make wrong assumptions about the remainder of the year. Third, the correlation between locations may vary from year to year so the estimate of the long-term winds at the WECS site may be unreliable. These possible errors can be reduced slightly by either measuring winds for the three windiest months of the year, or by measuring winds for the months of peak power demand if seasonal load matching is important.

\subsection{Extended Onsite Data Collection}

The third method of site analysis involves extended onsite wind measurements, usually for a full year or more. While this method is more reliable, it is also more expensive and time consuming. However, costs may vary depending on the type of instrument required, the cost of installation and maintenance, and data analysis. Chapter 6 presents several generic types of wind measuring devices, their relative costs, accuracies, and the wind information one can expect to get from each type of instrument.

When planning an onsite measurement program, a WECS dealer, manufacturer, or a meteorologist should be consulted. These individuals can 
help determine the actual cost of an extensive wind measurement program, the type of data analysis that can be performed, and the information that can be gleaned from the study. However, this type of analysis is not economically feasible for most small-WECS users.

A suggested procedure for establishing a wind measurement program includes:

- a listing of the information needed to evaluate WECS economics and performance

- an estimate of the time and money available for data analysis

- the actual siting of the instrument.

Once these items have been considered, the wind instrument that meets all data needs at an affordable cost should be selected. No matter which instrument is selected, it should be sited as carefully as the WECS. It should be placed at the same height as the WECS, and it should be durable enough to withstand the environmental conditions to which it will be exposed.

In determining what wind information is needed, the user might want to consider how important it is to have wind energy available in certain seasons or at certain times of the day. If considered important, he should select a wind instrument that will permit averaging the power output of a WECS by season, and/or by the hour of the day. Furthermore, if the user is considering an energy storage system, such as batteries, he may need to estimate the maximum expected return time (MERT); i.e., the maximum time the wind might remain below the cut-in speed of the WECS. Since no power would be produced during this time, either the storage system must be sufficient to meet energy needs for this period, or there must be some form of backup power.

Estimating the time and money available for data analysis may result in tradeoffs. For example, a smart data logger (see Chapter 6) may actually perform the analysis automatically as the data is collected, but the cost would be more than for a simpler instrument. On the other hand, a simple wind-run anemometer can provide useful information, if the user is willing to read it frequently and regularly, such as every six hours, and to perform a great deal of arithmetic.

If the MERT for the cut-in speed of the WECS is needed, some wind stations have statistics available that might help. However, return times can be estimated if the user decides to collect onsite data. If a wind-run anemometer is used, it must be read frequently during periods of low wind in order to define the time that the WECS would not have been generating power. Some sophisticated data loggers can be programmed to measure return times automatically.

While method three is the most accurate approach to site analysis, some uncertainty exists as to how well the year (or more) of collected data represents the true long-term winds at the WECS site. The entire year of data collected, or one of the seasons during the year, may have been abnormally windy or calm. Consulting a meteorologist who is familiar with the area, or a long-term resident, may give some qualitative insight into whether the site analysis will show more or less power output from the WECS than might be expected in an average year.

To date, statistical comparisons of a site with a nearby weather station have not proven sufficiently reliable to correct the wind data collected onsite (for a year or more) before doing a detailed economic analysis. Therefore, the year of onsite data collected should be used for the economic analysis. If the economic value of WECS appears marginal after the site data has been analyzed, the user may want to make a subjective analysis of the representativeness of the year of data.

\subsection{Site Analysis Considerations}

Except in situations where it is the only obvious solution to a power generating problem, the decision to purchase a WECS must depend upon some level of economic and performance analysis. The purchaser must be convinced that the cost of the power generated by the WECS will be cheaper over the life of the machine than the power generated by other alternatives, or that any greater cost would be outweighed by other considerations, such as the desirability of achieving energy independence. In some situations the cost of WECS power may have to be considerably cheaper than the alternatives, because the purchaser may prefer the convenience and historical reliability of central grid power. Obviously, the behavior of the wind at the machine site has an important bearing on the ultimate cost of the power generated. The accuracy to which these wind characteristics must be known and the resulting accuracy of the economic and performance analysis will depend upon the application of the machine and the size of the investment in wind systems. 


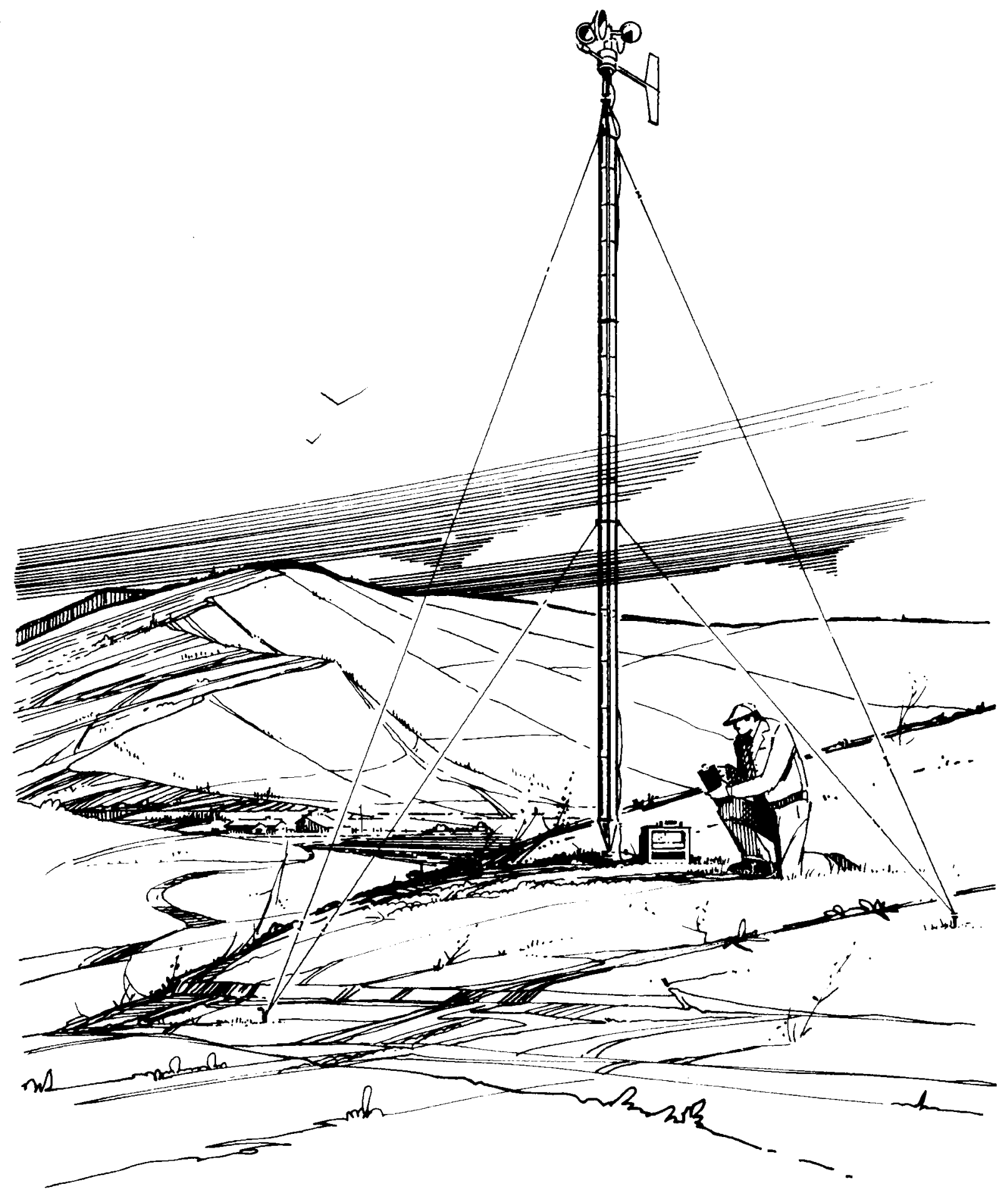




\section{Chapter 6}

\section{Wind Measurements}

A wind measurement program provides data to improve wind resource assessments and to increase confidence in site evaluation. In this chapter, five steps are described for planning and executing a measurement program. These steps are:

1. Determine exactly how the wind data will be used.

2. Select an instrument system that provides the needed data.

3. Estimate the cost of data collection and analysis.

4. Obtain and install the instrument system.

5. Collect the data.

A sixth step, analysis of data, is discussed in Chapter 5 and $A$ ppendices $C$ and $D$. The first three steps are fundamental and should be completed prior to making the final decision to conduct a measurement program (the last three steps).

\subsection{Determine Data Use}

The first step in planning a wind measurement program is to determine how the data collected will be used. Here, emphasis is on data use rather than data. Identification of appropriate data requires determination of the intended WECS use. For example, if a WECS is being considered for its annual power production, then the annual power production will be estimated using the wind data. In this case, mean wind speeds and wind speed distributions will be used. If, however, a WECS is being considered for providing power during periods of peak power demand, more detailed power estimates will be needed. At a minimum, the variation of power with time-of-day and season should be estimated. Also, the length of periods when the WECS would not provide power and the seasonal variations of these periods may need to be estimated. In this case, monthly average wind speeds and wind speed distributions do not provide adequate information. The instrument system selected in the second example must provide more data than the instrument system in the first example.
In addition to the intended WECS use, various data analysis options should be examined. Appendices $C$ and $D$ describe a number of ways to use wind data and should be studied as a part of the planning process. Once the data analysis techniques have been selected, the types of wind data needed and the most convenient form for the data can be determined. If the data uses are clearly specified, time and expense in data analysis can be reduced because the data can be organized in a useful way during data collection.

To help select an instrument system, identify a range of options for acceptable data use. The options should be classified as either desirable or essential. Essential items can be used to develop criteria for the minimum acceptable instrument system. The total list, essential plus desirable items, can be used to determine the maximum usable system.

\subsection{Select Wind Measurement System}

Wind measurement systems are composed of three primary parts: sensors, signal conditioning, and display or recorder. Sensors measure the wind and produce a signal that is directly related to the wind. The signal conditioning equipment converts the signal received from the sensor into a form that can be used by the recorder or display. Recorders and displays provide information in usable forms. The goal in selecting an instrument system is to select sensors and displays and recorders that provide the data needed for the intended analysis. Other factors to consider include cost, instrument accuracy and reliability.

This section discusses sensors and displays and recorders, and describes instrument systems in some detail. For this discussion, instrument systems are assumed to include appropriate signal conditioning equipment.

\subsubsection{Wind Sensors}

For WECS siting applications, the important sensors for wind speed are cup and propeller anemometers; for wind directions, it is a wind vane. Other sensors are primarily research tools that are expensive and require careful attention during use. When in use, cup anemometers and wind vanes are generally independent sensors separated by a few feet. When propellers and vanes are used, the propeller is attached to the vane. Because the two 
sensors are not totally independent, failure of the vane can cause failure of the propeller anemometer.

The rotation of anemometers is used to generate a signal that is proportional to wind speed. In most cases, the signal is electrical, although some anemometers produce mechanical signals. These signals may be continuous or intermittent. Continuous signals permit the wind speed to be determined at any instant. Intermittent signals can only be used to determine the average wind speed during a specific interval.

An example of a continuous signal would be the output of a small d.c. generator. If an anemometer is connected to a d.c. generator, the output of the generator can be displayed using a voltmeter or ammeter. The needle of the meter will rise and fall with each wind gust, and the average wind speed is reflected by the average position of the needle. An example of an intermittent signal would be a flashing light. An anemometer can be connected to the light switch so that the number of light flashes in one minute equals the average wind speed during the minute. To use this anemometer, the flashes for one minute would need to be counted. At the end of the minute, the count would only give the average speed. No information would be available on the speed during gusts within the minute.

Wind vanes produce continuous signals; however, there are two types of signal. One type relates the signal to discrete direction sectors, i.e., north, northwest, etc. As long as the wind continues within the sector, the signal remains constant even though there may be small direction fluctuations. The other type relates the signal to the instantaneous wind direction. The signal continuously changes even though the wind remains from the same general direction. For most WECS siting studies, wind vanes that relate direction to discrete wind sectors are adequate.

\subsubsection{Displays and Recorders}

Generally, displays provide the user with current, but not past, information. Recorders, on the other hand, provide past information and may not provide current information. Some recorders include a display. Selection of an appropriate system depends on the user, as well as the user's needs.

Displays frequently used with wind instruments include: dials, digital displays, and lights. Dials as displays are common. When used with anemometers, dials are similar to speedometers where the information is transferred by needles or pointers.
Digital displays are common and are found on small handheld calculators and clocks. In digital displays, information is presented directly by numerals and letters, rather than by needles or pointers. Flashing lights display intermittent anemometer signals. Lights can also be used to indicate wind direction when the signal is related to discrete sectors. The display consists of several lights, each light associated with one sector. When the display consists of four lights, the direction can be determined to one of eight sectors if it is possible to illuminate two lights at a time. For example, if the light associated with north were lit, the wind would be from the north. If the light associated with west were lit, the wind would be from the west. A northwest wind would be indicated by illuminating both the north and west lights.

Recorders used in wind measurement systems fall into three general classes: counters, strip chart recorders, and magnetic tape recorders. A given wind system may include recorders from one or more of the basic classes. One common type of system uses counters to store data initially and magnetic tape to transfer the data from the recorder to the point of data analysis.

The simplest recorder is the single counter or accumulator. This device records only the total amount of wind passing the sensor (a wind-run anemometer). An odometer on a car, which gives total mileage, is an example of this recorder. To estimate wind speed, it is necessary to record or determine elapsed time and divide the total amount of wind passing the sensor by the elapsed time. That is,

$\begin{aligned} & \text { Monthly average } \\ & \text { wind speed }(\mathrm{mph})\end{aligned}=\frac{\text { miles of wind passage }}{\text { hours in month }}$

Many counters give a direct readout of the wind passage. These counters may be actuated by electrical or mechanical signals. Wind-run anemometers frequently include both the sensor and counter in a single package. For remote siting applications, totally mechanical wind-run anemometers have an advantage over electrical systems in that they do not require a source of electricity. Consequently, they are not affected by either power outages or battery failures. Wind-run anemometers are particularly useful where the data analysis will be restricted to estimating WECS annual power production, or at most, to estimating the seasonal variation of WECS output power because they provide only the essential information which reduces the cost of data collection and analysis. 
A number of electric and electronic devices are being used as accumulators. In one of these devices, an " $E$ " cell, current generated by the anemometer causes a gap in a mercury column to move. The change in location of the gap is directly proportional to the wind passage. An adjustable scale, calibrated in miles, can be set to read zero each time a recording period is begun. Other electric and electronic accumulators generally require more sophisticated electronic equipment to determine wind passage.

Data loggers combine a number of accumulators. A simple data logger might consist of 10 accumulators, each accumulator associated with a given wind speed range. At the end of the observation period, the contents of the accumulators (registers) give the wind speed frequency distribution, which can be used to estimate both WECS power output and mean speed. A power estimate derived from a measured frequency distribution will be more accurate than one based on a measured mean speed and an assumed distribution.

As data loggers become more complex (and expensive), they may be used to record wind speeds by direction and/or time of day. Available wind power statistics, based on the cube of the wind speed (see Chapter 2), and estimates of power, based on WECS characteristics output (see Appendix D), may also be recorded by data loggers. Data loggers that perform electronic calculations using the input signals and then record the results of the calculations are called "smart" data loggers. Smart data loggers significantly reduce the time and expense of data analysis, but they increase the cost of an instrument system.

Strip chart recorders have been a standard means of recording data for years. In these devices, the signal from the sensor moves a pen or other marking device back and forth across a moving piece of paper. Typically, the paper moves at speeds between 1 and 6 inches per hour. Unlike many other recorders, the strip chart serves as a display device, as well as a recorder: the ink trace is a continuous wind record in which time of occurrence is determined by position along the chart. For a strip chart to be useful, the beginning and ending times of the recording must be carefully recorded, and the chart must move at a constant rate.

Analysis of data recorded on strip charts starts with extracting the data from the charts. The data must then be compiled in a usable format. These preparatory steps are tedious, and many opportu- nities for error exist. Therefore, magnetic tape recorders are rapidly replacing strip chart recorders as primary data collection devices. They are particularly useful where data processing and analysis are being done on a computer.

Magnetic tape recorders can be used to record data directly from sensors, or they can be used to record data output from a data logger. In the first case, with a minimum amount of information lost prior to recording, the data can be analyzed in one way and then re-analyzed in another. However, retaining the information requires a relatively large number of tapes for data collection and increases data analysis costs. In the second case, a large part of the data analysis is completed prior to recording, but the flexibility of further analysis is lost. As a result, the number of data tapes required and the cost of completing the analysis are small. Probably, magnetic tape recorders will be used by professionals in a WECS siting study because of the cost of recorders, signal conditioning, and the equipment needed to read and process the magnetic tapes.

\subsubsection{Wind Measurement System}

In this section, four general wind measurement system classes are defined on the basis of data storage capability, and the advantages and disadvantages of the systems are discussed (see Table 12). These four classes of wind measurement systems are:

Class Data Storage Capability

I None

II Limited to a single storage register.

III Processed information stored in data logger with more than one storage register, but sequential information lost.

IV Processed or unprocessed information with sequential information retained.

Class I instrument systems do not have any data storage capability. If data are to be collected, a human observer must monitor the system and record the data. These systems are appropriate where observations can be made on a regularly scheduled basis, such as at National Weather Service offices and airports. In wind energy applications, they are most useful for monitoring the performance of an installed WECS. If they are used in siting studies, wind speed observations will be biased toward high wind speeds, unless data are recorded at regularly scheduled times. This bias 
TABLE 12. Instrument Systems

$\begin{array}{ll}\text { Class } & \text { Recording Device } \\ 11 \quad \begin{array}{l}\text { Single Odometer or } \\ \text { Storage Register }\end{array}\end{array}$

III Data Logger

IV Strip chart/magnetic tape recorder
Primary Wind Energy

Application
Comparison of current
wind speed with WECS
output

Siting studies, determine weekly and monthly average wind speeds.

Siting studies, determine variety of wind characteristics.

Siting studies for larger systems, professional siting studies.

\begin{tabular}{l} 
Advantages \\
\hline $\begin{array}{l}\text { Gives current wind con- } \\
\text { ditions, low instrument } \\
\text { cost }\end{array}$ \\
Low cost, easy to use, \\
good for remote loca- \\
tions. \\
Summarizes data when \\
collected, data come \\
from system ready for \\
final analysis, can be used \\
in remote locations, can \\
provide diurnal load \\
matching data.
\end{tabular}

Retains information about each wind observation, type of data analysis can be determined after data collection, can be used to estimate wind persistence statistics.

Disadvantages
$\begin{aligned} & \text { No recorder; human } \\ & \text { observations biased toward } \\ & \text { high wind speeds }\end{aligned}$
Provides minimal informa-
tion, limits possible data
analysis.
Costs more than Class I
systems, information on
individual wind observations
lost, may require sophisti-
cated equipment to retrieve
and present data for analysis.

Data must be summarized following collection, relatively high cost, requires attention during data collection to avoid data loss. results because people are curious about wind speed during high speed conditions and are most likely to make observations during those conditions.

Class II instrument systems characterize the wind with a single number. Wind-run anemometers are classic examples of these systems. Other instruments in the class record available or extractable wind energy. Use of these instruments requires that the storage register or accumulator be read twice and that the time between readings be known. If a wind-run anemometer is used, the average speed for the observation period is found by dividing the wind-run (difference in readings) by the time readings. If energy is recorded, the average power (available or extractable) is found by dividing the difference in readings by the time between readings.

Class II systems provide a minimal characterization of the wind resource. They are particularly useful in remote locations where access and power for system operation are limited. If the instruments are read on a regular basis (weekly or monthly), both the total wind resource and its seasonal variation can be estimated with data from these systems. Class II systems do not provide information on wind characteristics such as frequency distributions, diurnal wind speed variations, or gustiness. When average wind speeds obtained from windrun anemometers are used to estimate available power or WECS performance characteristics, a wind speed frequency distribution must be assumed. The techniques discussed in Appendix $C$ are based on an assumed wind speed frequency distribution that is a function of only the average speed.

Class III instrument systems record data in summaries. Typical ways in which data are summarized are:

- wind speed frequency distributions (Appen$\operatorname{dix}$ C)

- wind roses (Appendix A)

- average wind speeds or wind speed frequency distributions by time of day (Appendix D).

By carefully selecting the data logger in Class III systems, it is possible to collect and store data in a form ready for final data analysis. To do this, care must be taken to ensure that all needed summaries 
are formed and stored in the data logger. Because information on individual observations is lost in the summaries, it is not possible to significantly change the types of summaries after data collection.

Class III instruments are ideal for many WECS siting applications and provide more information on wind characteristics than Class II systems. Class III systems are particularly useful if diurnal load matching is important, since the data can be organized by time of day. Many of these systems are designed for operation in remote locations and contain their own power sources. In general, Class III systems cost and weigh more than Class II systems. The Class III systems are also more likely to require special equipment to retrieve the data from instrument system storage and make it available for analysis.

Class IV instrument systems store data in a form that retains information about the individual wind observations, including their sequence. As a result, Class IV systems store more data than the other systems. The data from these systems can be summarized in one form for analysis, then in another. As long as the recorded data are not lost, flexibility in analysis is retained, even after data collection is completed. Data collected by these systems can be used in WECS siting studies, even if the details of data analysis were not determined prior to the data collection. Class IV systems are especially useful when information is needed on the duration of wind speeds above and below given levels. For instance, data from Class IV systems can be used to determine the average duration and frequency of occurrence of periods with wind speeds below WECS cut-in speed.

The disadvantages of Class IV systems are related to data handling and cost. The summary and analysis of data from Class IV systems require the handling of large quantities of data. If done manually, the chances of error are large, and the process can be time-consuming and expensive. In addition, Class IV systems tend to be more expensive initially than instrument systems in other classes. These factors tend to limit the use of Class IV systems in small WECS siting. They are most likely to be used by siting specialists or in siting a larger small WECS. Finally, Class IV systems generally require more attention during data collection to ensure that a high percentage of the potentially available data are recovered than do Class II and III systems. As a result, they are less suited for remote data collection than are Class II and III systems.

\subsubsection{Accuracy and Reliability}

In wind measurement systems, accuracy describes the difference between the measured value of a wind characteristic and the true value. Reliability describes an instrument system's ability to produce useful data over an extended period of time. Both characteristics are determined by the combined accuracies and reliabilities of the sensor, signal conditioning, and recorder in the system. If the system fails or any one of these components produces a gross error in the measured value of a wind characteristic, the data will not be useful. Quantitative descriptions of instrument system accuracy are more readily available than are descriptions of reliability.

Anemometers are generally calibrated in wind tunnels, where the airflow is steady. Under these conditions, they may produce a signal that is accurate to within $\pm 1 \%$ of the true wind speed. In gusty winds, however, anemometers speed up faster than they slow down and as a result, indicate wind speeds that are slightly high. The accuracies quoted for anemometers are, therefore, better than can be realistically expected from sensors used in WECS siting. Under normal use in the atmosphere, good anemometers should be accurate within $5 \%$ to $10 \%$.

Wind direction accuracy depends on the accuracy of the sensor and the accuracy with which the sensor is aligned. A perfect sensor will not give an accurate wind direction if it is not carefully oriented directionally. That is, the sensor must be aligned so that it produces a north signal when the vane points north. When a wind vane is properly aligned, it should be accurate to within $\pm 5^{\circ}$ during steady winds. During gusty winds, the wind sensor will lag behind the direction as it changes, but the average direction should be correct.

Properly adjusted signal conditioning and recording devices should not be significant sources for error in wind measurements, given the basic inaccuracies of wind sensors. As a result, wind measurement systems should be accurate from $5 \%$ to $10 \%$ in wind speed and $\pm 5^{\circ}$ in wind direction. The limited information available on wind systems in the real environment indicates that good quality, relatively expensive systems meet these accuracies. However, insufficient information is available to draw any conclusion with respect to the real environment performance of relatively inexpensive wind systems. 
Reliability may be built into a wind system that is simple and rugged, or it may be obtained from lightweight, complex systems by careful maintenance, frequent operational checks and duplication of components. The best indicator of a wind system's reliability is the past performance of similar systems. Systems that have been used for years in remote applications are more likely to be highly reliable than those that have not. Newly developed systems may be reliable, but caution in their use is needed because of limited information on past performance. Another indicator of system reliability is simplicity of design. Systems with a few simple parts should be more reliable than systems with a large number of parts.

In assessing wind system reliability, particular attention should be given to the recording device and problems related to its failure. Recording device failure during a data collection period may result in the loss of all data for the period, or it may only result in the loss of data for that portion of the period following the failure. For example, if either the sensor or odometer fails in a wind-run anemometer system, all data during the collection period are lost unless the time of failure can be determined. If the time of failure is determined, the reading of the odometer (assuming it has not been damaged) may be used to compute the mean wind speed for the period between the last reading and time of failure.

Data loggers in Class III instruments may lose usable information in the event of system failure. Data losses can result from sensor failure, loss of electrical power, and malfunctions in the data display or recording system. Another significant source of data loss is human error (such as accidental erasure of the stored data, misreading displays, and improper operation of the data logger and its recording system).

Strip-chart recorders have a long performance record; however, they cannot be considered extremely reliable. Typical strip-chart recorder problems include: failure of chart drives, failure of chart marking mechanisms and paper jams. Recorders using ink are susceptible to data losses because of frozen ink in the winter and dried-up ink supplies in the summer. Magnetic tape recorders are replacing strip-chart recorders in meteorological data collection; however, they, too, have occasional reliability problems. Recorders and magnetic tape readers can damage tapes. Tapes can be accidentally erased, and misalignment of heads in either the recorder or reader can make data recovery difficult.

The key to high percentage data recovery rates (high reliability) in meteorological measurement programs is frequent inspection to make sure that the measurement system is operating properly. System reliability can be increased significantly by placing signal conditioning and recording devices in a protected, climate-controlled environment whenever possible.

\subsection{Estimate Costs}

The last step in planning a wind measurement program is estimating its costs. Typically, the primary cost elements of a wind measurement program are:

- the instruments

- instrument installation

- instrument inspection and maintenance

- data collection

- data analysis

Inflation is an additional factor that may be considered, particularly when WECS purchase is delayed until the completion of the measurement program. The first two cost elements are one-time, fixed expenses. The remaining elements, including inflation, are continuing expenses. The final cost of each of these elements depends upon the duration of the measurement program.

\subsubsection{Instruments}

The largest single expense in a wind measurement program is generally the instrument system (see Table 13 for typical prices of instrument systems). Inexpensive systems are generally designed for home and school use, and some are advertised specifically for wind energy site selection studies. Frequently, these instruments are available from WECS dealers. The prices given for moderately expensive systems are typical of the costs of instrument systems used by meteorologists. In general, the prices given in the table are closer to the bottom of the price range than to the top.

Class III and IV instruments can be rented. However, renting instruments converts the instrument 
TABLE 13. Typical Instrument System Costs

$\begin{array}{ccc}\begin{array}{c}\text { Instrument } \\ \text { System } \\ \text { Class }\end{array} & \begin{array}{c}\text { Inexpensive } \\ \text { System }\end{array} & \begin{array}{c}\text { Moderately } \\ \text { Expensive } \\ \text { System }\end{array} \\ \text { I } & \$ 50 & \$ 250 \\ \text { II } & 75 & 300 \\ \text { III } & 900 & 2000 \\ \text { IV(a) } & 300 & 1500 \\ \text { (b) } & 1500 & 6000\end{array}$

(a)Strip chart recorder

(b) Magnetic tape recorder

cost from a one-time expense to a continuing expense. Renting can also increase the total cost of a measurement program, especially if the duration of the program approaches one year. Typically, monthly rental rates are $10 \%$ of the purchase price. (Appendix $\mathrm{E}$ lists sources of wind instruments.)

\subsubsection{Instrument Installation}

Expenses for instrument installation will vary greatly from one measurement program to another. Generally, they will be higher for more expensive instrument systems than for inexpensive ones. Also, expenses will tend to increase as the size of the WECS under consideration increases. The following items may be included in installation expenses:

- measurement site preparation

- purchase of an instrument tower with base, guy wires, and anchors

- tower erection and instrument installation

- preparation of an instrument shelter for signal conditioning and recording devices

- connection of electrical power to the measurement site

- purchase of extra signal cable to connect the instruments to the signal conditioning unit.

Some items in the list may not be needed for all installations. See the discussion on wind instrument installation, including selection of tower height, for details.

\subsubsection{Instrument Inspection and Maintenance}

The amount of inspection and maintenance required during a wind measurement program largely depends on the instruments used. For example, complex Class III and Class IV systems require more attention than simple Class II systems.

Wind instruments should be inspected whenever data are collected. This inspection should include a visual check to see if the instruments are damaged, and functional checks to determine if they are operating properly. When wind direction is being measured, the visual check should include a check of the wind vane orientation. On a less frequent basis (perhaps every three months), the output of the sensors should be checked, if possible, and the signal conditioning and recorder should be calibrated, using known signals as input.

Routine maintenance should be conducted according to the manufacturer's schedule and directions, unless experience indicates that more frequent maintenance is necessary. Generally, routine maintenance items include cleaning and lubricating the sensors and changing batteries. Worn or damaged parts identified during visual instrument inspections or routine repair may require corrective action. More expensive sensors may be repaired, while an inexpensive sensor may need to be replaced.

Expenses for instrument inspection and maintenance include the cost of labor and batteries, if used, in addition to the cost of replacement parts. Instrument dealers should be contacted to obtain the information required to estimate these costs, because the costs vary greatly from instrument to instrument.

\subsubsection{Data Collection}

Data collection expenses generally fall into two categories: supplies and labor. When Class I through Class III instrument sytems are used, the cost of supplies should be small and may be negligible. In these cases, the supplies may be no more than a notebook, paper and pen or pencil. When Class IV systems are used, the cost of supplies including those listed above, and strip charts and magnetic tapes, can be significant.

The cost of labor to retrieve data from the storage device may be the greatest expense of data collection. The more remote the measurement location, the greater the expense will be. As a min- 
imum, one hour of labor per month should be used in estimating this expense.

\subsubsection{Data Analysis}

Data analysis costs are primarily associated with the labor required to complete the analysis. If a Class II or III instrument system is used for data collection, these expenses should be minimal. Again, as a minimum, one hour per month should be assumed for data analysis costs. More time may be required if a Class III system has been used and various types of data analyses are planned. When Class IV systems with strip charts are used in data collection, data analysis will require more than one hour per month. For these systems, at least eight hours per month should be assumed for estimating the cost of extracting the data from strip charts. This estimate may be low for the beginning of the program and high for the end. Another two or three hours of labor should be assumed for summarizing the data each month.

If data are collected on magnetic tape, the cost of obtaining the data in printed form must be included in the expense of data analysis. Most likely a computer will be involved in this process; therefore, it may be convenient and economical to have the data analysis done on the computer at the same time. Instrument dealers should be able to provide the information needed to evaluate this possibility.

\subsubsection{Measurement Program Duration}

Both the cost and accuracy of a wind measurement program increase as the length of the program increases. Increases in cost can be determined from costs related to instrument use, maintenance, data collection, and analysis. The total cost of these elements for a two-year program will be about double that for a one-year program. However, increases in accuracy are not as easily determined; i.e., on the average, a two-year program does not yield results that are twice as accurate as those from a one-year program. Figure 35 shows a typical example of how the accuracy of long-term average wind speed estimates increases with the length of the measurement program. Clearly, measurement programs of more than two years do not yield an increase in accuracy proportionate to the increased costs.

Table 14 can be used to estimate the accuracy of long-term mean speed estimates. For example, to determine the range of accuracy, you would first select a confidence level. If the $90 \%$ confidence

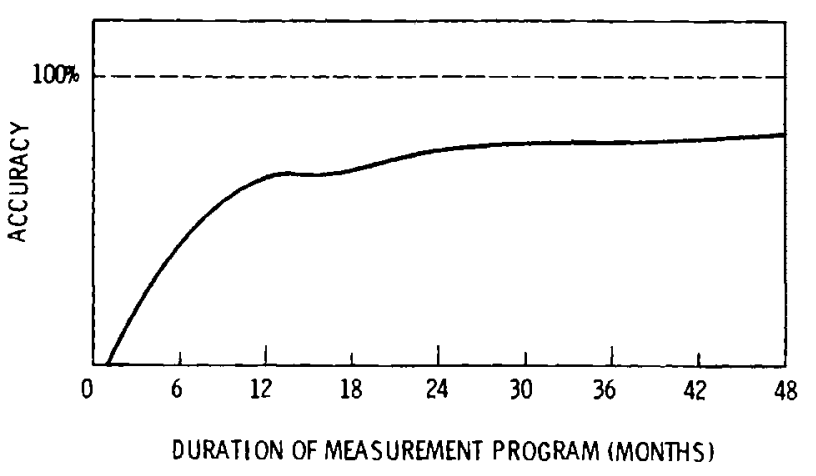

FIGURE 35. Increases in Accuracy of Long-Term Average Wind Speed Estimates with Increasing Measurement Program Duration

level is selected, you would be $90 \%$ certain that the true average wind speed will be in the range of 13.5 $\mathrm{mph}$ to $16.5 \mathrm{mph}$ if the measured wind speed were $15 \mathrm{mph}$ based on one year of measurements. To determine the above range you select the uncertainty corresponding to the confidence level selected $(90 \%)$ and the number of years of measurements (one year), using Table 14. In this example, the uncertainty is $10 \%$. The range is then determined by finding $10 \%$ of the measure average speed, 1.5. The lower end of the range is found by subtracting this value from the average speed, and the upper end of the range is found by adding the value to the average.

Similarly, if the observed average speed is 10 $\mathrm{mph}$ at the end of a three-year measurement program, there is a $50 \%$ chance that the true long-term average speed is between 9.5 and $\mathbf{1 0 . 5} \mathrm{mph}$, and a $90 \%$ chance that it is between 9.2 and $10.8 \mathrm{mph}$. These ranges consider random variations in wind speeds and are based on an assumed 5\% uncertainty in the observed wind speed. Table 14 and Figure 35 can only be applied to estimates of the accuracy of long-term (annual) average speed. However, it has also been determined that at the end of a one-year measurement program, there is a $90 \%$ chance that the observed monthly and seasonal average speeds are within $10 \%$ of their respective long-term averages.

Little information exists on the accuracy of estimates of wind characteristics other than average speed. It is highly unlikely, however, that the estimates of other characteristics would be more accurate than estimates of the long-term (annual) average speed.

Wind measurements should be made in all seasons unless the intended energy use is seasonal. In 
TABLE 14. Uncertainty in Estimating the Long-Term Average Wind Speed, \%

\begin{tabular}{|c|c|c|c|c|}
\hline \multirow{2}{*}{$\begin{array}{c}\text { Measurement, } \\
\text { Yrs }\end{array}$} & \multicolumn{4}{|c|}{ Confidence, $\%$} \\
\hline & 50 & 90 & 95 & 99 \\
\hline 1 & 6 & 10 & 12 & 15 \\
\hline 2 & 6 & 9 & 10 & 13 \\
\hline 3 & 6 & 8 & 9 & 11 \\
\hline 4 & 5 & 7 & 8 & 10 \\
\hline 5 & 5 & 6 & 7 & 8 \\
\hline
\end{tabular}

this way, the possible introduction of a systematic error (bias) into the wind speed estimates can be avoided by averaging data from both high wind and low wind seasons. A bias may also occur if more than one year (but less than two years) of data is collected. Therefore, it is good practice to plan measurement programs for 12 -month periods.

\subsubsection{Example}

The following example shows how individual costs can be combined to estimate measurement program costs. Assume that a Class II instrument system costing $\$ 150$ was selected to obtain monthly average speeds to estimate the long-term (annual) average. The instrument was to be mounted on top of a $30-\mathrm{ft}$ guyed pipe costing $\$ 35$ (including guy wires, anchors, and base). The measurement program duration was anticipated to be two years. In this case, the instrument maintenance and inspection, data collection, and data analysis costs would be minimal: Assume one hour per month at $\$ 5.00$ per hour for each of these costs. The resulting cost of the measurement program would be $\$ 545$. The cost of a one-year program would be $\$ 365$.

\section{Computation of Estimated Measurement} Program Costs

\begin{tabular}{|c|c|}
\hline Instruments & $\$ 150$ \\
\hline Installation & $\$ 35$ \\
\hline \multicolumn{2}{|c|}{ Inspection \& Maintenance } \\
\hline \multicolumn{2}{|c|}{$\$ 5 / \operatorname{mon} \times 12$ mon. $\times 2$ yrs. $=\$ 120$} \\
\hline Data Collection & \\
\hline \multicolumn{2}{|c|}{$\$ 5 /$ mon. $\times 12$ mon. $\times 2$ yrs. $=\$ 120$} \\
\hline \multicolumn{2}{|c|}{ Data Analysis } \\
\hline$\$ 5 / \mathrm{m}$ & $=\$ 120$ \\
\hline Estimated Cost & $\$ 545$ \\
\hline
\end{tabular}

If the average measured speed at the end of the two-year program is $15 \mathrm{mph}$, there is a $90 \%$ chance (Table 14) that the true long-term average is between 13.65 and $16.35 \mathrm{mph}$. With the same observed speed at the end of a one-year program, there is a $90 \%$ chance that the true average is between 13.50 and $16.50 \mathrm{mph}$. The range of uncertainty at the end of the two-year program is 2.7 $\mathrm{mph}$, while at the end of the one-year program it is $3.0 \mathrm{mph}$. The cost of reducing the range of uncertainty by $0.3 \mathrm{mph}$ is the difference between the costs of one- and two-year programs or $\$ 180$.

From this information, the program planner can decide if the reduction in uncertainty is worth the cost. It is unlikely that the cost of measurement programs exceeding two years can be justified in small WECS siting, considering the decreasing value of each additional year of data collection (less increase in accuracy). In general, one-year measurement programs should be adequate.

At this point, after acquiring information on systems, needs, and cost, there are three options. If the estimated cost of the measurement program is acceptable, the instrument system can be obtained and installed. If the estimated costs are too high, a less ambitious measurement program can be considered or siting decisions can be made on the basis of the best available data. In some instances, other options, including participation in governmental loan programs, may be available. WECS dealers should be aware of such opportunities in their service areas.

\subsection{Obtain and Install Wind Instruments}

After deciding on a measurement program, the instruments must be obtained and installed. An instrument system should have been selected in the planning stage. (Catalogs and price lists for wind instruments can be obtained from the sources listed in Appendix E.) If the beginning date of the measurements is important, the time for delivery of the instruments should be determined prior to their purchase, since it may take up to three months to receive them after an order is placed.

While waiting for delivery of the instruments, the measurement location can be selected. Ideally, measurements should be taken at the intended WECS location and at the anticipated hub height. If the instruments cannot be placed in this position, they should be placed near the intended location in the same wind environment to be experienced by the WECS. Generally, measurements should be 
taken in an open area, rather than above the roof of a building. (See Chapters 3 and 4 for the effects of terrain and obstacles on wind.)

Wind characteristics should be measured at or near the intended WECS hub height, since wind characteristics change with height above ground (see Chapters 2, 3 and 4). That is, wind measurements at one height do not accurately estimate wind characteristics at another. Errors can be lessened by making measurements near hub height and then correcting the measurements for the difference between the measurement and hub height, although errors can only be eliminated by measuring at hub height. In rough terrain, wind measurements should be made at hub height, since the techniques used to correct wind data for differences in height are unreliable.

After the wind instruments are delivered, but prior to their installation, they should be given a functional check and calibration, if possible. Relatively expensive instrument systems generally come with detailed instructions for calibration, functional checks, maintenance, and installation. Less expensive instruments may only come with installation instructions.

In many instances, anemometer operation can be checked with a car or truck. On a calm day, the anemometer output should be about equal to the car's speedometer reading if the anemometer is held several feet above the car roof and the car is driven at a constant speed. Repeating this process at several speeds will give an approximate calibration if the anemometer is operating properly, or reveal serious operating problems if it is not. Do not attempt this process unless there is an isolated section of road available.

Signal conditioning equipment, displays, and recording devices are checked by putting simulated signals corresponding to anemometer outputs for known wind speeds into the signal conditioning and reading the display or recorder output to see if it corresponds to the input signal. This check should be performed for signals representing zero, as well as for three or four additional wind speeds. Typical speeds simulated might be $0,10,20,30$, and $40 \mathrm{mph}$. An electronics repair shop can provide assistance in checking signal conditioning, displays, and recorders.

If strip chart recorders are included in the instrument system, the chart speed should also be checked. Allow the chart to run for a fixed amount of time (several hours), and then measure the amount of chart travel. The chart speed is the chart travel in inches divided by the time of the test in hours.

Placement of instruments on supports (towers) affects their accuracy. Sensors should be mounted on a mast above their support because typical supporting structures like instrument towers and telephone towers alter airflow. For example, the wind speed decreases on the upwind and downwind sides of a structure. The decrease is a maximum on the downwind sides. If the instruments cannot be mounted above the supporting structures, mount them as far from the structure as possible. This will minimize the effect of the supporting structures. Generally, wind sensors should be placed at a distance equal to at least three structure-diameters from the structure. On large towers, where this separation may be too difficult to achieve, a 10-ft separation is standard.

If mounted on the side of a tower, sensors are best located on the side of the structure opposite the least frequent wind direction. For example, if east winds are the least frequent at a site, the sensors should be placed on the west side of the supporting structure. In WECS siting applications, the sensors may be located on the opposite side of the structure from the wind direction having the lowest wind energy resource. (Appendix A describes how to determine the wind energy as a function of direction.)

\subsection{Data Collection}

Once the instrument is installed, data collection, the longest phase in the measurement program, begins. Activities such as keeping wind records and inspecting the instrument system, become routine but must be done carefully and regularly if the wind measurement program is to be of value. During data collection, instruments should be visited frequently to ensure that they are operating properly and to reduce the amount of data lost in case of malfunctions. Visits should be made at least weekly, if the measurement site is easily accessible. If the site is remote, less frequent visits may be necessary but they should be made at least once a month. Visits to the measurement site should be regularly scheduled events. Before visiting the site, be sure to check the date and set your watch. Also, make sure to take record books, writing instruments, and tools, if needed. 


\subsubsection{Site Visits}

At the site, the data must be obtained from the system as the first item. Once the data are obtained, the instrument system should be inspected. The system should be checked after the data are obtained to prevent an accidental data loss during the system check. A checklist of items to be done during each visit to the site will ensure that the items are accomplished in the correct order and that nothing is omitted. The following example lists items to be checked if a single wind-run anemometer is used:

1. record data

2. visually inspect anemometer

3. check anemometer support

4. check recorder operation

5. check switches on instrument system.

If a more complex instrument system is used, steps 1 and 5 should be expanded. Step 1 would become a series of steps that give a detailed procedure for extracting data from the system; that is, steps to prevent data losses from such causes as skipping data logger channels, accidentally resetting accumulators to zero, and erasing data contained in memories or on magnetic tape. Step 5 should be expanded to list all switches in instrument systems that could affect data collection and should give the correct position for each switch.

When strip chart or magnetic tape recorders are included in the instrument system, the check list should include annotation of the strip charts and magnetic tapes. This annotation identifies the information recorded, the date and time that data recording started on the chart or tape, and the time that it was completed. Strip chart annotation should be on the chart and magnetic tape annotation should be on an adhesive label attached to the tape reel or cassette.

\subsubsection{Written Records}

Written descriptions of the data and status of the instrument system are essential for a successful data collection program. Information trusted to memory may be forgotten. Since loose pieces of paper may be easily misplaced, records should be kept in bound notebooks. Wire-bound notebooks used for school are adequate. It is convenient to keep wind data and instrument inspection records in separate notebooks.

\section{- Wind Data Record}

A sample page from a data notebook for a measurement program using a wind-run anemometer is shown on page 50 . The first three columns contain data entered during the measurement site visit, and the fourth and fifth columns contain the results of intermediate calculations needed to estimate the average wind speed contained in the sixth column. When recording the accumulator readout, care must be taken to avoid errors, such as transposing digits. In this example, the accumulator counts each 0.1 mile of wind passage. The hours column contains the elapsed time between readings of the accumulator, e.g., there are 25 hours between 11:00 a.m. on October 11 and noon on October 12. The wind passage colu mn is the difference between accumulator readings divided by 10 . (The difference in accumulator readings must be divided by 10 to convert the difference to miles of wind passage.) For example, the wind passage is $(02931-00134) / 10=274.7$ miles for the first recording period. The average wind speed for this period is then 279.7 miles $/ 25$ hours or $11.2 \mathrm{mph}$.

The example log book entries demonstrate several things. The instrument system operation checks should be done frequently at the beginning of the measurement program. As in this example, the instruments are checked and data collected three times in the first week before the weekly schedule is established. The average wind speed should be computed immediately following each site visit for a qualitative evaluation of anemometer performance.

Because the computation of wind speed is based on the elapsed time between readings of the accumulator, it is necessary to maintain a consistent time reference. Particular attention must be given to this when the country changes from Standard to Daylight Savings Time or vice versa. To avoid problems that arise from gaining or losing an hour, note whether the time recorded is Daylight or Standard. Note that there is an extra hour in the elapsed time between 1:30 a.m. on October 25 and 1:50 p.m. on November 1.

Finally, the 1:30 p.m. accumulator reading on November 29 is less than the reading at 11:00 a.m. on the 22nd. During this period, the accumulator has gone past 99999; therefore, the accumulator read on the 29th should be treated as 110795 in 


\section{Sample Page from a Wind Data Record Book}

\begin{tabular}{|c|c|c|}
\hline Date & Time & Reading \\
\hline $10 / 11 / 79$ & 11:00 a.m. (a) & 00134 \\
\hline $10 / 12 / 79$ & $12: 00$ noon $(\mathrm{a})$ & 02931 \\
\hline $10 / 14 / 79$ & 9:00 a.m. (a) & 04762 \\
\hline $10 / 18 / 79$ & 1:30 p.m. (a) & 09975 \\
\hline \multicolumn{3}{|c|}{$10 / 11 / 79-10 / 18 / 79$} \\
\hline $10 / 25 / 79$ & $11: 30$ a.m. (a) & 31264 \\
\hline $11 / 1 / 79$ & 1:50 p.m. & 49397 \\
\hline $11 / 8 / 79$ & 9:00 a.m. & 67662 \\
\hline \multicolumn{3}{|c|}{$10 / 11 / 79-11 / 8 / 79$} \\
\hline $11 / 15 / 79$ & $10: 30$ a.m. & 83139 \\
\hline $11 / 22 / 79$ & 11:00 a.m. & 99364 \\
\hline $11 / 29 / 79$ & 1:30 p.m. & 10795 \\
\hline $12 / 6 / 79$ & $12: 30$ p.m. & 31773 \\
\hline \multicolumn{3}{|c|}{$11 / 8 / 79-2 / 6 / 79$} \\
\hline $12 / 13 / 79$ & $10: 30$ a.m. & 52633 \\
\hline
\end{tabular}

\begin{tabular}{|c|c|c|}
\hline Hours & $\begin{array}{c}\text { Wind Passage, } \\
\text { miles }\end{array}$ & $\begin{array}{l}\text { Speed, } \\
\text { mph }\end{array}$ \\
\hline \multicolumn{3}{|c|}{ Start measurement program } \\
\hline 25.0 & 279.7 & 11.2 \\
\hline 45.0 & 183.1 & 4.1 \\
\hline 100.5 & 521.3 & 5.2 \\
\hline 170.5 & 984.1 & 5.8 \\
\hline 166.0 & 2128.9 & 12.8 \\
\hline 171.3 & 1813.3 & 10.6 \\
\hline 163.2 & 1826.5 & 11.2 \\
\hline 671.0 & 6752.8 & 10.1 \\
\hline 169.5 & 1547.7 & 9.1 \\
\hline 168.5 & 1622.5 & 9.6 \\
\hline 170.5 & 1143.1 & 6.7 \\
\hline 167.0 & 2097.8 & 12.6 \\
\hline 675.5 & 6407.1 & 9.5 \\
\hline 166.0 & 2086.0 & 12.6 \\
\hline
\end{tabular}

(a) Daylight Savings Time

determining the wind passage for the period. This is the same phenomenon as car mileage passing 100,000 miles; the odometer starts over and the 1 must be imagined. Data must be collected from wind-run anemometers often enough so that there is no doubt about whether the accumulator has started over or not.

\section{- Instrument Inspection Record}

The instrument inspection record should contain a complete history of the instruments used in a mea- surement program from the time the instruments are received until the program is completed. Initial entries should describe the instruments, the preinstallation inspection and calibration, the measurement site, and the installation. These entries may be brief but they should contain enough information so the measurement program could be repeated at a later date. Subsequent entries in the book should be dated and contain a brief reason for the entry, and pertinent remarks. (See example of instrument record book entries.)

\section{Sample Instrument Log Entries}

9/26/79 Received anemometer (add catalog name and number and serial number, e.g., Science Associates Catalog \#481, Serial No. 49731) intact.

10/1/79 Wind almost 0 . Checked anemometer against car speedometer along road parallelling State Highway 193 between mileposts 74 and 77, using stopwatch.

\begin{tabular}{|c|c|c|}
\hline \multirow[b]{2}{*}{ Speedometer } & \multicolumn{2}{|c|}{ Accumulator } \\
\hline & Beginning & End \\
\hline 10 & 00007 & 00038 \\
\hline 20 & 00039 & 00069 \\
\hline 30 & 00070 & 00099 \\
\hline 40 & 00100 & 00131 \\
\hline
\end{tabular}

\begin{tabular}{|c|c|c|c|}
\hline \multicolumn{2}{|c|}{$\begin{array}{c}\text { Elapsed Time, } \\
\text { Min + Sec }\end{array}$} & $\begin{array}{c}\text { Car Speed, } \\
\text { mph }\end{array}$ & $\begin{array}{l}\text { Anemometer } \\
\text { Speed, mph }\end{array}$ \\
\hline $18+21$ & (18.35) & 9.8 & 10.1 \\
\hline $9+02$ & ( 9.03) & 19.9 & 19.9 \\
\hline $5+56$ & ( 5.93) & 30.4 & 29.3 \\
\hline $4+33$ & ( 4.55) & 39.6 & 40.9 \\
\hline
\end{tabular}


10/11/79 Installed anemometer on 30-ft mast on top of the hill southwest of the barn (about 500 feet from the barn).

$$
\begin{array}{rll}
11: 00 \mathrm{a} . \mathrm{m} . & 00134 \\
11: 18 \mathrm{a} . \mathrm{m} . & 00148 \\
\text { Wind speed }=\left(\frac{148-134}{10}\right) & \frac{60 \mathrm{~min} / \mathrm{hr}}{18 \mathrm{~min}}=4.7 \mathrm{mph}
\end{array}
$$

10/12/79 Checked anemometer - light wind, anemometer rotating slowly.

10/14/79 Checked anemometer - wind calm, anemometer stopped.

10/18/79 Checked anemometer (start routine of weekly checks), wind gusty.

$$
\begin{aligned}
11: 30 \text { a.m. } & 21289 \\
11: 45 \text { a.m. } & 21334 \\
\text { Wind speed }\left(\frac{334-289}{10}\right) \quad & \left(\frac{60}{15}\right)=18.0 \mathrm{mph}
\end{aligned}
$$

The first entry in this sample gives a description of the anemometer and indicates that it was received in good physical condition. A copy of the manufacturer's description of the anemometer can be taped to the record book following this entry to provide additional details, if desired.

The second entry describes the functional check of the anemometer. The check was performed by driving three miles at constant speed and recording the anemometer output and elapse time. The data collected during this check are contained in the first four columns of the table under the $10 / 1 / 79$ entry. The first column is the nominal car speed taken from the speedometer, the second and third columns contain the accumulator readings at the beginning and end of each run, and the fourth column contains the elapsed time for the run taken from the stopwatch. The numbers in parentheses in column four are elapsed times in minutes to the closest 0.01 minute. The final two columns contain the actual average car speed computed from three miles and the elapsed time and the simulated wind speed computed from the anemometer output and the elapsed time. The computed car and wind speeds agree quite well. Therefore, the anemometer appears to be operating properly.

The third entry describes the installation and site. It also provides an indication that the anemometer was operating properly following installation. If a wind vane is included in the instrument system, this entry should include a description of some landmark that can be used to check the wind vane orientation. This description must include the bearing of the landmark from the measurement system. Another item that should be included in this entry is a list of all nearby obstacles and terrain features that might affect the wind at the measurement site and their positions relative to the instruments.

The remaining entries in the example are routine entries. Occasionally, these entries should contain sufficient data to indicate that the anemometer is functioning at the time of the inspection, as shown in the last entry.

\subsubsection{After The Site Visit}

Computing the average wind speed is usually done after the site visit. To compute the average wind speed for the first week of the sample measurement program, the total wind passage and elapsed time must be used. If the average speed for the three periods had been averaged [i.e., $(11.2+4.1$ $+5.2) / 3$ ], the result would be $6.8 \mathrm{mph}$ instead of the correct value, $5.8 \mathrm{mph}$. Similarly, the monthly (four-week) wind speed average should be computed from the sums of the weekly wind passages and elapsed time. The annual average wind speed can be computed from the sums of the 52 weekly totals or from the sums of 13 four-weekly totals. In these computations, more than adequate accuracy can be maintained if times are recorded to the closest tenth of an hour (six minutes).

When strip chart recorders are used, the chart speed should be determined after the visit by measuring the distance along the chart from the beginning of the data to the end and dividing by the elapsed time. This process is also the first step in 
extracting the data from the strip chart. In the event of strip chart recorder failure, the last chart speed computed can be assumed for use in extracting any data recorded prior to the failure.

\subsubsection{Data Collection Check List}

A complete check list of steps to follow during a measurement program can be divided into three sections: the first section lists preparatory steps, the second lists steps to be taken during the visit to the measurement site, and the final section lists steps required following the visit:
A. Before site visit
1) check date
2) set watch
3) take record books and writing instrument
4) take tools, if needed
B. During site visit
1) record data
2) visually inspect anemometer
3) check anemometer support
4) check recorder operation
5) check switches on instrument system
C. After site visit
1) compute average wind speed. 


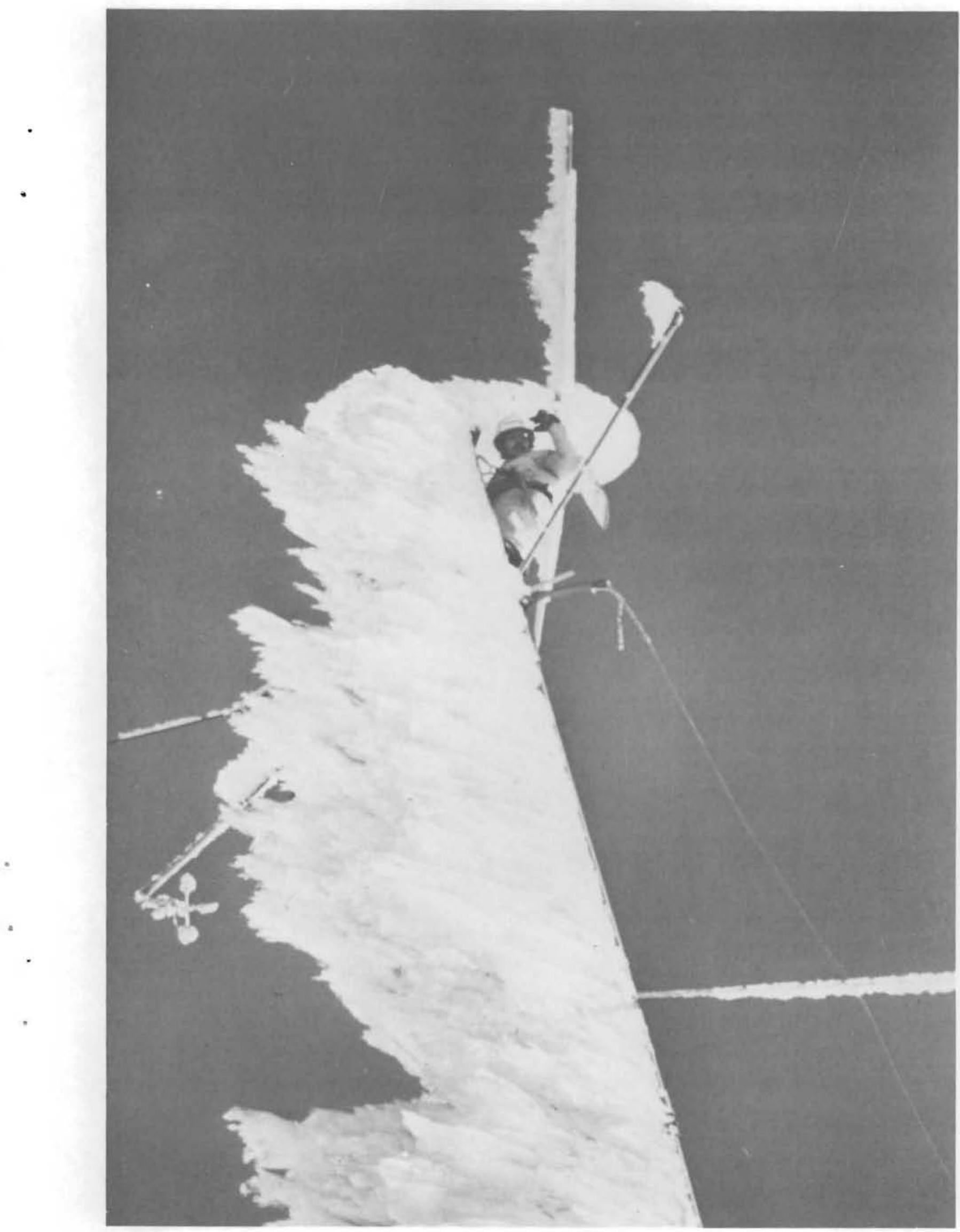




\section{Chapter 7}

\section{Environmental Hazards for WECS Operations}

Environmental hazards may influence the economic feasibility of a WECS or of a particular machine. For example, if salt spray reduces the expected life of a WECS by one-half, the cost of wind energy to the user sharply increases at sites exposed to salt spray. A good siting strategy can not only maximize the wind speed but can also reduce hazards. However, many hazards cannot be avoided. In such cases, the user must either purchase a WECS designed to survive in the local environment or in some way protect the WECS from the hazard. In each instance, the potential economic impact must be evaluated.

\subsection{Turbulence}

Air turbulence consists of rapid changes in the speed and/or direction of the wind. The turbulence most harmful to WECS is the small-scale, rapid fluctuation often caused by the wind flowing over a rough surface or a barrier. Turbulence has two adverse effects: 1) a decrease in harnessable power and 2) vibrations and unequal loading on the WECS that may eventually weaken and damage it.

To characterize the turbulence at a site, the user should determine the prevailing wind power direction (see Appendix A). (a) When the prevailing wind is blowing, the predominant areas of turbulence at a proposed WECS site can be detected by one or more 4-ft lengths of ribbon tied to a long pole or kite string. How much the ribbons flap indicates the amount of turbulence (see Figure 36). The size of a zone of turbulence downwind of a barrier changes with atmospheric conditions. The turbulent zone will generally be largest on moderately windy, but sunny, days. Sunny spring or early summer afternoons are good times to check for the maximum size of a turbulence zone. The expected location and intensity of turbulence produced by barriers and landforms are described in Chapters 3 and 4 of this handbook.

(a) If more than one wind direction frequently occurs, the user should investigate each to understand fully the potential turbulence hazard.

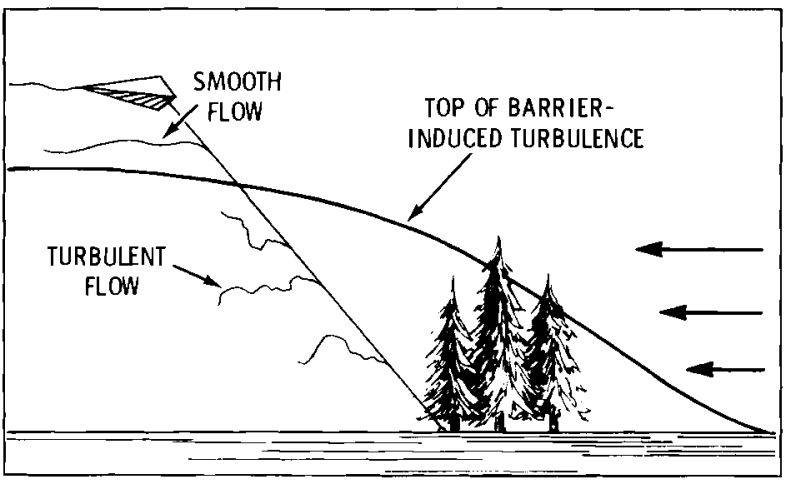

FIGURE 36. Simple Method of Detecting Turbulence

\subsection{Strong Wind Shear}

Strong wind shear is simply a large change in speed or direction over a small distance. Strong wind shear is usually associated with turbulence and may pose a hazard to small WECS in some locations. If a large change occurs over a distance less than or equal to the diameter of the rotor disc (see Figure 3 for definition of rotor disc), then unequal forces will be acting on the blades. Over a period of time these forces could damage the WECS. Generally the longer the blades, the more susceptible the WECS is to shear hazards. However, shear can be a hazard to any WECS that has its rotor disc too near the ground, a cliff wall, or any barrier.

\subsection{Extreme Winds}

High winds may damage WECS blades and the supporting towers. The blades become vulnerable if the protection systems designed into many WECS fail in extreme winds. Towers must be capable of supporting the WECS in all wind speeds that normally occur in the local area.

Extreme wind data should be obtained for nearby weather stations when planning to install a WECS (see Appendix A for sources of wind data). Maps of the entire United States showing maximum wind speeds as "fastest mile of wind" do not provide enough detail and are often misleading.

\subsection{Thunderstorms}

Thunderstorms produce several hazards, such as severe winds, heavy rains, lightning, hail, and possibly tornadoes. Thunderstorms occur on over $\mathbf{4 0}$ 
days per year in most parts of the United States, with the largest number of intense thunderstorms occurring in Florida and the Great Plains.

Tornadoes occur most often in the central part of the United States in an area called "tornado alley," extending from southwestern Texas to northern Illinois. Since WECS, like houses, are not designed to withstand tornadoes, the prospective buyer must assess the risk of tornado damage in his area before deciding on a WECS.

Reports of lightning strikes on small WECS show damage varying from minor to complete loss of the system. Considering the widespread occurrence of thunderstorms and the cost of a WECS, a WECS should be protected from lightning strikes wherever it is located.

Hail often causes heavy damage to buildings; it may also cause damage to a wind machine and its support structure. Large hail is most frequently observed in Texas, Oklahoma, Kansas and Nebraska.

\subsection{Icing}

Ice accumulation on blades, towers, and transmission lines can cause hazards or reduce the efficiency of wind machines. There are two types of icing: rime ice and glaze ice. Rime ice differs from glaze principally because of its source. It forms from frost or freezing fog rather than rain. Rime icing occurs mainly at high elevations. It is drier, less dense, and therefore less hazardous than glaze; however, it can, over a period of time, accumulate.

Glaze icing, formed from freezing rain, is the most hazardous form of icing. It occurs most frequently in valleys, basins, and other low elevations. When rain falls through a subfreezing layer of air at the ground, the drops freeze on contact with the surface. Under favorable conditions, freezing precipitation can rapidly accumulate on a cold surface to thicknesses of more than two inches.

The areas of most frequent, heavy icing include: an area extending from the Texas panhandle northeastward to the New England coast, basins and gorges in the western United States, and most mountain tops.

\subsection{Heavy Snow}

Snow causes three principal hazards to a WECS: 1) service and maintenance can be made difficult by excessive snow depths; 2) excessively heavy snowfall may damage parts of the turbine; and 3) blowing snow may infiltrate the machine parts and cause breakage from freezing and thawing. How long a typical storm lasts and how long snow remains on the ground are important considerations. The eastern sides of the Great Lakes as well as mountainous regions are particularly vulnerable to heavy snowfall and blowing snow.

\subsection{Floods and Slides}

Floods and slides are local problems of which users should be aware. In general, all structures should be kept out of floodplains. If an ideal wind site is located in a river valley, the user should build a structure to withstand flood conditions. He should also investigate the potential for earth slides and the stability of the soil foundation at any potential wind site.

\subsection{Extreme Temperatures}

Extremely high or low temperatures will adversely affect most WECS. Lubricants frequently freeze in very cold temperatures, causing rapid wear on moving parts. Many paints, lubricants, and other protective materials deteriorate in high temperatures. The user should review the local climatology and then consider the possible added expense of protecting the WECS against extreme temperatures.

\subsection{Salt Spray and Blowing Dust}

Salt spray and blowing dust may cause damage unless the machines are properly constructed and maintained. The corrosive properties of salt spray should be taken into account for any site within 10 miles of the sea.

Blowing dust may damage the system if it penetrates the moving parts, such as the gears and turning shafts. Many diverse regions of the country (urban, agricultural, desert, valley and plain areas) are subject to suspended dust. However, mountainous, forested and coastal regions have few major dust storms. The highest frequency of dust occurs in the southern Great Plains, but blowing dust also occurs often in portions of the western states, northern Great Plains, Mojave Desert region and the Southeast. 


\section{References}

American Wind Energy Association (AWEA). 1977. Survey of Historical and Current Site Selection Techniques for the Placement of Small Wind Energy Conversion Systems. Report to Pacific Northwest Laboratory. Bristol, IN 46507.

Changery, M. J., W. T. Hodge and J. V. Ramsdell. 1977. Index-Summarized Wind Data. BNWL-2220 WIND-11, Pacific Northwest Laboratory, Richland, WA 99352.

Cliff, W. C. 1977. The Effect of Generalized Wind Characteristics on Annual Power Estimates from Wind Turbine Generators. PNL-2436, Pacific Northwest Laboratory, Richland, WA 99352.

Eldridge, F. R. 1975. Wind Machines. NSF-RS-N-75051, National Science Foundation Report prepared by Mitre Corp., available from U.S. Government Printing Office, Washington, DC 20402.

Elliott, D. L. 1977. Synthesis of National Wind Energy Assessments. BNWL-2220 WIND-5, Pacific Northwest Laboratory, Richland, WA 99352.

Frenkeil, J. 1962. Wind Profiles over Hills (in Relation to Wind-Power Utilization). Quarterly Journal of the Royal Meteorological Society 88(376): 156-169.

Frost, W. and D. Nowak. 1979. Handbook of Wind Turbine Generator Siting Techniques Relative to Two-Dimensional Terrain Features. Prepared for Pacific Northwest Laboratory by FWG Associates, Inc., Tullahoma, TN 37388.
Hewson, E. W., J. F. Wade, and R. W. Baker. 1979. Vegetation as an Indicator of High Wind Velocity. Prepared for the Energy Research and Development Administration by Oregon State University, Corvallis, OR 97331.

Meroney, R. N. 1977. Wind in the Perturbed Environment: Its Influence on WECS. Presented at American Wind Energy Association Conference, Boulder, CO, May 11-14, 1977, Colorado State Univ., Fort Collins, CO 80523.

Park, J. and D. Schwind. 1978. Wind Power for Farms, Homes and Small Industry. RFP-2841/ 1270/78/4, Nielsen Engineering and Research, Inc., Mountain View, CA 94040.

Rao, K. S., J. C. Wyngaard, and O. R. Coté. 1973. The Structure of the Two-Dimensional Internal Boundary Layer over a Sudden Change of Surface Roughness. Journal of the Atmos. Sciences, 31(12): 738-746.

Sandborn, V. A. 1977. Placement of Wind-Power Systems. EY-76-S-06-2438, Colorado State University, Fort Collins, CO 80523.

Van Eimern, J., R. Karschon, L. A. Razumova, and G. W. Robertson. 1964. Windbreaks and Shelterbelts. Technical Note 59, World Meteorological Organization, Geneva, Switzerland.

Verholek, M. G. 1977. Summary of Wind Data from Nuclear Power Plant Sites. BNWL-2220 WIND-4, Pacific Northwest Laboratory, Richland, WA 99352. 


\section{Appendix A}

Sources and Uses of Wind Climatology 


\section{Appendix A}

\section{Sources and Uses of Wind Climatology}

The National Climatic Center (NCC) at Asheville, North Carolina, is usually the best source of wind data. The NCC will, for the cost of reproduction (usually a few cents per copy), provide local climatalogical data summaries for sites in or near a locality. These data may be obtained by writing to:

\section{Director}

National Climatic Center

Federal Building

Asheville, North Carolina 28801

Climatic summaries, including wind data, are available in different forms, varying from summaries similar to Table A.1 to more detailed summaries with wind variation by hour of day, month and year. Generally, wind summaries are similar to Table A.1.

Wind roses have frequently been constructed for stations. Figure A.1 illustrates a typical wind rose. Each arrow shaft in the figure is proportional in length to the percentage of time that the wind blows along the shaft (toward the center). Numbers at the end of each arrow shaft indicate the average wind speed for that direction. The number three in the center indicates the percent of calm winds.

An index has been developed that lists all sites in the United States for which wind summaries are available. These sites include past and present National Weather Service Stations, Federal Aviation Administration sites, Civil Aeronautics Administration sites, and military installations. The index, Index-Summarized Wind Data, (Changery, Hodge and Ramsdell, 1977) can be obtained from the NCC. The Selective Guide to Climatic Data Sources also summarizes sources of wind data. This guide may be purchased from:

Superintendent of Documents U.S. Government Printing Office

Washington, DC 20402

If one is interested in wind data available within a particular state, a document entitled Index of Original Surface Weather Records is available from the NCC on a state-by-state basis. This index lists all

TABLE A.1. Sample Wind Summary with Percentage Frequencies of Wind Direction and Speed

\begin{tabular}{|c|c|c|c|c|c|c|c|c|c|}
\hline \multirow[b]{2}{*}{ Direction } & \multicolumn{7}{|c|}{ Windspeed Intervals (mph) } & \multirow[b]{2}{*}{ Total } & \multirow{2}{*}{$\begin{array}{c}\text { Average } \\
\text { Speed }\end{array}$} \\
\hline & $0-3$ & $4-7$ & $8-12$ & $13-18$ & $19-24$ & $25-31$ & $32-38$ & & \\
\hline$N$ & 1 & 1 & & & & & & 2 & 4.0 \\
\hline NNE & 1 & 2 & 1 & & & & & 4 & 5.8 \\
\hline NE & 3 & 8 & 3 & & & & & 14 & 5.9 \\
\hline ENE & 1 & 5 & 2 & & & & & 8 & 6.3 \\
\hline $\mathrm{E}$ & 1 & 2 & & & & & & 3 & 4.0 \\
\hline ESE & 1 & 2 & & & & & & 3 & 4.1 \\
\hline $\mathrm{SE}$ & 1 & 3 & 2 & & & & & 6 & 7.1 \\
\hline SSE & & 3 & 2 & 1 & & & & 6 & 7.8 \\
\hline S & 1 & 3 & 3 & 1 & & & & 8 & 8.3 \\
\hline SSW & 1 & 3 & 5 & 5 & 1 & & & 15 & 11.5 \\
\hline SW & 1 & 4 & 5 & 5 & 2 & & & 17 & 11.7 \\
\hline WSW & 2 & 2 & 1 & & & & & 5 & 5.2 \\
\hline W & 1 & 1 & & & & & & 2 & 4.0 \\
\hline WNW & 1 & 1 & & & & & & 2 & 3.9 \\
\hline NW & & 1 & & & & & & 1 & 5.0 \\
\hline NNW & 1 & & & & & & & 1 & 2.0 \\
\hline Calm & 3 & & & & & & & 3 & \\
\hline Total & 20 & 41 & 24 & 12 & 3 & 0 & 0 & 100 & 7.6 \\
\hline
\end{tabular}




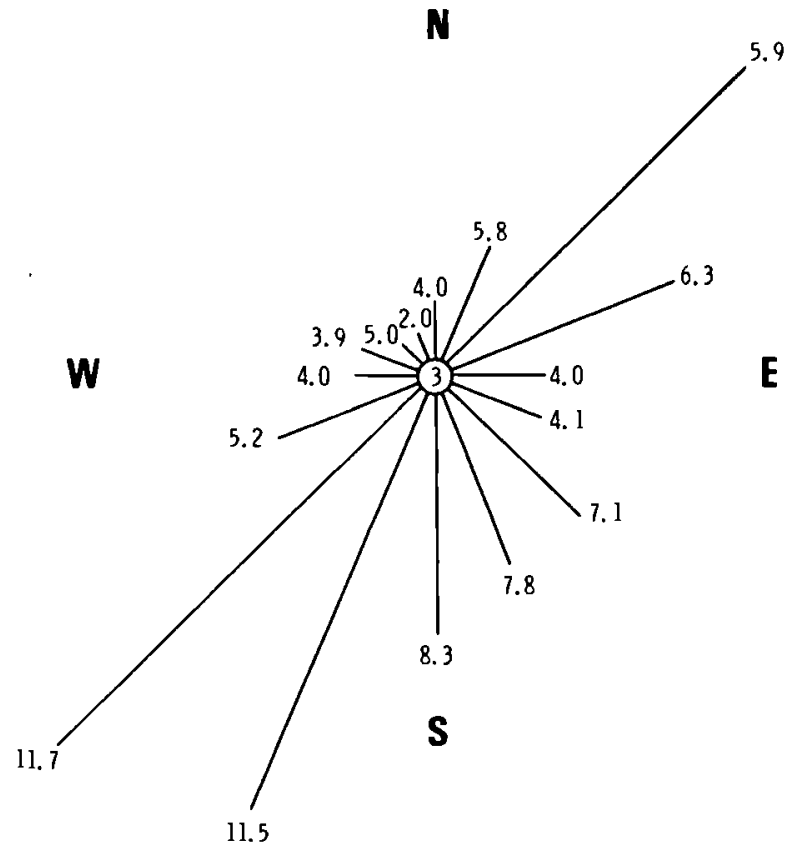

FIGURE A.1. Sample Wind Rose (Constructed from Table A.1) locations within a state at which weather data have been collected. Time periods for which data have been collected as well as the daily frequency and type of weather observation are included. By using this document a potential WECS user can identify sites within his state for which he may wish to order wind data.

Wind climatology can also be obtained from utilities operating nuclear power plants. Verholek (1977) summarized wind data from over 100 nuclear sites at the locations shown in Figure A.2. The summaries include wind speed frequencies by direction, graphs of wind speed versus duration of speed, height and location of the wind sensor, the average wind speed, the available wind power, and descriptions of the site and the surrounding terrain.

Other possible sources of wind data are: the United States Soil Conservation Service, the Agricultural Extension Service, United States and State Forest Services, some public utilities, airlines, industrial plants, and agricultural and meteorological departments at local colleges and universities.

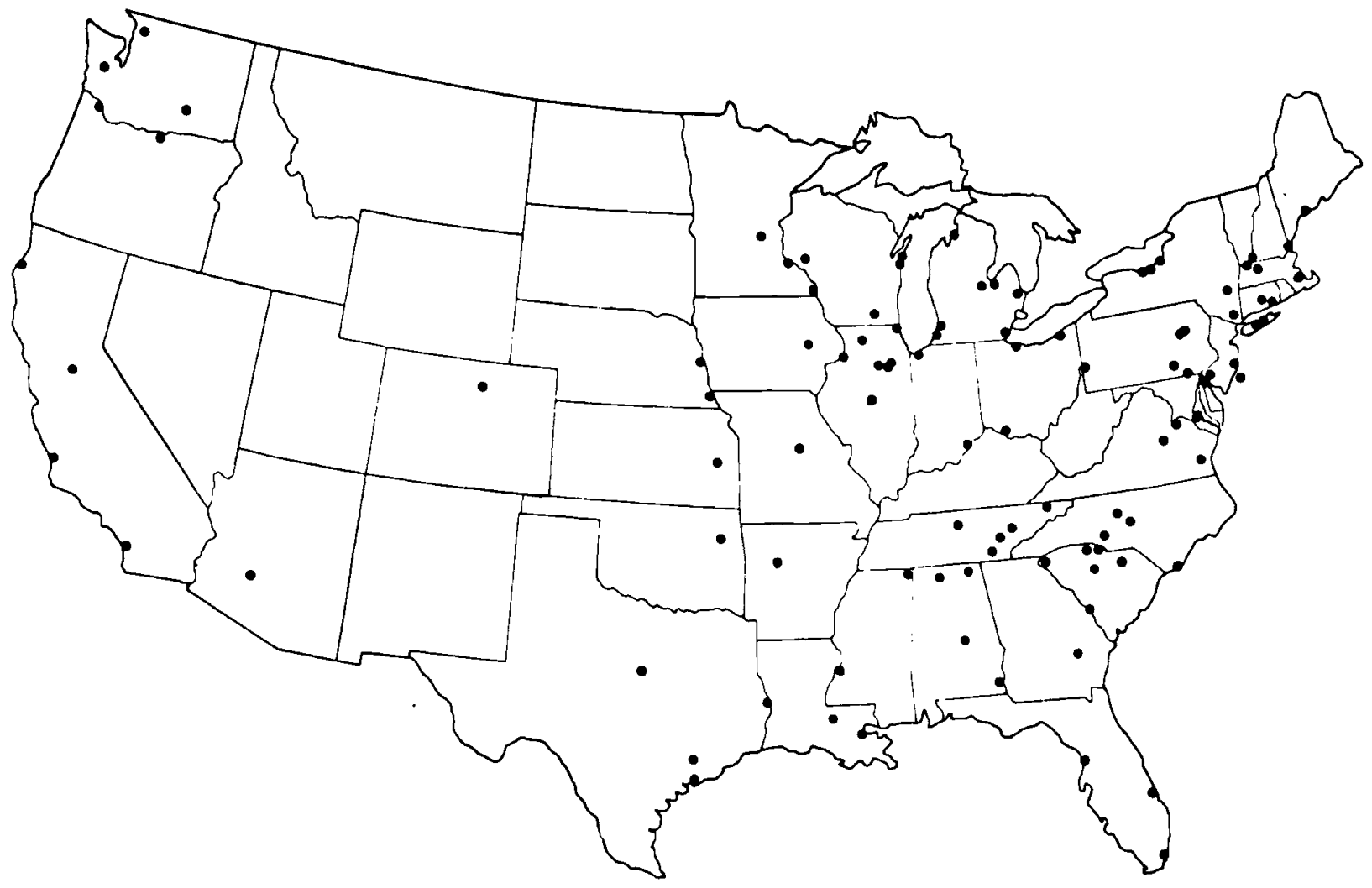

FIGURE A.2. Nuclear Power Plant Sites (Verholek, 1977) 
Wind summaries for a potential WECS site are extremely useful. In complex terrain, such as hilly or mountainous areas, they are particularly valuable for developing good siting strategy and estimating power output. Wind summaries from nearby weather stations can often be substituted for onsite measurements in flat terrain.

Wind roses (Figure A.1) show the percentage of time that the wind blows from certain directions and the mean wind speed from those directions. The user can construct a crude wind power rose from a wind summary table by first cubing the average wind speed for each direction, then multiplying the cubed speeds by the percentage frequency of occurrence for each wind direction. An example of this technique is given in Figure A.3, where Table A.1 has been used to construct the wind power rose. The derived numbers are roughly proportional to the power contained in the winds blowing from each direction.

In Figure A. 3 most of the available wind power is associated with winds blowing from the southwest, the prevailing power direction. The user should determine the prevailing power direction for his siting area and any other directions with which significant wind power is associated. To minimize the adverse effects of barriers, he should locate the WECS away from barriers upwind along any of these directions.
SAMPLE CALCULATION:

IN TABLE A. 1 WIND FROM THE NORTH BLOWS $2 \%(.02)$ OF THE TIME AVERAGING 4.0 MPH.

$4.0 \times 4.0 \times 4.0 \times .02=1.3$

1.3 IS PLOTTED AT THE TAIL OF THE ARROW SHOWING WINDS COMING INTO THE SITE FROM THE NORTH

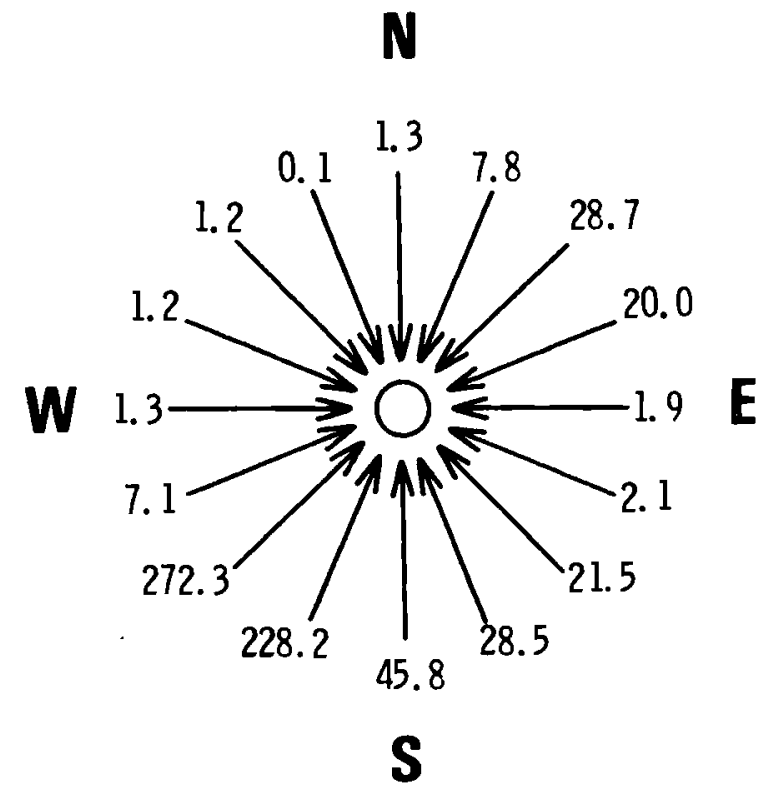

FIGURE A.3. Sample Wind Power Rose (Constructed from Table A.1) 
. 


\section{Appendix B}

Initial Estimate of Wind Energy Potential 


\section{Appendix B}

\section{Initial Estimate of Wind Energy Potential}

The best indicator of WECS practicality is the local history of WECS use. If WECS have been or are being used in the vicinity, users can supply useful information about the type, size, and application of their WECS; adequacy of the power output; siting procedures used; and accuracy of the estimated power output.

If there is no local history of WECS use, Figure B.1 provides a rough estimation of the wind power potential over the continental United States. In general, areas where available wind power is above 100 watts per square meter $\left(\mathrm{W} / \mathrm{m}^{2}\right)$ merit further investigation. Good WECS sites do exist in regions where available power is less than $100 \mathrm{~W} / \mathrm{m}^{2}$, but are generally limited to small areas of locally enhanced winds, such as hills, mountains, ridges or seacoasts.

Regional wind energy rsource assessments are being completed for the 50 United States, Puerto Rico, and the Virgin Islands. These will be combined into a detailed Wind Energy Resource Atlas, PNL-3195, that will become publicly available in 1981 through NTIS (see Chapter 1 for the address).

Before ruling out the practicality of wind energy, the reader should examine the parts of Chapter 4 that discuss local landforms. If the annual average wind speeds at nearby weather stations are at least $8 \mathrm{mph}$, or if there are local terrain features to enhance the wind, small WECS may be a viable energy source.

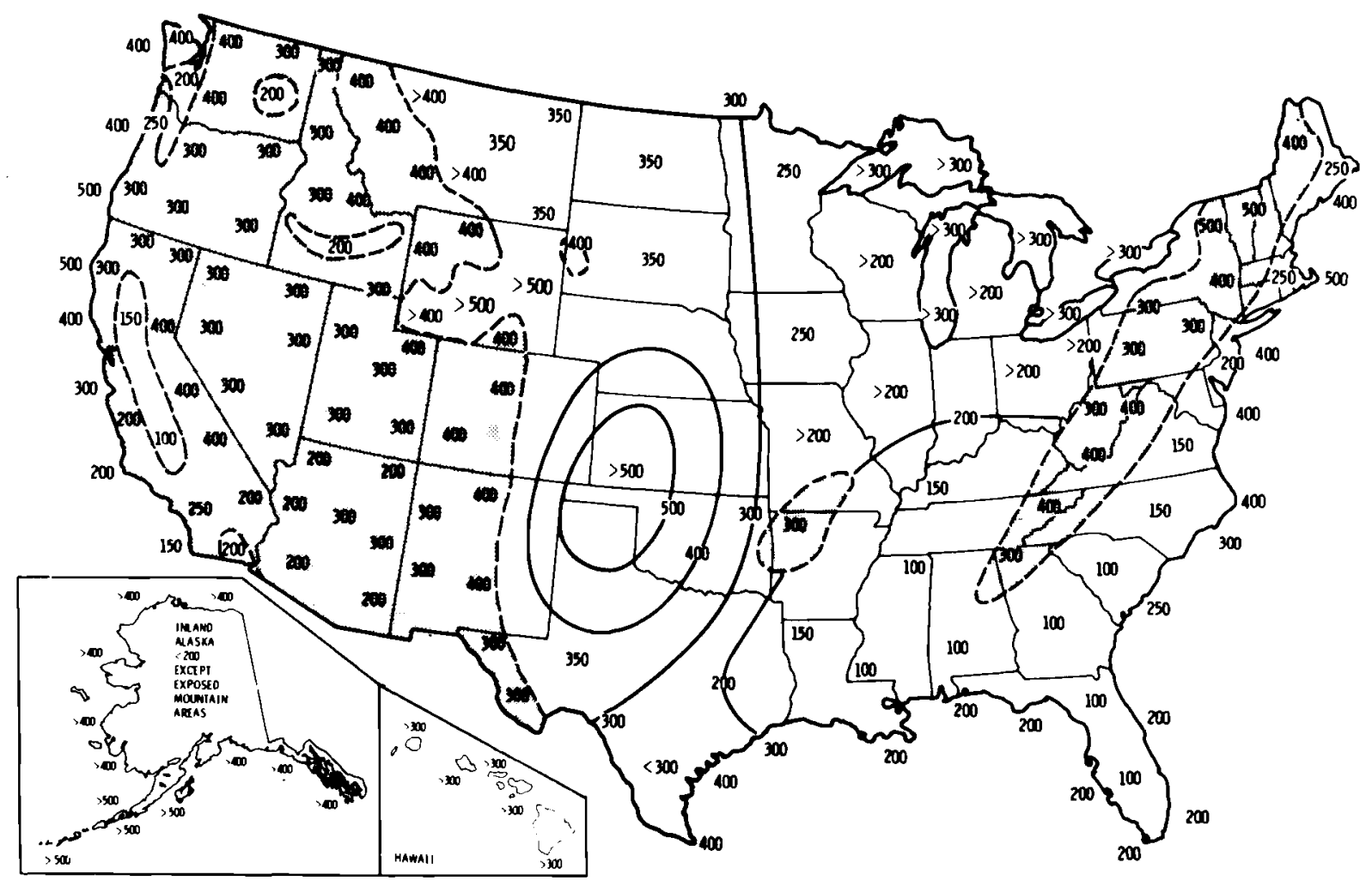

FIGURE B.1. Annual-Average Wind Power at $50 \mathrm{~m}$ Above Higher Elevations, $\mathrm{W} / \mathrm{m}^{2}$ (Elliott, 1977) 



\section{Appendix C}

Estimating Output Power from Annual Average Wind Speeds and WECS Characteristics 


\section{Appendix C}

\section{Estimating Power Output from Annual Average Wind Speeds and WECS Characteristics}

\section{WECS Characteristics Needed}
$\mathrm{Cl}=$ Cut-In Speed = Wind speed below which the generator produces no electricity.
RS = Rated Speed = The lowest speed at which the generator produces power at its rated capacity.

$\mathrm{CO}=$ Cutout Speed $=$ The speed above which the generator does not operate (because of hazardous winds). If the machine does not cut out, use a high speed (such as $50 \mathrm{mph}$ ).

\section{Procedure to Estimate Average Annual Output Power}

$A A=$ Annual Average Wind Speed

1. The following relationships give the two required ratios:

$$
\frac{\mathrm{CO}}{\mathrm{RS}}, \frac{\mathrm{AA}}{\mathrm{RS}}
$$

2. These two ratios are used in Figure C. 1 to determine

$$
\frac{\text { average output power }}{\text { rated power }}
$$

3. This value multiplied by the rated power of the WECS gives the average output power (this will probably be in $\mathrm{kW}$ ).

4. Finally, the average output power (in $\mathrm{kW}$ ) multiplied by the number of hours per year $(24 \times 365$ $=8760$ ) gives the average annual output power ( $k W$ hours per year).

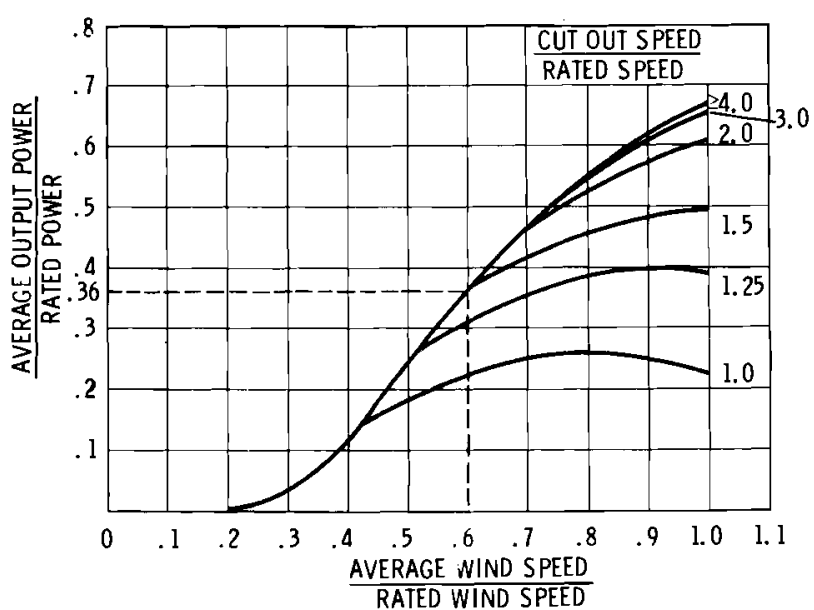

FIGURE C.1. Estimate of Expected Average Output Power for Wind Turbines (Cliff, 1977). (The dotted lines refer to Example Problem No. 1.)

\section{Other Useful Estimates}

To estimate down time and running time:

1. Compute these two ratios:

$$
\frac{\mathrm{CO}}{\mathrm{AA}}, \frac{\mathrm{Cl}}{\mathrm{AA}}
$$

2. These ratios were used in Figure C. 2 to estimate the percentage of time the WECS will not be generating $(100-\%$ down time $=\%$ running time).

To estimate the percentage of time the WECS will be running at rated capacity:

1. Compute these ratios:

$$
\frac{C O}{A A}, \frac{R S}{A A}
$$

2. Estimate how much of the time the WECS will run at rated capacity from these ratios and the information in Figure C.3. 


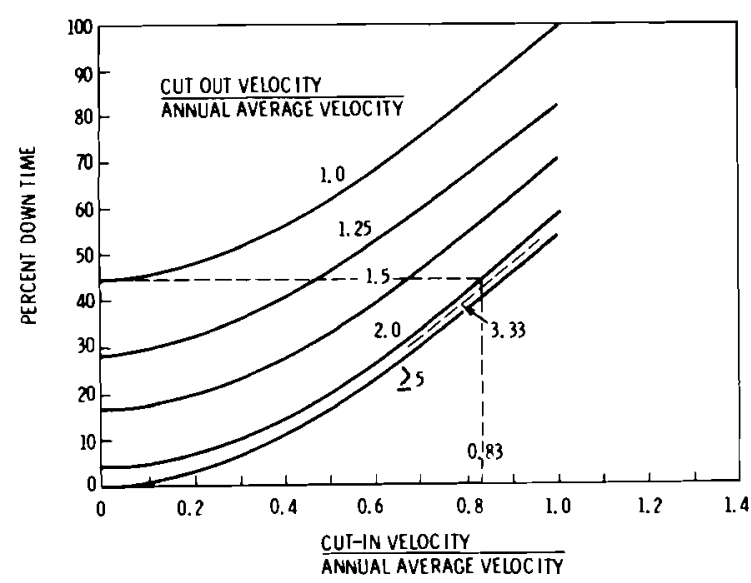

FIGURE C.2. Percent Down Time (Cliff, 1977). (The dotted lines refer to Example Problem No. 1.)

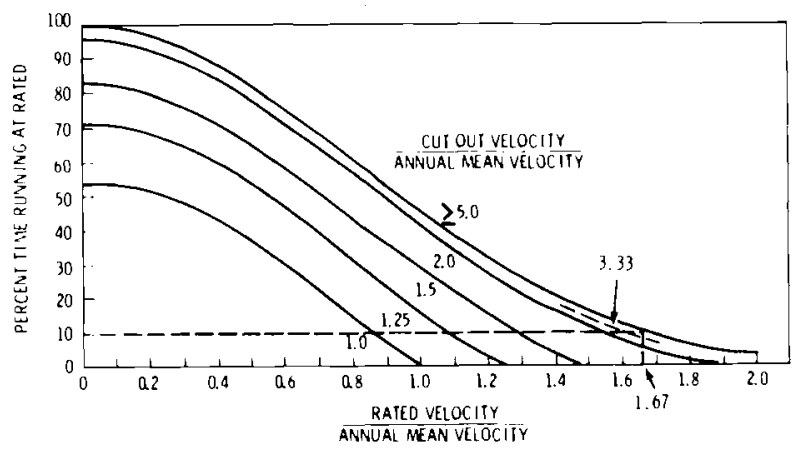

FIGURE C.3. Percent Time Running at Rated (Cliff, 1977). (The dotted lines refer to Example Problem No. 1.)

\section{Example Problem No. 1}

Given: $\begin{aligned} \mathrm{Cl} & =10 \mathrm{mph} \quad \text { Rated Power }=5 \mathrm{~kW} \\ \mathrm{RS} & =20 \mathrm{mph} \\ \mathrm{CO} & =40 \mathrm{mph} \\ \mathrm{AA} & =12 \mathrm{mph}\end{aligned}$

Estimate:

1. Average annual output power

2. Percent running time

3. Percent time running at rated

1. $\frac{\mathrm{CO}}{\mathrm{RS}}=\frac{40}{20}=2.0 \quad \frac{\mathrm{AA}}{\mathrm{RS}}=\frac{12}{20}=0.60$

$$
\begin{aligned}
& \text { Average power }=\frac{\text { average power }}{\text { rated power }} \times \text { rated power } \\
& =0.36 \times 5 \mathrm{~kW}=1.8 \mathrm{~kW}
\end{aligned}
$$

Annual power $=$ average power $\times \frac{\text { hours }}{\text { year }}$ $=1.8 \mathrm{~kW} \times \frac{8760 \text { hours }}{\text { year }}=15768 \frac{\mathrm{kW} \text { hours }}{\text { year }}$

2. $\frac{\mathrm{CO}}{\mathrm{AA}}=\frac{40}{12}=3.33 \quad \frac{\mathrm{Cl}}{\mathrm{AA}}=\frac{10}{12}=0.83$

$\%$ down time $=45 \%$, running time $=100 \%-45 \%$ $=\underline{\underline{55 \%}}$

3. $\frac{\mathrm{CO}}{\mathrm{AA}}=\frac{40}{12}=3.33 \quad \frac{\mathrm{RS}}{\mathrm{AA}}=\frac{20}{12}=1.67$

$\%$ running at rated $=\underline{\underline{10 \%}}$

\section{Monthly or Hourly Estimates}

Average power, down time, running time, and time running at rated capacity can also be computed for individual months of the year and for hours of the day providing long-term monthly average and hour-of-day average wind speeds are available. The procedure is basically the same as shown in the sample problem, but the annual average (AA) is replaced by the monthly or hour-of-day (diurnal) average speed. In addition, the factor 8760 hours/year becomes either the number of hours per month ( 720 hours for a 30-day month) or 365 hours/year if annual power for an hour of the day is being computed.

Monthly and hourly power calculations will permit the user to estimate better the match between wind power produced and power demand both on a seasonal and a diurnal basis.

\section{Example Problem No. 2}

Given: $\begin{aligned} \mathrm{Cl} & =10 \mathrm{mph} \text { Rated Power }=5 \mathrm{~kW} \\ \mathrm{RS} & =20 \mathrm{mph} \\ \mathrm{CO} & =40 \mathrm{mph}\end{aligned}$

and the values in Table C. 1 (extracted from Table 11), estimate average diurnal output power. 

TABLE C.1. Annual Wind Averages, Time of Day (Extracted from Table 11)

\begin{tabular}{ccc} 
Hour & & $\begin{array}{c}\text { Average Wind } \\
\text { Speed, mph }\end{array}$ \\
\cline { 3 - 3 } 01 & & 9.1 \\
04 & & 9.1 \\
07 & & 9.0 \\
10 & 11.0 \\
13 & & 11.3 \\
16 & & 10.4 \\
19 & 9.4 \\
22 & & 8.8
\end{tabular}

1. $\frac{\mathrm{CO}}{\mathrm{RS}}=\frac{40}{20}=2.0$

Replace AA of previous problem with hourly average $(\mathrm{HA})$ and compute:

$\begin{array}{ll}\frac{\text { Hour }}{01} \frac{\text { Hourly Averages/Rated Spe }}{\frac{\mathrm{HA}}{\mathrm{RS}}}=\frac{9.1}{20}=0.46 \\ 04 & \frac{\mathrm{HA}}{\mathrm{RS}}=\frac{9.1}{20}=0.46 \\ 07 & \frac{\mathrm{HA}}{\mathrm{RS}}=\frac{9.0}{20}=0.45 \\ 10 & \frac{\mathrm{HA}}{\mathrm{RS}}=\frac{11.0}{20}=0.55 \\ 13 & \frac{\mathrm{HA}}{\mathrm{RS}}=\frac{11.3}{20}=0.57 \\ 16 & \frac{\mathrm{HA}}{\mathrm{RS}}=\frac{10.4}{20}=0.52 \\ 19 & \frac{\mathrm{HA}}{\mathrm{RS}}=\frac{9.4}{20}=0.47 \\ 22 & \frac{\mathrm{HA}}{\mathrm{RS}}=\frac{8.8}{20}=0.44\end{array}$

Using the ratios above and Figure C.1, find hourly average values for average output power/rated power as shown in Table C.2.

TABLE C.2. Values for Average Output Power/ Rated Power

\begin{tabular}{|c|c|}
\hline $\begin{array}{l}\text { Hour of } \\
\text { of day }\end{array}$ & $\begin{array}{c}\text { Average Power } \\
\text { Rated Power }\end{array}$ \\
\hline 01 & 0.18 \\
\hline 04 & 0.18 \\
\hline 07 & 0.17 \\
\hline 10 & 0.26 \\
\hline 13 & 0.30 \\
\hline 16 & 0.24 \\
\hline 19 & 0.19 \\
\hline 22 & 0.15 \\
\hline
\end{tabular}

2. Use Figure C.1, CO/RS, and the eight $\mathrm{HA} / \mathrm{RS}$ values just computed to find the eight values for average output power/rated power.

3. Average power $=\frac{\text { average power }}{\text { rated power }} \times$ rated power

$$
\begin{aligned}
& \text { Hour } 01=0.18 \times 5 \mathrm{~kW}=0.90 \mathrm{~kW} \\
& \text { Hour } 04=0.18 \times 5 \mathrm{~kW}=0.90 \mathrm{~kW} \\
& \text { Hour } 07=0.17 \times 5 \mathrm{~kW}=0.85 \mathrm{~kW} \\
& \text { Hour } 10=0.26 \times 5 \mathrm{~kW}=1.30 \mathrm{~kW} \\
& \text { Hour } 13=0.30 \times 5 \mathrm{~kW}=1.50 \mathrm{~kW} \\
& \text { Hour } 16=0.24 \times 5 \mathrm{~kW}=1.20 \mathrm{~kW} \\
& \text { Hour } 19=0.19 \times 5 \mathrm{~kW}=0.95 \mathrm{~kW} \\
& \text { Hour } 22=0.15 \times 5 \mathrm{~kW}=0.75 \mathrm{~kW}
\end{aligned}
$$

Figure C. 4 depicts an average day of the year. It shows that, for this example, the user can expect most of the wind power to be produced during the day, from 9:00 a.m. to about 6:30 p.m. During this time, the WECS output power will average more than one kW over the course of the year. If the user needs most of his power during the day, the load match is good. If the power is needed at night, the economics will not be as favorable.

This same type of data analysis can be performed for certain seasons of the year. By averaging monthly diurnal wind speeds, plots similar to Figure C. 4 can be produced for any season or grouping of months. The user may find such an analysis useful if power is needed at a certain time of day and during certain months of the year.

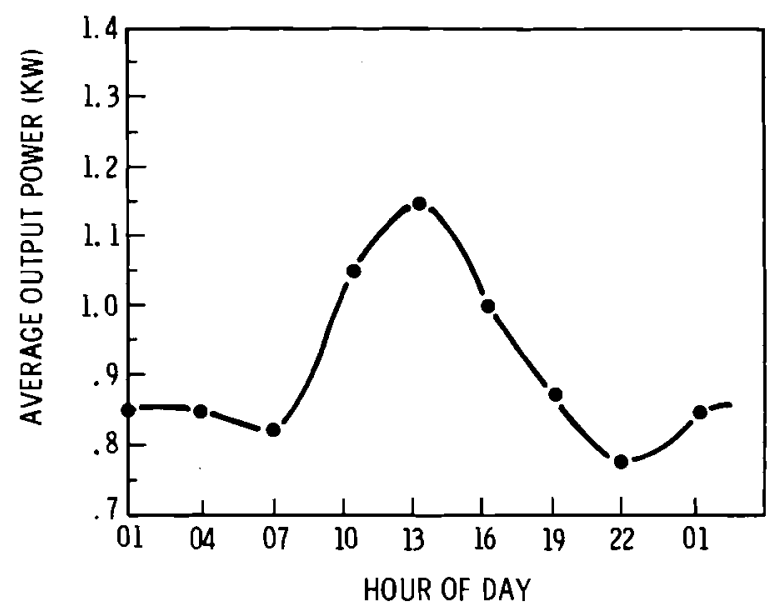

FIGURE C.4. Plot of Average Output Power by Time of Day 


\section{Appendix D}

Computation of Output Power from Wind Summaries 


\section{Appendix D}

\section{Computation of Output Power from Wind Summaries}

The data needed for computing output power from a wind summary are the output power graphs or tables for the WECS being considered (see Figure D.1) and a wind summary (provided in Table D.1). First, determine the mid points of each speed class in the wind summary. Speed classes entirely below the cut-in speed of the WECS need not be considered. However, the midpoints of each speed class may need to be multiplied by a height or height-roughness correction factor. If there is no appreciable difference in surface roughness between the weather station and the WECS site, simply select the proper height correction factor from Table 3.1, following the instructions in Chapter 3. (If the height difference is $\mathbf{1 0} \mathrm{ft}$ or less, this correction can be neglected.) If there is a difference in surface roughness between the weather station and the WECS site, Table 2 and the instructions in Chapter 3 should be used to select the proper height-roughness correction factor to be applied to the midpoints of each speed class. Using the power output graph or table for a particular WECS (such as Figure D.1), determine the output power for the midpoint (or corrected midpoint) of each speed class (Table D.2). Be certain to convert all wind speeds to the same units before reading the output power. The final step is to multiply the output power for each speed class by the hours that the speed occurred (Table D.3); then add these products to obtain the total power expected per year.

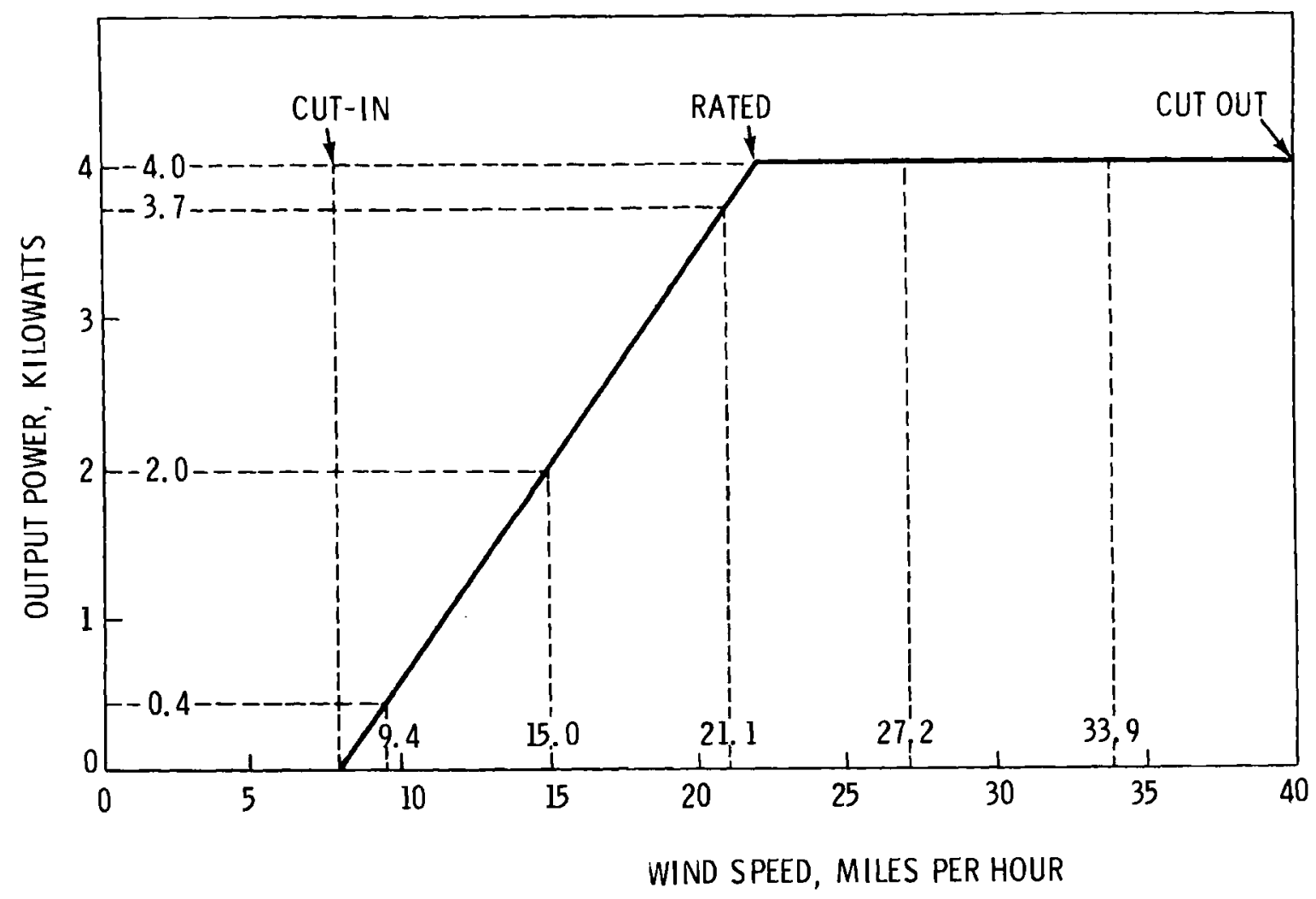

FIGURE D.1. Hypothetical Output Power Curve 
TABLE D.1. Hypothetical Wind Summary (\% Frequency of Occurrence)

\begin{tabular}{|c|c|c|c|c|c|c|c|c|c|c|}
\hline \multirow[b]{2}{*}{ Direction } & \multicolumn{8}{|c|}{ Speed (mph) } & \multirow[b]{2}{*}{ Percent } & \multirow{2}{*}{$\begin{array}{l}\text { Mean } \\
\text { Wind } \\
\text { Speed }\end{array}$} \\
\hline & $1-3$ & $4-6$ & $7-10$ & $11-16$ & $17-21$ & $22-27$ & $28-33$ & $34-40$ & & \\
\hline$N$ & 0.7 & 2.0 & 2.3 & 1.7 & 0.6 & 0.2 & 0.0 & & 7.5 & 9.3 \\
\hline NNE & 0.4 & 1.2 & 1.4 & 1.3 & 0.4 & 0.1 & 0.0 & & 4.7 & 9.8 \\
\hline NE & 0.4 & 1.3 & 1.4 & 0.6 & 0.2 & 0.0 & 0.0 & & 3.9 & 8.1 \\
\hline ENE & 0.3 & 0.7 & 0.4 & 0.3 & 0.0 & 0.0 & & & 1.7 & 6.8 \\
\hline E & 0.4 & 0.7 & 0.3 & 0.1 & 0.1 & 0.0 & 0.0 & & 1.7 & 6.5 \\
\hline ESE & 0.4 & 0.8 & 0.3 & 0.1 & 0.0 & & & & 1.7 & 5.6 \\
\hline $\mathrm{SE}$ & 0.7 & 1.5 & 1.2 & 0.4 & 0.1 & 0.0 & & & 3.9 & 6.7 \\
\hline SSE & 0.6 & 1.7 & 1.2 & 0.4 & 0.1 & & & & 4.0 & 6.8 \\
\hline$S$ & 0.9 & 2.1 & 2.0 & 0.7 & 0.2 & 0.0 & & & 5.9 & 7.3 \\
\hline SSW & 0.4 & 1.6 & 2.4 & 1.6 & 0.2 & 0.0 & & & 6.3 & 8.9 \\
\hline SW & 0.5 & 1.5 & 2.3 & 3.0 & 1.0 & 0.2 & & & 8.3 & 11.0 \\
\hline WSW & 0.3 & 0.9 & 1.1 & 1.0 & 0.3 & 0.0 & & & 3.6 & 9.6 \\
\hline W & 0.6 & 1.6 & 1.4 & 1.2 & 0.4 & 0.1 & 0.0 & 0.0 & 5.3 & 9.0 \\
\hline WNW & 0.6 & 1.7 & 1.8 & 1.9 & 1.1 & 0.5 & 0.1 & 0.0 & 7.6 & 11.3 \\
\hline NW & 0.8 & 2.5 & 3.0 & 3.6 & 2.2 & 1.4 & 0.4 & 0.1 & 14.0 & 12.8 \\
\hline NNW & 0.6 & 2.2 & 2.8 & 2.5 & 1.3 & 0.5 & 0.1 & 0.0 & 10.0 & 11.0 \\
\hline CALM & & & & & & & & & 9.8 & \\
\hline$\%$ of Time Wind & & & & & & & & & & \\
\hline In Speed Range & 8.6 & 24.1 & 25.3 & 20.4 & 8.1 & 3.0 & 0.6 & 0.1 & 100.0 & 8.8 \\
\hline
\end{tabular}

\section{Example of an Output Power Computation from a Wind Summary}

Given: 1) the hypothetical power curve for a WECS in Figure D.1.

2) the hypothetical percentage frequency of wind speed and direction summary in Table D.1

3) that the wind summary data was collected at a typical airport site (high grass roughness) at $30 \mathrm{ft}$ above ground

4) the WECS site is to be $60 \mathrm{ft}$ above ground in a rural area of low woods.

Estimate the annual output power of the WECS.

The roughness-height correction factor, using Table 2 , is $1.11 \div 1.00=\underline{1.11}$.

Selecting the midpoints of each speed class in Table D.1, correcting for roughness-height differences and determining output power at the adjusted midpoints results in Table D.2.

TABLE D.2. Roughness-Height Correction

Midpoints of Speed Classes (mph)

(from Table D.1)

$\begin{array}{llllll}8.5 & 13.5 & 19.0 & 24.5 & 30.5 & 37.0\end{array}$

Corrected Midpoints (mph)

(multiply by 1.11)

$\begin{array}{llllll}9.4 & 15.0 & 21.1 & 27.2 & 33.9 & 41.1\end{array}$

Power at Corrected Midpoints (kW)

(from Figure D.1)

$\begin{array}{llllll}0.4 & 2.0 & 3.7 & 4.0 & 4.0 & 0.0\end{array}$

Converting percent frequency of occurrence of each speed class to hours per year yields Table D.3. 


\section{Appendix D}

\section{Computation of Output Power from Wind Summaries}

The data needed for computing output power from a wind summary are the output power graphs or tables for the WECS being considered (see Figure D.1) and a wind summary (provided in Table D.1). First, determine the midpoints of each speed class in the wind summary. Speed classes entirely below the cut-in speed of the WECS need not be considered. However, the midpoints of each speed class may need to be multiplied by a height or height-roughness correction factor. If there is no appreciable difference in surface roughness between the weather station and the WECS site, simply select the proper height correction factor from Table 3.1, following the instructions in Chapter 3. (If the height difference is $10 \mathrm{ft}$ or less, this correction can be neglected.) If there is a difference in surface roughness between the weather station and the WECS site, Table 2 and the instructions in Chapter 3 should be used to select the proper height-roughness correction factor to be applied to the midpoints of each speed class. Using the power output graph or table for a particular WECS (such as Figure D.1), determine the output power for the midpoint (or corrected midpoint) of each speed class (Table D.2). Be certain to convert all wind speeds to the same units before reading the output power. The final step is to multiply the output power for each speed class by the hours that the speed occurred (Table D.3); then add these products to obtain the total power expected per year.

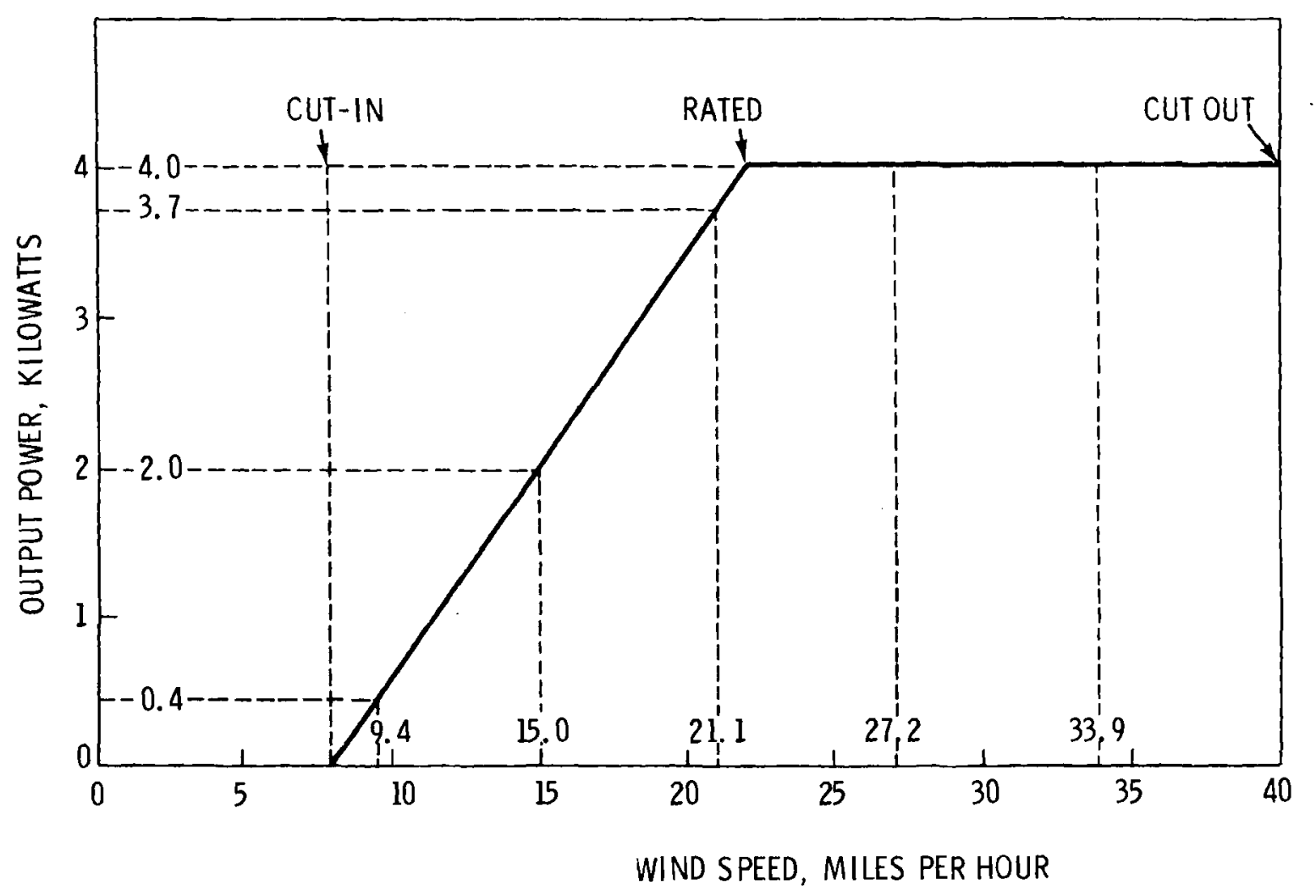

FIGURE D.1. Hypothetical Output Power Curve 
TABLE D.1. Hypothetical Wind Summary (\% Frequency of Occurrence)

\begin{tabular}{|c|c|c|c|c|c|c|c|c|c|c|}
\hline \multirow[b]{2}{*}{ Direction } & \multicolumn{8}{|c|}{ Speed (mph) } & \multirow[b]{2}{*}{ Percent } & \multirow{2}{*}{$\begin{array}{l}\text { Mean } \\
\text { Wind } \\
\text { Speed }\end{array}$} \\
\hline & $1-3$ & $4-6$ & $7-10$ & $11-16$ & $17-21$ & $22-27$ & $28-33$ & $34-40$ & & \\
\hline$N$ & 0.7 & 2.0 & 2.3 & 1.7 & 0.6 & 0.2 & 0.0 & & 7.5 & 9.3 \\
\hline NNE & 0.4 & 1.2 & 1.4 & 1.3 & 0.4 & 0.1 & 0.0 & & 4.7 & 9.8 \\
\hline NE & 0.4 & 1.3 & 1.4 & 0.6 & 0.2 & 0.0 & 0.0 & & 3.9 & 8.1 \\
\hline ENE & 0.3 & 0.7 & 0.4 & 0.3 & 0.0 & 0.0 & & & 1.7 & 6.8 \\
\hline $\mathrm{E}$ & 0.4 & 0.7 & 0.3 & 0.1 & 0.1 & 0.0 & 0.0 & & 1.7 & 6.5 \\
\hline ESE & 0.4 & 0.8 & 0.3 & 0.1 & 0.0 & & & & 1.7 & 5.6 \\
\hline SE & 0.7 & 1.5 & 1.2 & 0.4 & 0.1 & 0.0 & & & 3.9 & 6.7 \\
\hline SSE & 0.6 & 1.7 & 1.2 & 0.4 & 0.1 & & & & 4.0 & 6.8 \\
\hline S & 0.9 & 2.1 & 2.0 & 0.7 & 0.2 & 0.0 & & & 5.9 & 7.3 \\
\hline SSW & 0.4 & 1.6 & 2.4 & 1.6 & 0.2 & 0.0 & & & 6.3 & 8.9 \\
\hline SW & 0.5 & 1.5 & 2.3 & 3.0 & 1.0 & 0.2 & & & 8.3 & 11.0 \\
\hline WSW & 0.3 & 0.9 & 1.1 & 1.0 & 0.3 & 0.0 & & & 3.6 & 9.6 \\
\hline w & 0.6 & 1.6 & 1.4 & 1.2 & 0.4 & 0.1 & 0.0 & 0.0 & 5.3 & 9.0 \\
\hline WNW & 0.6 & 1.7 & 1.8 & 1.9 & 1.1 & 0.5 & 0.1 & 0.0 & 7.6 & 11.3 \\
\hline NW & 0.8 & 2.5 & 3.0 & 3.6 & 2.2 & 1.4 & 0.4 & 0.1 & 14.0 & 12.8 \\
\hline NNW & 0.6 & 2.2 & 2.8 & 2.5 & 1.3 & 0.5 & 0.1 & 0.0 & 10.0 & 11.0 \\
\hline $\begin{array}{l}\text { CALM } \\
\% \text { of Time Wind }\end{array}$ & & & & & & & & & 9.8 & \\
\hline In Speed Range & 8.6 & 24.1 & 25.3 & 20.4 & 8.1 & 3.0 & 0.6 & 0.1 & 100.0 & 8.8 \\
\hline
\end{tabular}

\section{Example of an Output Power Computation from a Wind Summary}

Given: 1) the hypothetical power curve for a WECS in Figure D.1.

2) the hypothetical percentage frequency of wind speed and direction summary in Table D.1

3) that the wind summary data was collected at a typical airport site (high grass roughness) at $30 \mathrm{ft}$ above ground

4) the WECS site is to be $60 \mathrm{ft}$ above ground in a rural area of low woods.

Estimate the annual output power of the WECS.

The roughness-height correction factor, using Table 2 , is $1.11 \div 1.00=1.11$.

Selecting the midpoints of each speed class in Table D.1, correcting for roughness-height differences and determining output power at the adjusted midpoints results in Table D.2.

TABLE D.2. Roughness-Height Correction

Midpoints of Speed Classes (mph)

(from Table D.1)

$\begin{array}{llllll}8.5 & 13.5 & 19.0 & 24.5 & 30.5 & 37.0\end{array}$

Corrected Midpoints (mph)

(multiply by 1.11)

$\begin{array}{llllll}9.4 & 15.0 & 21.1 & 27.2 & 33.9 & 41.1\end{array}$

Power at Corrected Midpoints (kW)

(from Figure D.1)

$\begin{array}{llllll}0.4 & 2.0 & 3.7 & 4.0 & 4.0 & 0.0\end{array}$

Converting percent frequency of occurrence of each speed class to hours per year yields Table D.3. 
TABLE D.3. Conversion of \% Frequencies of Occurrence

Speed Class (mph)

Corrected Speed Class (mph)

\% Frequency of Occurrence

Hours of Occurrence per Year

(Hours $=\% \times 8760 \div 100)$

$\begin{array}{rrrrr}8.5 & 13.5 & 19.0 & 24.5 & 30.5 \\ 9.4 & 15.0 & 21.1 & 27.2 & 33.9 \\ 25.3 & 20.4 & 8.1 & 3.0 & 0.6 \\ 2216 & 1787 & 709 & 263 & 52\end{array}$

Summation of output at each corrected speed class midpoint: (output power $=$ output $(\mathrm{kW})$ at midpoint $x$ hours of occurrence per year)

$$
\begin{aligned}
& 0.4 \times 2216=886.4 \\
& 2.0 \times 1787=3574.0 \\
& 3.7 \times 709=2623.3 \\
& 4.0 \times 263=1052.0 \\
& 4.0 \times \quad 52=\underline{208.0}
\end{aligned}
$$

Total kW hr/yr $\underline{8343.7}$
The output power computed is an estimate of the power flowing directly from the generator before losses caused by resistance in the wiring, inverters, or battery storage are considered. Such losses are important. Since they are dependent upon the design of the system, they should be discussed with the WECS dealer. 


\section{Appendix E}

Sources for Wind Instruments 


\section{Appendix E}

\section{Sources for Wind Instruments}

Meteorological instruments are available from a variety of sources. Frequently, instruments are available from hardware and marine supply stores. They can also be found in kit form at electronics stores. Numerous other sources can be identified with a little library research. However, WECS dealers generally carry one or more instrument lines for use in siting studies.

Current information on sources of wind instruments can be found in scientific and professional trade journals. Every November, the American Association for the Advancement of Science publishes a guide to scientific instruments. The guide contains a list of anemometer manufacturers and dealers, along with their addresses, but it is not complete. Additional sources can be found in advertisements in the Bulletin of the American Meteorological Society and the Journal of the Air Pollution Control Association. Instrument sources identified through these publications tend to be well-established, and with few exceptions, the instrumentation tends to be relatively expensive. Information on sources of less expensive instrumentation can be found in the Wind Power Digest, published by the AWEA.

The following list gives the names and addresses of sources for wind instruments. Some of these sources lease instruments, in addition to selling them, and others provide siting services for a fee. Lower priced instruments are available from those sources indicated by asterisks. The list may not be complete.

\section{Anemometer/Wind Data Collection System Suppliers(a)}

1. Aeolian Kinetics Box 100

Providence, RI 02901

2. Alnor Instrument 7301 N. Caldwell Niles, IL 60648

3. Ambient Analysis, Inc. P.O. Box 4056 Boulder, CO 80302

4. Approach Fish, Inc. 314 Jefferson Street Clifton Forge, VA 24422

5. *Belfort Instruments 1600 S. Clinton Street Baltimore, MD 21224

6. Bendix Instruments 1400 Taylor Avenue Baltimore, MD 21204

7. Campbell Scientific, Inc. P.O. Box 551 Logan, UT 84321

8. *Clean Energy Products 3534 Bayley North Seattle, WA 98103

9. Climatronics 140 Wilbur Place Bohemia, NY 11716
10. Climet Instrument Company P.O. Box 151

Redlands, CA 92373

11. Datametrics 340 Fordham Road Wilmington, MA 01887

12. Disa Electric 779 Susquehanna Avenue Franklin Lakes, NY 07417

13. *DWYER Instruments, Inc. P.O. Box 373 Michigan City, IN 46360

14. EG\&G 151 Bear Hill Road Waltham, MA 02154

15. *ENERTECH Corp. Box 420 Norwich, VT 05055

16. Epic 150 Nassau Street New York, NY 10038

17. Flow Technology Box 21346 Phoenix, AZ 85036

18. Forestry Suppliers Box 8397 Jackson, MS 39204
19. Geomet, Inc. 15 Firstfield Road Gaithersburg, MD 20760

20. HANDAR 3327 Kifer Rd. Santa Clara, CA 95051

21. *Heath Company Dept. 389-570 Benton Harbor, MI 49022

22. *Helion, Inc. P.O. Box 445 Brownsville, CA 95919

23. HNU Systems 30 Ossipee Road Newton, MA 02164

24. Kahl Scientific Instrument Box 1166 El Cajon, CA 92022

25. La Barge, Inc. 500 Broadway Bldg. St. Louis, MO 63102

26. Lab-Items Assoc. Box 321 San Francisco, CA 94101

27. Lund Enterprises, Inc. 1180 Industrial Avenue Escondido, CA 92025

(a) This listing is neither an endorsement of the suppliers nor a guarantee of the utility, accuracy or reliability of their products or services. 
28. *Maximum

42 South Avenue

Natick, MA 01760

29. Meteorology Research, Inc. 464 W. Woodbury Road Altadena, CA 91001

30. Met One

P.O. Box 60279

Sunnyvale, CA 94088

31. ${ }^{*}$ R. A. Morrill and Assoc. Box 1382

Corvallis, OR 97330

32. * Natural Power, Inc. Francestown Turnpike New Boston, NH 03070

33. *Northwind Power Co., Inc. Box 315 Warren, VT 05674

34. Optronics International 7 Stuart Road Chelmsford, MA 01824

35. PAKD Instruments 832 Ridge Dr. Fallbrook, CA 92028

36. *Real Gas and Electric Co. P.O. Box 193 Shingletown, CA 95402

37. *Sencenbaugh Wind Electric P.O. Box 11174 Palo Alto, CA 94306

38. * Science Associates 230 Nassau Street Princeton, NY 08540
39. Sierra-Misco, Inc. 1825 Eastshore Highway Berkley, CA 94710

40. Sign-X Laboratories, Inc. Essex, CT 06426

41. R. A. Simerl Instrument Div. 238 West Street Annapolis, MD 21401

42. *M. C. Stewart Company Ashburnham, MA 01430

43. *Sunflower Power Company Rt 1, Box 93-A Oakaloosa, KS 66066

44. TSI Box 3394 St. Paul, MN 55156

45. Taylor Instrument Glen Bridge Road Arden, NC 28704

46. Tech Ecology, Inc. 506 Logue Ave. Mountain View, CA 94043

47. Teledyne Geotech 3401 Shiloh Road Garland, TX 75041

48. Teledyne Gurley 514 Fulton Street Troy, NY 12181

49. Teledyne Hastings-Raydist Box 1275 Hampton, VA 23661

50. Texas Electronics, Inc. P.O. Box 7225

Dallas, TX 75209
51. Thermonetics 1028-A Garnet Avenue San Diego, CA 92109

52. C. W. Thornthwaite Assoc. Route 1 Elmer, NY 08318

53. *WeatherMeasure Corp. P.O. Box 41256 Sacramento, CA 95841

54. WEATHERtronics, Inc. 2777 Del Monte St. West Sacramento, CA 95691

55. Westberg Manufacturing Sonoma, CA 95476

56. *Wind Power Systems, Inc. P.O. Box 17323 San Diego, CA 92117

57. WTG Energy Systems, Inc. P.O. Box 87 Angola, NY 14006

58. Xonics, Inc. Environmental Systems Div. 6862 Hayvenhurst Avenue Van Nuys, CA 91406

59. R. M. Young Company 2801 Aero-Park Drive Traverse City, MI 49684

60. Zi-Tech

Box 26

Palo Alto, CA 94302 
Appendix F

Units Conversion 


\title{
Appendix $F$
}

\section{Units Conversion}

\author{
Length \\ Feet $=$ Meters $\times 3.28$ \\ Meters $=$ Feet $\times 0.305$ \\ Miles $=$ Kilometers $\times 0.621$ \\ Kilometers $=$ Miles $\times 1.609$ \\ Miles $=$ Nautical miles $\times 1.15$ \\ Nautical Miles $=$ Miles $\times 0.869$ \\ Kilometers $=$ Nautical miles $\times 1.852$
}

Speed

Miles per hour $(\mathrm{mph})=$ Meters per second $\times 2.24$

Meters per second $=\mathrm{mph} \times 0.447$

$\mathrm{mph}=$ Knots $\times 1.15$

Knots $=\mathrm{mph} \times 0.869$

Knots $=$ Meters per second $\times 1.94$

Meters per second $=$ Knots $\times 0.514$

Kilometers per hour $=$ Meters per second $\times 3.6$

\section{Area}

Square feet $=$ Square meters $\times 10.76$

Square meters $=$ Square feet $\times 0.093$

Power

$$
\begin{aligned}
\text { Horsepower } & =\text { Watts } \times 0.00134 \\
\text { Watts } & =\text { Horsepower } \times 746 \\
\text { Horsepower } & =\text { Kilowatts } \times 1.34 \\
\text { Kilowatts } & =\text { Horsepower } \times 0.746 \\
\text { Kilowatts } & =\text { Watts } \times 1000
\end{aligned}
$$





\section{Distribution}

No. of

Copies

\section{OFFSITE}

No. of

Copies

\author{
A. A. Churm \\ DOE Chicago Patent Group \\ 9800 S. Cass Avenue \\ Argonne, IL 60439 \\ C. I. Aspliden \\ Department of Energy \\ 600 E Street, N.W. \\ Washington, DC 20545 \\ G. P. Tennyson \\ Department of Energy \\ Albuquerque Operations Office \\ 4501 Indian School Road N.E. \\ Suite 151 \\ Albuquerque, NM 87110 \\ DOE Technical Information Center \\ Peter Smeallie \\ AWEA Windletter \\ 2222 Q Street, N.W. \\ Washington, DC 20008 \\ Dr. Paul B. MacCready, Jr. \\ AeroVironment, Inc. \\ 145 Vista Avenue \\ Pasadena, CA 91107
}

Mr. Howard Lusks

Agency for International Development

Room 2252 NS

LAC/DR

Washington, DC 20523

Clarissa Quinlan

Alaska State Energy Office

338 Denali Street

Anchorage, AK 99501

Paul N. Vosburgh

Alcoa Allied Products

Aluminum Company of America

Alcoa Center, PA 15069

Dr. K. C. Spengler

American Meteorological Society

45 Beacon Street

Boston, MA 02108

Ben Wolff

American Wind Energy Association

1621 Connecticut Avenue, N.W.

Fifth Floor

Washington, DC 20009
Richard Katzenberg

American Wind Energy Association

Natural Power, Inc.

New Boston, NH 03070

Energy Coordinator Environmental Resources Section

U.S. Army Corps of Engineers

Seattle District

P.O. Box C 3755

Seattle, WA 98124

BCF Energy Company

3014 B West Ramsey

Banning, CA 92220

E. J. Warchol

Bonneville Power Administration

P.O. Box 3621

Portland, OR 97208

S. J. Hightower

Bureau of Reclamation

Denver Federal Center

Building 67, Code 254

Denver, CO 80225

M. Ginosar/J. Lerner

California Solar Energy Commission

Energy Resources, Conservation and

Development Commission

1111 Howe Avenue, Mail Stop 15

Sacramento, CA 95825

Ed Kennell

Clean Energy Products

Wind Power Systems \& Components

3534 Bagley N.

Seattle, WA 98103

Lawrence Lewin

Department of Mechanical Engineering

Colorado State University

Fort Collins, CO 80523

10

Dr. R. N. Meroney

Colorado State University

Fort Collins, CO 80523

E. H. Gilmore

Department of Agriculture

Agriculture Research Service

Bushland, TX 79012 
No. of Copies

L. A. Liljedahl

Department of Agriculture

Agriculture Wind Energy Program

Building 001, Room 126 BARC-West

Beltsville, MD 20705

Jay Tappan

Department of Energy

State of Oregon

Labor and Industries Building

Room 111

Salem, OR 97310

Harry Moses

Carbon Dioxide and Climate

Research Program

Office of Health and Environmental Research

U.S. Department of Energy

Mail Stop E-201 Germantown

Washington, DC 20545

W. S. Pintz

Department of Minerals and Energy

P.O. Box 2352

Konedobu

Paupua, New Guinea

Dr. Edgar Demeo

Electric Power Research Institute

3412 Hillview Avenue

Palo Alto, CA 94303

Dr. Olle Ljungstrom

FFA, The Aeronautical Research Institute Forskningsstationen i Stockholm

Drottning Kristinas Vag 47

S-114 29 Stockholm, Sweden

R. B. Lawford

Fisheries \& Environment

25 St. Clair Avenue East

Toronto, Canada M4T $1 \mathrm{M} 2$

Dr. W. Frost

FWG Associates, Inc.

R. R. 3, Box 331

Tullahoma, TN 37388

R. J. Barchet/L. Krawitz

General Electric Company

P.O. Box 8555

Philadelphia, PA 19101

R. C. Koch

Geomet, Inc.

15 First Field Road

Gaithersburg, MD 20760
No. of

Copies

Gerald T. Norman

Global Weather Consultants, Inc.

12 S. First St., Suite 701

San Jose, CA 95113

Mr. James R. Turner

Research Director

Idaho Power Company

P.O. Box 70

Boise, ID 83707

Dr. T. R. Kornreich

JBF Scientific Corporation

1925 North Lynn Street

Suite 308

Arlington, VA 22209

Dr. J. B. Knox

Lawrence Livermore Laboratory

University of California

P.O. Box 808

Livermore, CA 94550

Mr. Si Liff

Los Angeles County

Community Development Department

3175 W. 6th Street

Los Angeles, CA 90020

Ms. Abbey Page

Maine Office of Energy Resources

55 Capitol

Augusta, ME 04330

Marlatt and Associates

3611 Richmond Drive

Fort Collins, CO 80521

Frank R. Eldrige, Jr.

MITRE Corporation

1820 Dolley Madison Boulevard

McLean, VA 22102

V. F. Garrett

Montana Energy and MHD Research and

Development Institute, Inc.

P.O. Box 3809

Butte, MT 59701

J. Konigsberg

Montana Energy Office

Capital Station

Helena, MT 59601

Phillip French

NASA Scientific and Technical

Information Facility

P.O. Box 8757

Baltimore/Washington International Airport

Baltimore, MD 21240 
No. of

Copies

R. A. Wolf

NASA Scientific and Technical

Mail Stop 500-201

Cleveland, $\mathrm{OH} 44135$

M. J. Changery

National Oceanic and Atmospheric

Administration

National Climatic Center

Federal Building

Asheville, NC 28801

R. J. Templin

National Research Council of Canada

National Aeronautical Establishment

M-2 Montreal Road

Ottawa, Ontario K1A OR 6

Dr. Hugo Juan Erramuste, Director Secretariat of Science and Technology Director Research and Development National Atomic Energy Commission Buenos Aires, Argentina

Mr. Butch Neel

Neel Farms Inc.

Box 1

Windom, KS 67491

Mr. Ross Bisplinghoff/Ms. Peggy McDonald

N.E. Solar Energy Center

70 Memorial Drive

Cambridge, MA 02142

John L. Zimmerman

New England Wind Energy

Conversion Services

RDL Box 52E

Moretown, VT 05660

P. W. Blakeley

New Zealand Electricity

Rutherford House

Lambton Quay

Wellington, New Zealand

Mr. Wilson Prichett, Manager

Alternative Energy Project

NRECA

1800 Massachusetts Avenue

Washington, DC 20036

Mr. Larry T. Klein

NUS Corporation

14011 Ventura Blvd.

Sherman Oaks, CA 91423
No. of

Copies

Ms. Shanna Reed

OMSI Energy Center

4015 SW Canyon Road

Portland, OR 97221

Mr. Don Bain

Oregon Department of Energy

Labor and Industry Building

Salem, OR 97310

6

E. W. Hewson/J. E. Wade

Oregon State University

Corvallis, OR 97331

Earl Davis

Pacific Gas and Electric Co.

215 Market St.

San Francisco, CA 94106

Ms. Karen Krenitsky

Phantom Enterprises, Ltd.

150 5th Avenue

Suite 700

New York, NY 10011

D. M. Tompkins

PRC Eng. Analysis $\mathrm{Co}$.

7600 Old House Road

McLean, VA 22102

E. McDonald

Project Manager

Raytheon Service Co.

Century Building, Rm 826

234 Jefferson Davis Highway

Arlington, VA 22202

Terry J. Healy/C. Hansen

Rockwell International

Rocky Flats Plant

P.O. Box 464

Golden, CO 80401

E. Kadlec/J. W. Reed

Sandia Laboratories

Division 5443

P.O. Box 5800

Albuquerque, NM 87115

Ted Kornreich/Harvey Lee Science Applications, Inc. 1764 Old Meadow Lane

McLean, VA 22102

R. M. Traci

Science Applications, Inc.

P.O. Box 2351

La Jolla, CA 92038

Distr-3 
I. Vas/Roger Taylor

Solar Energy Research Institute

1536 Cole Blvd.

Golden, CO 80401

Dr. C. M. Bhumralkar

Stanford Research

Institute, International

Menlo Park, CA 94025

Bruce Bailey

Atmospheric Sciences Research Center

SUNY Albany - ES 324

Albany, NY 12222

R. Crowder

Taylor Woodrow Construction, Limited

Taywood House

345 Ruislip Road

Southhall

Middlesex UBI 2QX

England

William G. Smith

Tennessee Energy Authority

707 Capital Boulevard Building

Nashville, TN 37219

Mr. Larry E. Cure

Assistant County Extension Agent

Texas Agricultural Extension Service

Texas A\&M University System

P.O. Box 762

Dumas, TX 79029

Mr. Gayland Bender

TSP Inc.

1112 W. Avenue N.

Sioux Falls, SD 57104

Mr. Glenn f. Underwood

Underwood Equipment, Inc.

JCT K-68 \& I-35

Ottawa, KS 66067

Dr. Demetrius Lalas

Department of Meteorology

University of Athens

Ippokratous

33

Athens 144, Greece

Dr. P. Yen

University of Hawaii at Monoa

Holmes Hall 240

2540 Dole Street

Honolulu, HI 96822
Dr. N. K. Wagner

Dept. of Civil Engineering

University of Texas

Austin, TX 78712

Dr. M. Garstang

University of Virginia

Charlottesville, VA 22903

R. E. Akins

Department of Engineering and Mechanics

Virginia Polytech Institute

Blacksburg, VA 24069

John Young

Washington Public Power Supply System

P.O. Box 968

Richland, WA 99352

David Kapus

Washington State Division of Engineering and Architecture

106 Maple Drive

Olympia, WA 98504

Ms. Susan Hosch

Washington State Energy Office

$400 \mathrm{E}$. Union Avenue, 1st Floor

Olympia, WA 98504

Wassillie Wassillie

P.O. Box 33

Iliamna, AK 99606

Bob Hamilton

PN723

Water and Power Resources Services

Box 043

$550 \mathrm{~W}$. Fort Street

Boise, ID 83724

Ms. Aileen Jeffries

Western Sun

P.O. Box 295

Winthrop, WA 98862

S. R. Epur/G. C. Thomann

Wichita State University

P.O. Box 44

Wichita, KS 67208

Mr. Carl Rounds

WINACT

2743 rd Avenue

Stayton, OR 97383 
No. of

Copies

Farrell Smith Seiler

Wind Energy Report

Box 14 - $104 \mathrm{X}$. Village Avenue

Rockville Centre, NY 11571

5

Dr. Carel DeWinkel

Energy Market Analysis Section

Wisconsin Power \& Light

P.O. Box 192

Madison, Wl 53701

Mrs. Lowell Anderson

45024 CO RD B

Center, CO 81125

Dr. V. Barros

28 De Julio 28

9120 Puerto Madryn

Chulret

R. Argentina

Bill Bernardi

201 D Sagamore Hill Road

Pittsburg, PA 15239

Kit Boise-Cossart

Hollister Ranch \#41

Gaviota, CA 93017

Mr. Michael A. Davidson

Route 4, Box 86

Anadarko, OK 73005

Mr. Martin Duke

Route 1, Box 51

Big Cabin, OK 74332

Mr. Jim Gottenhorn

Route 1, Box 530

Lk. Leelanau, MI 59653

Mr. Waldron G. Heany

P.O. Box 86

Lebanon, NE 69036

Mr. Mickey Jannol

Canal Randolph

818 West 7th Street

Los Angeles, CA 90017

Mr. Kerry J. Koller

237 N. Michigan Street

South Bend, IN 46601

Mr. Harold E. Kruchlavek

Rural Route 1, Box 73

Dorchester, MI 68343
No. of

Copies

Mr. Bob Mailander

Holyoke Rt

Wray, CO 80758

Mr. Joel McBee

Greater Newbury Port Clamshell

C/O YMCA

96 State Street

Newbury Port, MA 01950

Mr. Clare Nichols

1110 Scott

Dalhart, TX 79022

Mr. John M. Olson

Energy Consultant

3216 Reid Drive

Corpus Christi, TX 78404

Mr. William Pepper

P.O. Box 344

Bozeman, MT 59715

Mr. James A. Potter

Professional Engineer

112 Lazy Lane

Southington, CT.06489

Ms. Chris Salsbury

North 4609 Post

Spokane, WA 99205

Mr. Michael Scott

Energy Economist

The Masec Center

1256 Trapp Road

Eagan, MN 55121

Robert A. Simonsen

Route 1, Box 103

Quimby, IA 51049

Mr. V. L. Ward

Box 503

Ulysses, KS 67880

\section{ONSITE}

DOE Richland Operations Office

P.O. Box 550

Richland, WA 99352

H. E. Ransom

R. K. Stewart 
No. of

Copies

Pacific Northwest Laboratory

Battelle Boulevard

Richland, WA 99352

W. R. Barchet

J. C. Barnard

R. L. Conley

J. R. Connell

J. C. Doran

R. L. Drake

K. Drumheller

C. E. Elderkin

D. L. Elliott

R. L. George

P. C. Hays

T. R. Hiester

T. C. Jameson

G. A. Jensen (5)

A. H. Miller

M. M. Orgill

P. R. Partch

W. T. Pennell

E. H. Phinney

D. C. Powell

J. V. Ramsdell

D. S. Renne

H. L. Wegley

L. L. Wendell (335)

R. K. Woodruff

Technical Information - Library (5)

Publishing Coordination (2) 
